\title{
The Drive to Life on Wet and Icy Worlds
}

\author{
Michael J. Russell,,2 Laura M. Barge, ${ }^{1,2}$ Rohit Bhartia,,2 Dylan Bocanegra, ${ }^{3}$ Paul J. Bracher,, \\ Elbert Branscomb, ${ }^{6}$ Richard Kidd,, 2 Shawn McGlynn, ${ }^{7}$ David H. Meier, ${ }^{2}$ Wolfgang Nitschke, \\ Takazo Shibuya,, ${ }^{1,9}$ Steve Vance, ${ }^{1,2}$ Lauren White, ${ }^{1,2,10}$ and Isik Kanik ${ }^{1,2}$
}

\begin{abstract}
This paper presents a reformulation of the submarine alkaline hydrothermal theory for the emergence of life in response to recent experimental findings. The theory views life, like other self-organizing systems in the Universe, as an inevitable outcome of particular disequilibria. In this case, the disequilibria were two: (1) in redox potential, between hydrogen plus methane with the circuit-completing electron acceptors such as nitrite, nitrate, ferric iron, and carbon dioxide, and (2) in $\mathrm{pH}$ gradient between an acidulous external ocean and an alkaline hydrothermal fluid. Both $\mathrm{CO}_{2}$ and $\mathrm{CH}_{4}$ were equally the ultimate sources of organic carbon, and the metal sulfides and oxyhydroxides acted as protoenzymatic catalysts. The realization, now 50 years old, that membrane-spanning gradients, rather than organic intermediates, play a vital role in life's operations calls into question the idea of "prebiotic chemistry." It informs our own suggestion that experimentation should look to the kind of nanoengines that must have been the precursors to molecular motors-such as pyrophosphate synthetase and the like driven by these gradients - that make life work. It is these putative free energy or disequilibria converters, presumably constructed from minerals comprising the earliest inorganic membranes, that, as obstacles to vectorial ionic flows, present themselves as the candidates for future experiments. Key Words: Methanotrophy-Origin of life. Astrobiology 14, 308-343.
\end{abstract}

The fixation of inorganic carbon into organic material (autotrophy) is a prerequisite for life and sets the starting point of biological evolution. (Fuchs, 2011)

Further significant progress with the tightly membrane-bound $\mathrm{H}^{+}$-PPase family should lead to an increased insight into basic requirements for the biological transport of protons through membranes and its coupling to phosphorylation. (Baltscheffsky et al., 1999)

\section{Introduction}

T HE SUBMARINE alkaline hydrothermal theory for the emergence of life on early Earth, first posed in 1989 and reconsidered here, was originally suggested to have concerned a "high partial pressure of atmospheric $\mathrm{CO}_{2}$ " producing "neutral, or even slightly acid ... seawater ... which covered much of the globe at that time" and

acted as a reservoir for $\mathrm{Fe}^{2+} \ldots$ The oceanic crust was ultramafic or komatiitic ... The pyrrhotite $(\mathrm{FeS})$ content was generally high and,... at a distance from the oceanic ridges, seawater, occupying cracks in this crust, would have been involved in relatively low-temperature convection cells driven by crustal heat... This convecting seawater at $<200^{\circ} \mathrm{C}$ would have serpentinized the crust, becoming alkaline by this process of hydrolysis...Also, hydrogen would have been produced during serpentinization ... and methane formed from a portion of this hydrogen and $\mathrm{CO}_{2}$ by the Fischer-Tropsch reaction with $\mathrm{FeO}$ in silicates. Phosphate... and reduced sulphur... would have been released from mafic rocks to these relatively low-temperature solutions. (Russell et al., 1989)

The first experiments grounded in this hypothesis showed that "fine chimneys were apparently composed of greigite $\left(\mathrm{Fe}_{3} \mathrm{~S}_{4}\right)$ " and that

\footnotetext{
${ }^{1}$ NASA Astrobiology Institute, JPL Icy Worlds, USA.

${ }^{2}$ Jet Propulsion Laboratory, California Institute of Technology, Pasadena, California, USA.

${ }^{3}$ Art Center Bridge, Pasadena, California, USA.

${ }_{5}^{4}$ Beckman Institute, California Institute of Technology, Pasadena, California, USA.

${ }^{5}$ Department of Chemistry, Saint Louis University, St. Louis, Missouri, USA.

${ }^{6}$ Institute for Genomic Biology, UIUC, Champaign-Urbana, Illinois, USA.

${ }^{7}$ Division of Geological and Planetary Sciences, California Institute of Technology, Pasadena, California, USA.

${ }^{8}$ Bioénergétique et Ingénierie des Protéines (UPR9036), CNRS/IFR88, Marseille, France.

${ }^{9}$ Precambrian Ecosystem Laboratory (PEL), Japan Agency for Marine-Earth Science and Technology (JAMSTEC), Yokosuka, Japan.

${ }^{10}$ Department of Chemistry and Biochemistry, University of California, Santa Barbara, California, USA.
} 
precipitation of the semi-permeable colloidal membrane takes place at the interface between the two fluids where the $\mathrm{pH}$ change is abrupt... Such a continuous membrane would have an extensive reactive surface per unit volume, ... fine iron sulphide framboid sacks and chimneys could act as ... culture chambers and flow reactors ... for life to originate by phosphorylation and growth of organic molecules on the iron sulphide surfaces... Waste from such reactions would be carried away by the venting solutions. (Russell et al., 1989)

Since then, and particularly since the discovery of the Lost City alkaline hydrothermal vent field in 2000, which was broadly as anticipated (Russell et al., 1989; Shock, 1992; Kelley et al., 2001; Martin et al., 2008), further consideration has been given to the following:

(1) a somewhat more acidic early ocean with NO augmenting atmospheric $\mathrm{CO}_{2}$ and $\mathrm{SO}_{2}$ dissolved in the then hydrosphere, generating a steep redox gradient against hydrothermal $\mathrm{H}_{2}$ (Russell et al., 1993; Russell and Hall, 1997; Martin et al., 2007);

(2) the process of serpentinization, which is exothermic and strain-inducing and provides positive feedbacks to the hydrothermal convective drive (Kelley et al., 2001; Lowell and Rona, 2002; Russell et al., 2003, 2013; Vance et al., 2007);

(3) the fact that life's major preoccupations, both at its very start and as the basic necessities for all life today, are $\mathrm{C} 1$ metabolism and phosphate anhydride bond formation very far from equilibrium with its constituent phosphates (Baltscheffsky, 1971; Fuchs, 1989, 2011; Branscomb and Russell, 2013);

(4) nitrate, nitrite, and photolytic ferric iron and manganite having acted as high potential electron acceptors that enabled concomitant redox reactions (Nealson and Saffarini, 1994; Russell and Hall, 1997; Ducluzeau et al., 2009; Kopf et al., 2013);

(5) molybdenum in sulfide and/or green rust, bifurcating electrons, one exergonically and the other endergonically to drive carbon fixation (Boucherit et al., 1991; Nitschke and Russell, 2009, 2011, 2013; cf. Itaya et al., 1987; Helz et al., 2013);

(6) the ambient $\mathrm{pH}$ gradient of $\sim 5$ units having the theoretical potential, as a proton motive force, to drive the pyrophosphate:orthophosphate ratio to extreme heights to fuel proto-biochemistry (Russell and Hall, 1997, 2006; Russell et al., 2013), altogether focusing the thermodynamic disequilibria at, and across, the membrane sufficient to meet the criticisms of Pascal et al. (2013) while ensuring protection of organic products from the oxidizing potential of nitrate and nitrite as they are spent on the outer surface of the membrane ( $c f$. Sousa et al., 2013);

(7) the concentration and combinatorial interactions of products at low entropy in the confined space of the mineral compartments and more particularly in the interlayers of green rust comprising the membranes (Russell and Hall, 1997; Russell et al., 2003, 2013; Mielke et al., 2011);

(8) the complex precipitate membranes, consisting partly of iron sulfides dosed with $\mathrm{Ni}, \mathrm{Co}$, and $\mathrm{Mo}$, as well as ferrous/ferric oxyhydroxides, also dosed with $\mathrm{Ni}$ and
Mo, with potentially functional affinities to the active centers of the metalloenzymes - the green rust possibly acting as the first peristaltic free energy-converting structures and transporters prior to the emergence of transmembrane protein bundles of $\alpha$-helices (Russell et al., 1994, 2013; Nitschke and Russell, 2009; McGlynn et al., 2012; Schoepp-Cothenet et al., 2012; Branscomb and Russell, 2013; Nitschke et al., 2013); and

(9) acetate, water, and nitric oxide being the first waste products (Russell and Martin, 2004; Nitschke and Russell, 2013).

It is informative to compare this bottom-up or geological approach to life's emergence-one that places steep geochemically produced proton gradients and redox disequilibria at the forefront-with Peter Mitchell's first and only foray into considerations of how life originated, and this from a top-down perspective. In 1957, during the time Mitchell was struggling toward formulating his chemiosmotic theory for adenosine triphosphate (ATP) synthesis, that is, how the energy currency of all cells is minted through the proton motive force rather than a high-energy organic intermediate in the glycolytic pathway (Mitchell, 1961; Prebble, 2002), he attended the First International Symposium on the Origin of Life on the Earth, and he presented a paper that illustrated his mind-set at the time. He began,

I shall attempt to consider the mechanism whereby the contact between the organism and its environment is regulated, particularly in relation to the functions of the membranes that form the boundary between the organism and its environment. It will be appreciated that I cannot therefore consider the organism without its environment, and that from a formal point of view the two may be regarded as equivalent phases between which dynamic contact is maintained by the membranes that separate and link them. This circumstance serves at the outset to emphasize the fact that living organisms are distinguished, not by their momentary appearance, but by their behaviour and by their relationship to their environment. (Mitchell, 1959)

Referring to Mitchell's chemiosmotic theory-a theory judged by Orgel (1999) to compare with those of Heisenberg, Schrödinger, and Einstein (Lane, 2010)_Nick Lane reiterates the fact that life transcends mere "mass action" chemistry. Although facing the same thermodynamic landscape, life transcends simple chemistry (Lane, 2010) through the deployment of molecular, disequilibria- or free energy-converting nanoengines, many of them situated in membranes (Branscomb and Russell, 2013) — a point of view not accepted by Mitchell, though finally clinched by Boyer's demonstration of rotational catalysis in ATP synthase that undergoes conformational changes driven by the proton motive force (Boyer, 1975, 1997). All such engines work by mechanistically fusing an endergonic, "driven," free energy-creating process to a (necessarily stronger) exergonic, "driving," free energy-consuming one. For one example, Complex 1 exploits exergonic vectorial electron flow to drive protons from cytoplasm to periplasm endergonically in a system likened to the functioning of a steam engine (Efremov et al., 2010; Lane, 2010; Efremov and Sazanov, 2011a, 2011b; Baradaran et al., 2013)_ electrons conduct to an acceptor, so driving protons to the 
periplasm. It might be speculated that ancestors of Complex 1 are traceable back to the $[\mathrm{NiFe}]$ site of hydrogenases (Darrouzet et al., 1998; Hedderich, 2004). The rotary ATP synthase, equated to the Wankel combustion engine, then uses the proton gradient resulting from the efforts of Complex 1 and the like as the exergonic driver to endergonically condense adenosine diphosphate (ADP) and inorganic orthophosphate $\left(\mathrm{P}_{\mathrm{i}}\right)$ to ATP (Yoshida et al., 2001). ATP is the energy currency of the cell, but the process of making it forces it into a state in "astronomical disequilibrium" with respect to its hydrolysis products (Boyer, 1997; Branscomb and Russell, 2013). It is spent rapidly through the phosphorylation of organic molecules, thereby driving endergonic biosynthetic reactions through the elimination of the components of water.

The organic monomers that made up the relatively small pool acted on by ATP could not have been gleaned from the high entropy mix comprising the myriad of ill-assorted organic molecules comprising carbonaceous chondrites, many of them aromatic or highly branched, but were the product of C1 metabolism (Cody and Alexander, 2005; Fuchs, 2011). Yet we know that the abiotic reduction of carbon dioxide to formaldehyde or at least to a formyl group, for example, is highly endergonic, a reduction that challenges the theorist of autogenesis as it thwarts the experimentalist (Vladimirov et al., 2004). Of course, were there no steep thermodynamic barriers to be scaled in the fixation of carbon dioxide, there would hardly be a call for life to realize approaches toward redox equilibria on the outer surfaces of a wet rocky planet-catalyzed geochemical reactions would be adequate for the job. Nevertheless, there is an advantage to be gained from examining the transition from geochemistry to biochemistry from the bottom up, that is, to "look under the hood" at life's first free energy-converting nanoengines or "mechanocatalysts" (Russell, 2007; Nitschke and Russell, 2010; Branscomb and Russell, 2013; cf. He et al., 2012). Such an approach encourages us to see life as one of the last in a vast hierarchical cascade of emergent, disequilibriaconverting entropy-generating engines in the Universe (Russell et al., 2013). In doing so, we keep our sights on the "astro" in astrobiology.

In systems driven far from equilibrium, self-organized dynamic structures, acting as engines (i.e., "free energy converters"), arise spontaneously (Cottrell, 1979). Their effect is invariably to accelerate the rate at which the driving disequilibrium generates entropy and is thereby dissipated (Prigogine, 1978). Tellingly, the Universe itself, at the moment of its Big Bang birth, was by a vast measure the most extreme example, known or conceivable, of a farfrom-equilibrium system, born as it was in a condition of disequilibrium so great as to be virtually inestimable (Penrose, 2005). From this pinnacle of improbability, it could only, as the second law of thermodynamics demands, go endlessly "down" to ever increasing total entropy. Indeed, the history of the Universe has been "nothing but" the playing out of the dynamics of accelerated entropy production via emergent, self-organizing engines. All the dynamic structures and processes of the Universe, both great and small, from galactic superclusters to burning and dying stars, black holes, the writhing pirouettes of quasar jets, planetary systems, convective currents in myriad guises, to the poppies on the cool green hills of Earth-all are engines, all contributing members of this great self-organizing cascade of accelerated entropy production.

But in this medley of engines, black holes stand apart and have a special role to play. They are not only an end point in the production of entropy through gravitational collapse, at which the entropy per unit mass is a maximum; but almost all the Universe's entropy inventory is currently, and will increasingly be, in the form of supermassive black holes (Ruffini and Wheeler, 1971; Penrose, 2005; Scharf, 2012). Finally, they are themselves the most powerful and consequential engines in the Universe. When they accrete matter from other stars or the interstellar medium, they become extraordinarily powerful internal combustion engines, with fuel, carburetion, a combustion chamber, and multiple exhaust systems. They can be throttled from a quiet idling to an explosive roar of transgalactic impact. These engines are suspected of regulating the formation of stars and galaxies and driving their evolution, creating most of the magnetic flux in the universe, and ionizing the Universe itself shortly after the Big Bang (Meier, 2012).

We are thus justly, and most ironically, to be seen as the spawn of black holes, themselves the spawn of a Universe born in the greatest possible discomfort of disequilibrium. Without going into detail, we can follow the history of the Universe's engines from galactic and stellar processes through planetary accretion and geophysical convection to the emergence and evolution of life itself (Russell, 2007; Nitschke and Russell, 2010; Branscomb and Russell, 2013; Vattuone et al., 2013). And as the mist begins to lift from the divide that separates geochemistry from biochemistry, we can glimpse the biological bank that lies directly opposite. What is revealed is that, whereas life, like all other dynamic phenomena in the Universe, is forced to operate through the invention and deployment of engines to convert disequilibria-dissipating one to create another-the engines of living cells comprise a vast and uniquely complex heterarchical networked system of linked conversions. This great system, driven by externally supplied disequilibria, produces a myriad of internal "intermediate" and enabling disequilibria in the form of both structures and processes. These it uses, among much else, to drive the otherwise intractable reactions at the very beginnings of metabolic pathways up such steep thermodynamic gradients. The challenge before us, then, is to work out how it could all have gotten started.

In this contribution we consider the following:

(i) how the birth and earliest states of our own planet set the stage for life's onset,

(ii) the transition from geochemistry to biochemistry in a Hadean alkaline hydrothermal mound.

(iii) how well the top-down and bottom-up evidence converges on a model for life's origin,

(iv) exploration of those proto-biotic reactions that would have been at least mildly exergonic in the milieu offered by conditions within an alkaline submarine hydrothermal mound,

(v) identification of the endergonic challenge to the autotrophic pathways and the necessary requirement for carbon-fixation and proto-pyrophosphatase engines,

(vi) the nature of the guidance system that lifts life across the Darwinian threshold, and 
(vii) briefly how other wet and rocky worlds elsewhere in the Solar System and the Universe might be evaluated for the presence of extant or former life.

\section{The Birthing and Earliest Processes Operating on Our Own Planet}

To set the scene for life's emergence, it is instructive to consider the birth of our solar system and the earliest few million years of our planet. Following the main stage of accretion from solar dust, chondrites, planetesimals, and Theia's impact, molten Earth cooled rapidly, possibly through the operations of whole mantle convection (Halliday, 2004; Zahnle et al., 2007; Gargaud et al., 2012; Sleep et al., 2014). Among the myriad of elements bequeathed to our planet by the hypernovae responsible for engendering this solar system were the radiogenic fuels ${ }^{235} \mathrm{U},{ }^{40} \mathrm{~K}$, and ${ }^{26} \mathrm{Al}$ that would, in concert with gravitational energy, drive the thermal convective surfacing and resurfacing of Earth through mantle overturn, plumes, and/or impact melting (Turcotte and Schubert, 2002; Cockell, 2006; Harrison, 2009; Huss et al., 2009; Korenaga, 2013; Griffin et al.,
2014; Harris and Bédard, 2014). In the absence of fully fledged plate tectonics in the Hadean (Johnson et al., 2013; Griffin et al., 2014), mantle plumes would have done the same job, though less efficiently (Fig. 1) (Bédard, 2006). The latter process would bring fresh mantle-derived material or mantle itself to the surface of this and other hot, wet, rocky worlds. Magmatic plumes are effectively engines with some positive (catalytic) feedback provided by the exothermic basalt-to-eclogite transition first recognized as an additional driving force by Holmes (1931) (Bédard, 2006; Sleep et al., 2014).

While water, perhaps amounting to many present-day Earth oceans, was likely introduced from hydroxylated olivines in the solar disc (Alexander et al., 2012; Vattuone et al., 2013), much of the carbon was probably gained later as $\mathrm{CO}_{2}$ through delivery of icy comets from beyond the frost line, augmented by delivery of complex organic molecules in carbonaceous chondrites (Ehrenfreund and Charnley, 2000; Cody et al., 2001; Cody and Alexander, 2005; Yabuta et al., 2007; Orthous-Daunay et al., 2010; Kebukawa et al., 2011; Marty, 2012). Once absorbed into magma, any such organic molecules would pyrolyze to produce further carbon

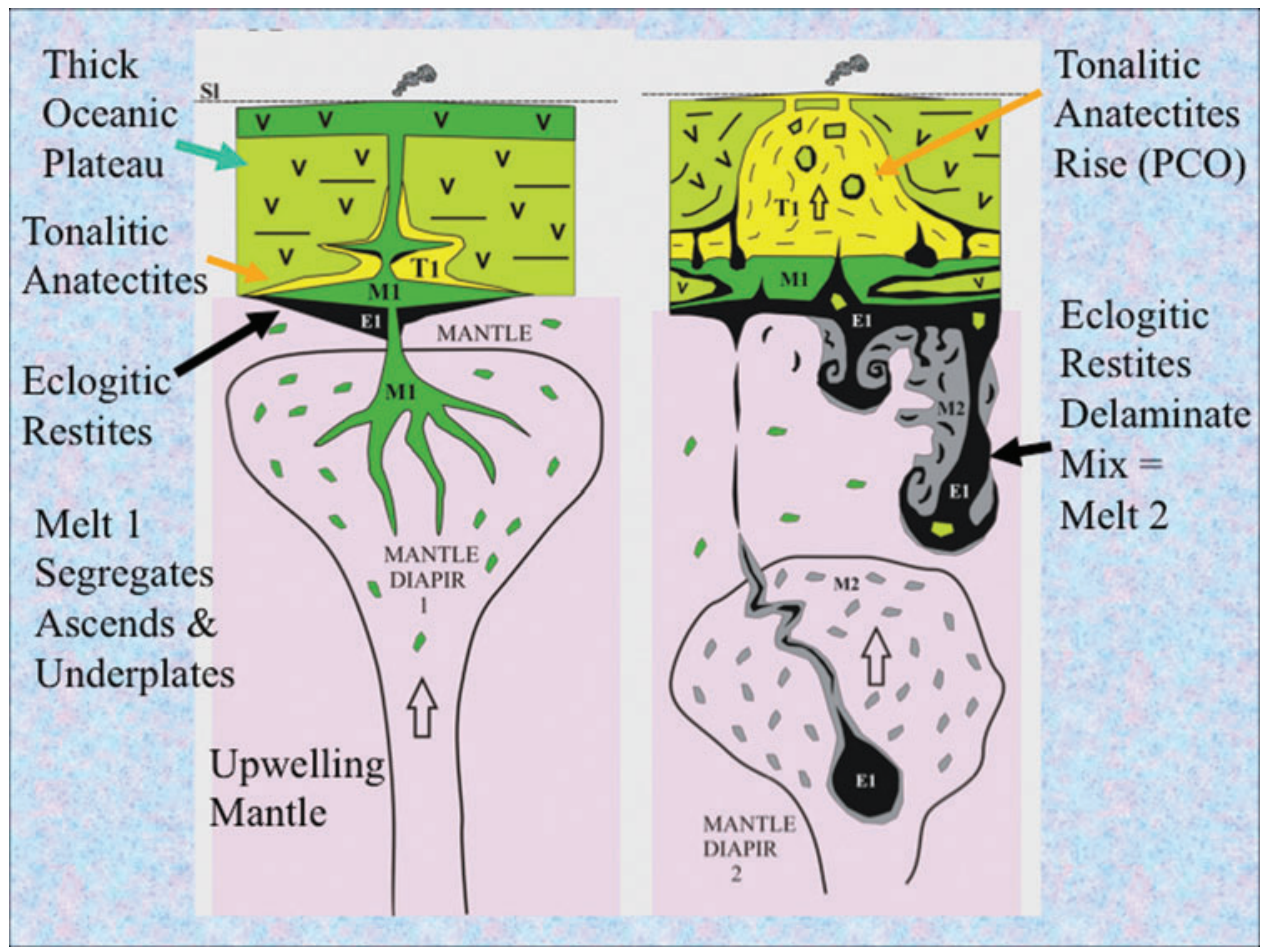

FIG. 1. Diagrams showing the remelting of a thick volcanic plateau by a reinvigorated mantle plume, illustrating a delamination tectonomagmatic engine producing fresh ancient ocean crust on Earth continuously for 200-300 million years (Bédard, 2006). Left-hand cartoon shows molten magma (M1) generating a thick volcanic crust. This same batch of magma also ponds at the base of the crust, where it differentially melts the more siliceous and less dense component of the preceding volcanic host to produce quartz-rich tonalitic melt (T1). The more magnesium-rich residue partially metamorphoses to dense eclogite which begins to sink (E1). The right-hand cartoon shows how the buoyant siliceous melt invades the plateau to produce acidic (silica- and nickel-rich) volcanism and accompanying hot springs that have the potential to dispense carbon dioxide to the atmosphere and metal-rich solutions to the ocean, respectively (and see Sobolev et al., 2005). At the same time the dense eclogite (E1) delaminates and falls into the mantle. The larger bodies bore channels that may be exploited by further rising hot mantle diapirs. Smaller delaminated bodies mix into the shallow upper mantle and catalyze the formation of a second mantle melt (M2). Extraterrestrial wet and icy worlds with interiors hot enough to produce mantle plumes and thereby new ocean crust as well as oxidized volatiles could also set the stage for the onset of metabolism and life (and see Gaidos, 2000; Pasek and Greenberg, 2012). Reproduced from Bédard (2006) with permission. 
oxides and carbonate, only to be released at high temperatures in volcanic and hydrothermal exhalations, mainly as $\mathrm{CO}_{2}$ with smaller amounts of $\mathrm{CO}$ (Shock, 1992; Wood et al., 1990, 2006; Charlou et al., 2002; Trail et al., 2011, 2012). That portion of $\mathrm{CO}_{2}$ still retained in the crust would either disproportionate to graphite and methane during high-temperature $\left(\sim 600^{\circ} \mathrm{C}\right.$ to $\left.500^{\circ} \mathrm{C}\right)$ serpentinization or be reduced to methane by inwardly diffusing hydrothermal hydrogen at, or above, $400^{\circ} \mathrm{C}$ (Welhan 1988; Kelley, 1996; Etiope and Sherwood Lollar, 2013; Etiope et al., 2013; Liu et al., 2013; McMahon et al., 2013; Ni and Keppler, 2013).

The first all-enveloping ocean rained out to a depth of perhaps $5 \mathrm{~km}$ or more from a proto-atmosphere that consisted of many bar of carbon dioxide and $\sim 2$ bar of nitrogen and significant sulfur dioxide around 4.4 billion years ago (Bounama et al., 2001; Halevy et al., 2007; Martin et al., 2007; Zahnle et al., 2007; Elkins-Tanton, 2008; Goldblatt et al., 2009; Kotwicki, 2009; Trail et al., 2011; Maruyama et al., 2013). Any short-lived tidal pools on the margins of rare and rapidly weathered volcanic edifices puncturing the deep ocean surface were repeatedly swamped by highamplitude tides generated by the more proximal Moon orbiting the more rapidly rotating Earth (Denis et al., 2011). Notwithstanding the suggestion that the early atmosphere was hydrogen-rich (Wordsworth and Pierrehumbert, 2013), $\mathrm{H}_{2}$ is likely to have gravitated rapidly to space, so beginning the oxidation of the planet's surface (Catling, 2006). Also, the solar wind blew up to $50 \%$ of the original inventory of atmospheric nitrogen to space (Ozima et al., 2005). The melting of bolides on impact may have produced occasional short-lived excursions to high $\mathrm{CH}_{4}$ partial pressures, though radiative reoxidation was likely rapid (Zahnle et al., 2010). And post the Moon-forming event, even large bolides could only have vaporized the near surface of the ocean at most (Abramov and Mojzsis, 2009). The Sun's radiation then only had around $70 \%$ of its present power, but the $\mathrm{CO}_{2}$, which predominated in the atmosphere, would have kept the ocean generally unfrozen except when a large portion of atmospheric $\mathrm{CO}_{2}$ was lost to hydrothermal convective interaction with the mafic crust and its sinking, or even subduction, to depth (Newman and Rood, 1977; Shibuya et al., 2010; Sleep et al., 2014). Even so, the $\mathrm{CO}_{2}$ would have been rapidly returned as the carbonated crust foundered and was subjected to thermal metamorphism (Dasgupta, 2013). Cosmic and solar clouds would also have masked the Sun on occasion and caused a drop in temperature. Since there was no solid core, a geomagnetic dynamo was not well developed, leaving the planet to the mercy of galactic and solar cosmic rays, which were especially strong during further occasional hypernova explosions in the then-crowded stellar environment (Baade and Zwicky, 1934; Montmerle et al., 2006; Labrosse et al., 2007; Melott and Thomas, 2011; Moeller and Hansen, 2013). Movement of the solar system in the Galaxy would have led to order-of-magnitude changes in cosmic ray intensity (Atri and Melott, 2012; Cohen et al., 2012). At the same time and for the same reason, protons and other charged particles from local gamma ray bursts both produced and entrained cascades of electrons, which thereby induced leader lightning strikes in thunderstorms (Gurevich et al., 1999; Gurevich and Karashtin, 2013). Cosmic and solar electron and proton rays are likely to have produced nitrogen oxides $\left(\mathrm{NO}_{x}\right)$ from $\mathrm{CO}_{2}$ and $\mathrm{N}_{2}$ on early
Earth, the first directly and the second through the effects of lightning (Yung and McElroy, 1979; Reeves et al., 1992; Bieber et al., 1999; Martin et al., 2007; McLaughlin et al., 2008; Grenfell et al., 2012). Chemically similar atmospheres and oceans likely occurred on early Venus and Mars, which may have been conducive to the emergence of metabolism and life on those planets also (Russell and Hall, 1999; Mahaffy et al., 2013; Michalski et al., 2013; Vattuone et al., 2013; Webster et al., 2013; Wetzel et al., 2013). The icy moons of Jupiter and Saturn, as well as the myriad of extrasolar Earth-like planets of the kind revealed by Kepler, are likely to have broadly comparable chemical polarities (Schulze-Makuch and Irwin, 2002; Rugheimer et al., 2013).

Whatever the mechanisms that produced new ocean floor on Earth, the crust was probably thicker than it is today (Korenaga, 2008, 2013; Griffin et al., 2014; Sleep et al., 2014; and see Van Mierlo et al., 2013). In the case of plate tectonic mechanisms, slow spreading leads to the exhumation of mantle peridotites through gravitational slippage (e.g., the Indian ocean floor southwest of the ridge; Sauter et al., 2013). Otherwise, lavas involved in overplating were likely composed of high magnesium basalts and komatiites. Thus, the Hadean ocean floor would have been mafic to ultramafic with scatterings of trondhjemites, phosphate-rich volcanic glass, and xenoliths of schreibersite-bearing meteorites (Cody et al., 2001; Bédard, 2006; Pasek et al. 2013; Griffin et al., 2014).

The all-enveloping acidulous ocean [a feature that may have been common to oceans in icy worlds such as Europa (e.g., Carlson et al., 1999; Kargel et al., 2000; SchulzeMakuch and Irwin, 2002; Hand et al., 2007, 2010; Zolotov and Kargel, 2009; Pasek and Greenberg, 2012), as well as the original hydrospheres of Mars and Venus (e.g., Vattuone et al., 2013)] was the recipient of four main types of exhalation: (i) acidic volcanic gases $\left(\sim 1500^{\circ} \mathrm{C}\right)$; (ii) hot $\left(\sim 400^{\circ} \mathrm{C}\right)$, carbonated and highly alkaline submarine springs driven by mafic intrusives; (iii) hot $\left(\sim 400^{\circ} \mathrm{C}\right.$ ) acidic tonalite-trondhjemite-granodiorite-associated submarine springs; and (iv) warm $\left(\sim 100^{\circ} \mathrm{C}\right)$ alkaline springs and seepages resulting from serpentinization (Russell et al., 1989; Shock, 1990, 1992; Bounama et al., 2001; Douville et al., 2002; Botcharnikov et al., 2003; Hopkinson et al., 2004; Kelley et al., 2005; Martin et al., 2006; Proskurowski et al., 2006; Dauphas et al., 2007; Frost and Beard, 2007; Martin et al., 2007; Shibuya et al., 2007, 2010, 2012; Zahnle et al., 2007; Elkins-Tanton, 2008; Koschinsky et al., 2008; Kemp et al., 2010; Shanks and Thurston, 2010; Heck et al., 2011; Reeves et al., 2011; Arndt and Nisbet, 2012; Mloszewska et al., 2012; Travis et al., 2012; Klein et al., 2013; Schrenk et al., 2013). The combined effects of these exhalations were to create strong redox disequilibria between the reduced mantle and the relatively oxidized volatisphere (Fig. 2). The chemical gradients were thus set for the onset of life. Volcanoes supplied oxidized entities such as carbon dioxide, the main substrate for life, along with polyphosphates, sulfur dioxide, and nitric oxide (the latter supplemented by UV, cosmic rays, lightning, and meteorite impacts acting on $\left.\mathrm{CO}_{2}+\mathrm{N}_{2}\right)$. The hot $\left(\sim 400^{\circ} \mathrm{C}\right)$ submarine acidic exhalations provided metals $\mathrm{Fe}>\mathrm{Mn} \gg \mathrm{Zn}>\mathrm{Co}>$ $\mathrm{Ni}>\mathrm{W}$ for catalysis and for the early enzymes. The hot ( $\sim 400^{\circ} \mathrm{C}$ ) alkaline springs supplied calcium and silica, and the warm $\left(\sim 100^{\circ} \mathrm{C}\right)$ alkaline springs and seepages produced 


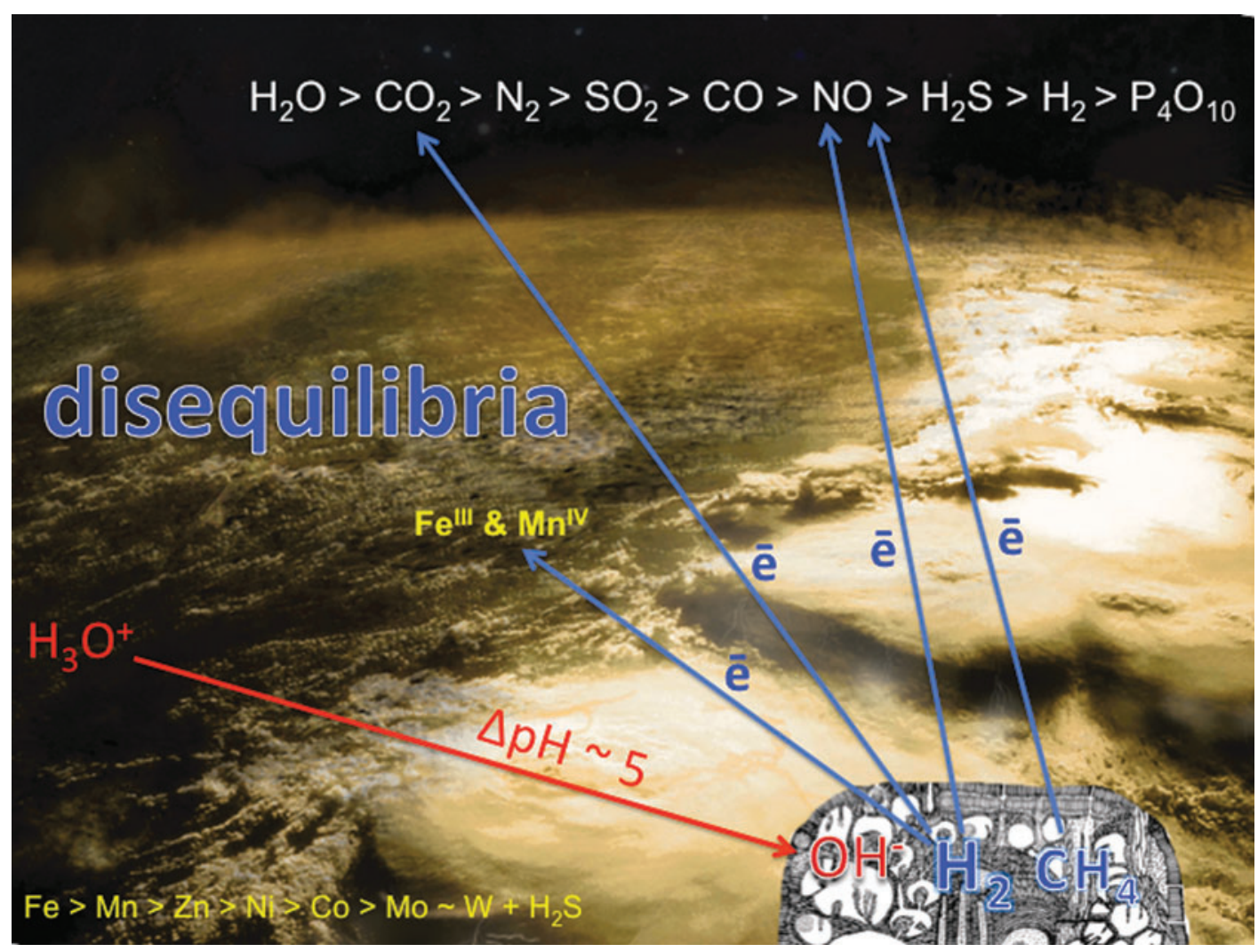

FIG. 2. The candidate $\mathrm{pH}$ and redox disequilibria driving the onset of biochemistry on wet rocky worlds. Oxidized and acidic volatiles are supplied to the atmosphere and hydrosphere by volcanoes (top); acidic $\sim 400^{\circ} \mathrm{C}$ springs supply the metals and $\mathrm{H}_{2} \mathrm{~S}$ to the ocean (lower left); iron and manganese from these springs are photooxidized (center); reduced entities exploited by emergent metabolism are mainly supplied in alkaline hydrothermal solution to a submarine precipitate mound (lower right) (Nealson and Saffarini, 1994; Douville et al., 2002; Proskurowski et al., 2006; Martin et al., 2007; Zahnle et al., 2007). These are the initial far-from-equilibrium conditions considered to have driven the onset of life.

the electron-rich fuels for metabolism, hydrogen, and methane along with materials such as ammonia and in some cases hydrogen sulfide (as $\mathrm{HS}^{-}$) as well as nanomolar thiomolybdate (Yung and McElroy, 1979; Kasting, 1990; Yamagata et al., 1991; Russell and Hall, 1997, 2006; Erickson and Helz, 2000; Douville et al., 2002; Krasnopolsky, 2006; Schumann and Huntrieser, 2007; Martin et al., 2008; Smirnov et al., 2008; Nitschke and Russell, 2009; Erlykin and Wolfendale, 2010; Grenfell et al., 2012; Schoepp-Cothenet et al., 2012; Gordon et al., 2013; Helz et al., 2013).

\section{The Hadean Hydrothermal Hatchery of Life- The First Transition}

The nature of the porous mounds produced at the warm alkaline submarine spring that we consider to have been the hatchery of life may be surmised from extant springs today, as well as from laboratory simulation experiments. At Lost City, chimney structures comprise brucite $\left(\mathrm{Mg}(\mathrm{OH})_{2}\right)$ enclosing friable filaments of aragonite (Kelley et al., 2005; Ludwig et al., 2006). The brucite appears to have precipitated around the aragonite $\left(\mathrm{CaCO}_{3}\right)$ as a result of the hydrothermal solutions mixing with ocean water (Kelley et al., 2005). Very high Fe-brucite $\left([\mathrm{Fe}, \mathrm{Mg}][\mathrm{OH}]_{2}\right)$ and ferrous/ ferric oxyhydroxides indicative of the mixing of similar hydrothermal solutions with ocean water have been intersected in peridotitic ocean floor on the Iberia Abyssal Plain (Hopkinson et al., 2004). A vestige of what may have been an extinct mound has also been recorded on the ultramafic floor of the western Indian Ocean (Bonatti et al., 1983). Those remains consist of the expanding clay, sepiolite $\left(\mathrm{Mg}_{4} \mathrm{Si}_{6} \mathrm{O}_{15}(\mathrm{OH})_{2} \cdot 6 \mathrm{H}_{2} \mathrm{O}\right)$, and poorly crystallized magnesium and iron (layered double?) hydroxides. Two analyses of the sepiolite revealed concentrations of $\mathrm{Ni}$ at 150 and $365 \mathrm{ppm}, \mathrm{Co}$ at 15 and $67 \mathrm{ppm}, \mathrm{V}$ at 23 and $78 \mathrm{ppm}$, and $\mathrm{Zn}$ at 120 and $225 \mathrm{ppm}$. Layered double hydroxides such as green rust (now termed fougèrite) comprise cationic brucitelike layers alternating with hydroxyls, water molecules, and/ or a variety of anions (Trolard et al., 1997; Braterman et al., 2004; Schoonen et al., 2004; Génin et al., 2005, 2006; Ruby et al., 2010).

How would such mounds compare to those generated on early Earth? While the alkaline solutions derived from serpentinization would have been much the same, except for the occasional bisulfide contribution, the anoxic acidulous Hadean Ocean ( $\mathrm{pH} \sim 5.5$ ), with its load of iron and other transition metals, silica, phosphate and polyphosphate, phosphite, sulfide (as $\left.\mathrm{H}_{2} \mathrm{~S}\right)$, as well as nitrate and nitrite, was very different (Macleod et al., 1994; Pasek et al., 2013). Without catalytic surfaces or biota to promote reactions, these entities would have remained supersaturated, only 
precipitating on meeting the hydrothermal alkaline effluents. Depending on depth, a portion of the iron may have precipitated as siderite (Macleod et al., 1994). If so, this iron carbonate could have been replaced by greigite $\left(\mathrm{Fe}_{3} \mathrm{~S}_{4}\right)$ as any bisulfide-bearing hydrothermal solutions percolated through the mound (Sagnotti et al., 2005). Alternatively, the iron could have been precipitated directly as mackinawite (FeS) (Mielke et al., 2011). And in place of brucite and ironrich brucite, the hydroxides would have been much more iron-rich. Indeed, because of oxidants in the Hadean Ocean, we imagine a major constituent of the first precipitate membranes would have been the mixed-valence brucite-like ferrous/ferric oxyhydroxide-fougèrite (green rust) (Trolard and Bourrié, 2012). In our attempts to simulate such springs in Hadean conditions, we have generated chimneys and micro- and nanocompartments comprising mackinawite $(\mathrm{FeS})$, greigite $\left(\mathrm{Fe}_{3} \mathrm{~S}_{4}\right)$, silica, as well as the ferrous-ferric oxyhydroxides (Russell et al., 1989, 1994; Mielke et al., 2010, 2011). Mielke and coworkers (2011) argued that these micro- and nanocompartments would restrict diffusion of hydrothermal fluids and thereby focus reactions with the invasive carbonic ocean at, or within, their boundaries "and act as 'low-entropy' traps whereby compatible products would be forced to interact through their proximity" (cf. Westheimer, 1962; Page and Jencks, 1971).

We argue here that metabolism was forced to emerge in such fine compartments to resolve the disequilibrium between the hydrogen and methane delivered in an off-ridge alkaline hydrothermal convection cell, with volcanic carbon dioxide and other oxidized entities such as nitric oxide dissolved in the acidulous Hadean Ocean (Nitschke and Russell, 2013) (Fig. 2). When particular critical disequilibria are reached on wet rocky worlds, convection and metabolism are two autocatalytic symmetry-breaking robust processes that take over from mere conduction and aqueous geochemistry, respectively (Russell, 2007). So although, in our opinion, early biochemistry emerged from, and was coupled to, the off-ridge or off-mantle plume convection cell, it does not follow that biochemistry is merely better geochemistry (Martin and Russell, 2007). However, knowing the environment from which life sprang and the commonalities between the geochemistry and metabolism can surely help us understand life's first steep ascents and faltering steps, as we explore below.

\section{Top-Down and Bottom-Up Evidence Converges on an Autogenic Model for Life's Origin}

At life's emergence, our planet was basic and relatively reduced on the inside yet somewhat acidic and oxidized on the outside (Russell and Hall, 1997). As such it compared to the polarity of a fuel cell or a simple-celled prokaryote (Russell et al., 2003; Nitschke and Russell, 2009; Lane et al., 2010; Barge et al., 2014). As we have seen, it exhales oxidized volatiles such as $\mathrm{H}_{2} \mathrm{O}, \mathrm{CO}_{2}, \mathrm{SO}_{2}$, and $\mathrm{NO}$ at high temperature-molecules that are reduced geochemically to $\mathrm{H}_{2}, \mathrm{CH}_{4}, \mathrm{H}_{2} \mathrm{~S}$, and $\mathrm{NH}_{3}$ as they are entrained in hydrothermal convection cells traversing the oceanic crust (Fig. 2). Although tempting, we must (have learned to!) resist the urge to assume that prokaryotes first emerged to "quicken" these geochemical processes (Nitschke and Russell, 2013; $c f$. Russell et al., 1998). It makes more sense to see the earliest cells as exploiting the fuels offered by this gigantic inanimate body, that is, as being dependent on the environment of early Earth (Nitschke and Russell, 2013; cf. Mitchell, 1959). This view refocuses our interest on a site where the fuels were presented in the most acceptable forms - an alkaline submarine spring where the same general polarity holds while the $\mathrm{H}_{2}, \mathrm{CH}_{4}, \mathrm{HS}^{-}$, and $\mathrm{NH}_{3}$ are concentrated, palatable, and steadily and continuously supplied, and there is all-important opportunity for the disposal of waste, that is, the release of entropy (Fig. 3) (Russell et al., 1989, 2010; Schoonen and $\mathrm{Xu}, 2001$; Smirnov et al., 2008; Mielke et al., 2010; Gordon et al., 2013).

From this point of view, it can be argued that the electrogeochemical state of the abiotic planet drove the emergence of an autotrophic metabolism, a metabolism given to the reduction of carbon dioxide and the concomitant oxidation of methane and hydrogen. In Table 1, we itemize features and requirements of life and compare these with what is on offer from the abiotic world, both with respect to various disequilibria and to the materials that could be put to use by emergent metabolism. The geological and geochemical studies of what is known of early Earth as they pertain to such an emergence of life appear to be converging with enzymological and phylogenetic retrodictions from what is known of the ancient metabolic pathways employed by organisms that occupy the lowest branches of the evolutionary tree, at least as they appear to us today (Table 1) (Say and Fuchs, 2010; Ducluzeau et al., 2014; Nitschke et al., 2013; Schoepp-Cothenet et al., 2013).

Life emerging from this world faced a two-front "endergonic" battle to attain the fixing of carbon and the generation of an extreme pyrophosphate/orthophosphate disequilibrium. We consider carbon fixation first and argue that hydrogen-split into two electrons and two protons at Fe-Ni sulfide clusters comprising the membrane-reduced the carbon dioxide that permeated the inorganic walls of the compartments where water activity was low to carbon monoxide, a mildly anti-entropic reaction involving redox bifurcation mediated probably by molybdenum or tungsten (McGlynn et al., 2009; Nitschke and Russell, 2013). At the same time, we surmise that the hydrothermal methane was oxidized endergonically with nitrate or nitrite to methanol at $\mathrm{Fe}^{\mathrm{III}}$ sites in fougèrite (green rust) in a reaction also involving molybdenum or tungsten sites with electrons released from hydrogen at another (higher potential) $\mathrm{Ni}-\mathrm{Fe}$ sulfide site (Antony et al., 2008; Nitschke and Russell, 2013) (Fig. 4). The methanol was further oxidized with nitrite or the ephemeral NO to formaldehyde at a Mo/W site before being re-reduced and thiolated to a methyl group on a $\mathrm{Ni}$-Fe sulfide cluster. Here, it condensed with the CO before being released on reaction with a second methane thiol as methyl thioacetate, a likely entry point into biosynthesis through further hydrogenations, condensations, phosphorylations, carboxylations, and aminations (Huber and Wächtershäuser, 1997, 2003; Russell and Martin, 2004; Nitschke and Russell, 2013). The polar arrangement, acting at the hydrothermal mound, has held steady over the 4 billion years, even to our own physiology, ideally poised around pH 7.4, with hydrogen for biosynthesis contributed now by NAD(P)H (Booth, 1985; Kellum, 2005; Russell, 2007; Williams and Ramsden, 2007; Spitzer and Poole, 2009) and the electron acceptor oxygen-in place of $\mathrm{CO}_{2}$, oxidized 


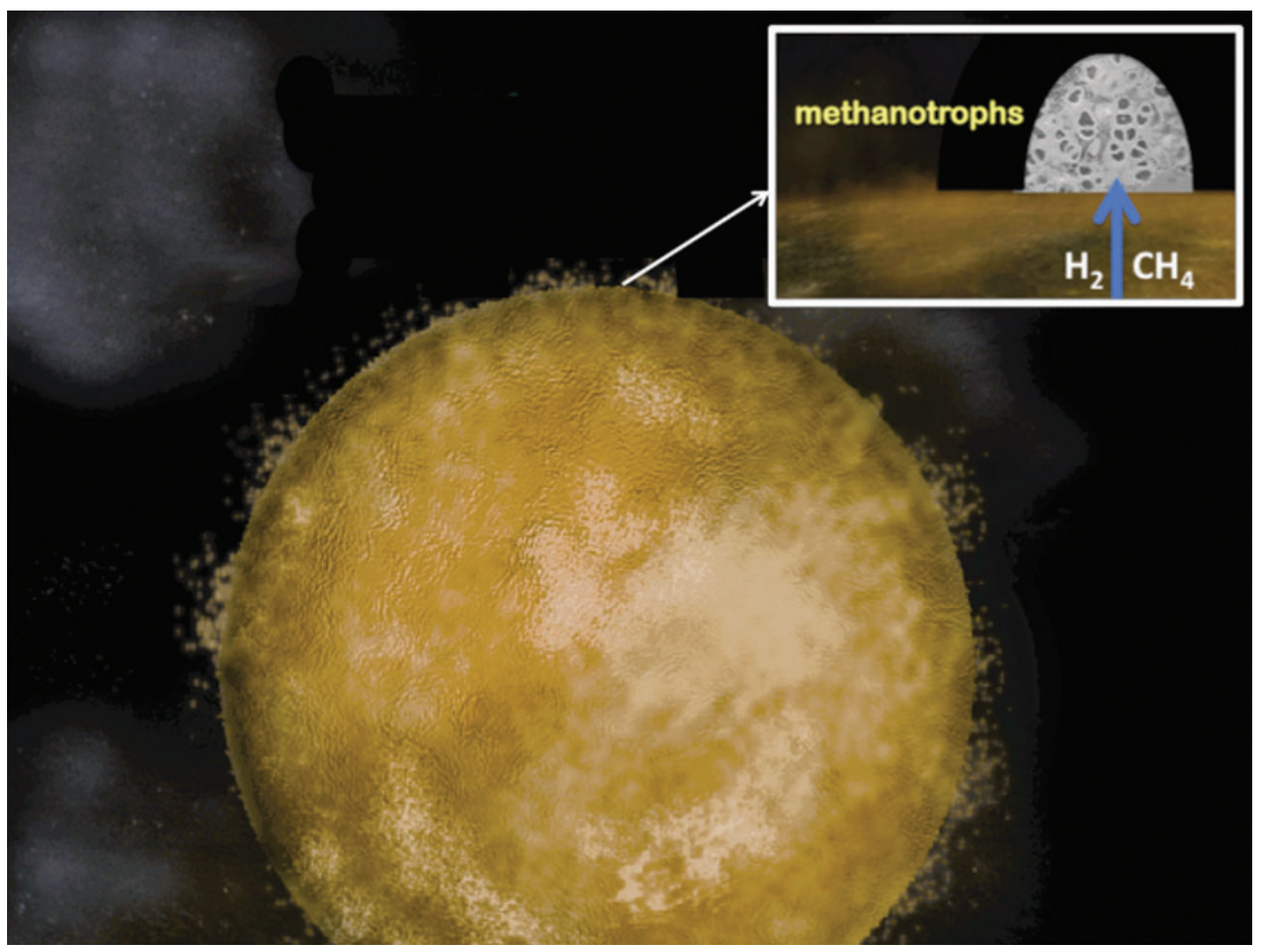

FIG. 3. Picture of the Hadean water world. The first ocean was $\geq 5 \mathrm{~km}$ deep, entirely submerging any proto-continents (Bounama et al., 2001; Elkins-Tanton, 2008). Inset sketch shows how a proto-biotic methanotrophic community could have been nurtured by the methane and hydrogen emanating at a submarine alkaline vent on the Hadean Earth's ocean floor. The polarity of the water world is similar to that of a prokaryote, generally reduced on the inside and oxidized on the outside so that electrons are transported by various mechanisms toward the exteriors of both (Russell and Hall, 1997). Protons (or acidic volatiles) are also continuously pumped to the exterior of both, the one through volcanoes and certain very hot springs, the other by various enzymes such as Complexes I, III, and IV. (Photographs courtesy of Minik Rosing and Billy Brazelton.)

nitrogen entities, and $\mathrm{Fe}^{\mathrm{III}}$ _produced through oxygenic photosynthesis. Then as now, trace elements, particularly some d-block metals, have to be delivered in optimal concentrations to play their part in hydrogenation, dehydrogenation, carboxylation, and electron transfer (Nitschke et al., 2013). It is likely that, in the absence of genetic guidance, some of the nitrate and nitrite may have been reduced all the way to ammonia on oxidation of a portion of the fougèrite to magnetite and of mackinawite to iron oxides and oxyhydroxides, so adding a peripheral source for assimilation of this key molecule (Table 2) (Hansen et al., 1996; Hansen and Koch, 1998; Gordon et al., 2013).

Figures 1-3 sketch the overall geological and geochemical context of the onset of this putative denitrifying methanotrophic acetogenic metabolism from the bottom up, while Fig. 5 demonstrates what we consider to be the two major dynamic phase transitions, that is, (i) from geochemistry to a metabolism whereby information is directly propagated through mineral and peptide recognitions, growth, and other thermodynamic physicochemical imperatives (Cairns-Smith, 2008; Milner-White and Russell, 2011; Greenwald and Riek, 2012; $c f$. Hoffmann, 2012; Kang et al., 2013) and (ii) from metabolism to a fully functioning recognizable biochemistry through coded guidance toward attractor states (Corliss, 1986; Koonin and Martin, 2005;
Yarus, 2011; Goodwin et al., 2012). A particular major commonality between modern cells and the hydrothermal mound lies in the structures of the metal sulfide and oxide enzymes and their similarity with mineral sulfides and oxides likely to be precipitated in the hydrothermal moundthemselves subject to proton, redox, and temperature gradients (Russell and Hall, 1997, 2006; Baymann et al., 2003; Volbeda and Fontecilla-Camps, 2006; Rickard and Luther, 2007; McGlynn et al., 2009; Rivas et al., 2009; Helz et al., 2013; Nitschke et al., 2013) (Fig. 4).

Our current hypothesis differs from our earlier formulations (Russell and Martin, 2004) in that we now invoke the use of methane as well as hydrogen as both fuel and substrate, and call on nitrate and nitrite to oxidize the $\mathrm{CH}_{4}$, while hydrogen, assisted by the ambient steep proton gradient, reduces $\mathrm{CO}_{2}$ to $\mathrm{CO}$ (Nitschke and Russell, 2013). We now consider that $\mathrm{CH}_{4}$ and $\mathrm{CO}_{2}$ are equal sources of carbon for proto-biosynthesis (Fig. 6a). This contrasts with the Huber and Wächtershäuser (1997) view that the primordial initiation reaction for a chemoautotrophic origin of life was the acetyl coenzyme A pathway pulled solely in the reductive direction from $\mathrm{CO}_{2}$ by pyrite formation.

The discovery of the Lost City vent field in 2000 inspired new interest in the alkaline hydrothermal hypothesis (Kelley et al., 2001; Martin et al., 2008). And the ongoing 
Table 1. Top-Down Imperatives of Life Compared to Bottom-Up Electrochemical Tensions AND THEIR LIKELY EXPENDITURES

References

Top down

Overall, life requires convection (or advection) for delivery of nutrients and removal of waste.

While minimizing internal entropy, cells export entropy to the environment through the use of molecular motors or nanoengines.

All life derives from a single ancestor.

All independent life-forms are cellular and compartmentalized with "chemiosmotic" membranes housing ATPases.

Gluconeogenesis predates glycolysis.

The first bacteria and archaea were autotrophic.

All autotrophic organisms use a redox gradient within the bounds of $\sim 180 \mathrm{mV}$ to $1.2 \mathrm{~V}$.

The acetyl coenzyme A pathway is the oldest and simplest known.

Redox bifurcation is used to overcome uphill reactions (quinones, flavins, NAD, methanophenazine, Mo and W enzymes).

LUCA enzymes comprise ferredoxins, acetyl-CoA synthase (ACS), carbon monoxide dehydrogenase $(\mathrm{CODH}),[\mathrm{NiFe}]$-hydrogenase, hydrogenlyase, and Mo-pterins, all assembled from a "redox protein construction kit."

Alkaline conditions support amine, phosphate, thiol, and sugar chemistries as well as general self-assembly and condensations.

Lost City Methanosarcinales that thrive at $\mathrm{pH} 9-10$ and $70-80^{\circ} \mathrm{C}$ use $\mathrm{H}_{2}$ and $\mathrm{CH}_{4}$ as fuels and sulfate (or perhaps nitrate) as electron acceptor and produce $\mathrm{CO}_{2}$ and possibly acetate as waste.

\section{Bottom up}

The emergence of life is coupled to convection.

Submarine alkaline systems resulting from serpentinization during hydrothermal convection are low entropy and feed $\mathrm{H}_{2}, \mathrm{CH}_{4}$, and minor $\mathrm{NH}_{3}$ to the ocean floor.

Submarine alkaline systems produce mounds comprising inorganic compartments.

All the inorganic elements required for life to emerge are supplied from either ocean or spring.

Inorganic compartments at the margins of submarine mounds may promote reactions between $\mathrm{CO}_{2}, \mathrm{NO}_{3}^{-}, \mathrm{NO}_{2}^{-}$and $\mathrm{Fe}^{\mathrm{III}}$ in the ocean and hydrothermal $\mathrm{H}_{2}$ and $\mathrm{CH}_{4}$

Proton and redox gradients are an inevitable aspect of interfacing an acidulous ocean and alkaline hydrothermal fluid across a spontaneously precipitated inorganic membrane.

Electrochemical gradient energy availability $($ redox $+\mathrm{pH})$ at such springs totals up to $\sim 1 \mathrm{~V}$.

Alkaline hydrothermal fluids promote certain reductions, aminations, condensations, and polymerizations.

Mo and W presence could enable uphill thermodynamic reactions through redox bifurcation.

The structures of mackinawite and greigite are affine with $[\mathrm{FeFe}]-$ and [FeNi]-hydrogenase and $\mathrm{ACS}$ and $\mathrm{CODH}$, and of fougèrite to methane monooxygenase.

Thermal gradients drive a convective polymerase chain reaction and the concentration of charged polymers through thermal diffusion.

The duration of alkaline springs in steady state is $>30,000$ years or $>10^{17} \mu \mathrm{s}$ - presumed time enough to drive disequilibria-driven pathways toward the production of the complex organic molecules required of life's first chemical and mechanical operations?
Open University Course Team, 1993; Russell and Arndt, 2005

Leduc, 1911; Westheimer, 1962; Wicken, 1987; Boyer, 1997; Hoffmann, 2012

Woese et al., 1990; Doolittle, 1999; Harris et al., 2003

Leduc, 1911; Mitchell, 1979a, 1979b; Kell, 1988; Boyer, 1997; Spitzer and Poole, 2009

Say and Fuchs, 2010; Fuchs, 2011

Berg et al., 2010; Fuchs, 2011

Thauer et al., 1977; Ducluzeau et al., 2009

Fuchs, 1989, 2011; Crabtree, 1997

Herrmann et al., 2008; Nitschke and Russell, 2009; Kaster et al., 2011; Buckel and Thauer, 2013

Baymann et al., 2003; Nitschke and Russell, 2009; Schoepp-Cothenet et al., 2012; Nitschke et al., 2013

$a b$ intra; Mellersh and Smith, 2010; Cafferty et al., 2013

Brazelton et al., 2011; Lang et al., 2012

Baross and Hoffman, 1985; Russell et al., 1989, 1994, 2010; Shock, 1992

Russell et al., 1989, 1994, 2003, 2013; Nitschke and Russell, 2009, 2013; Simoncini et al., 2011

Russell et al., 1989, 1994; Kelley et al., 2005; Mielke et al., 2010, 2011; McGlynn et al., 2012

Russell and Hall, 1997, 2006; Nitschke and Russell, 2009

Nitschke and Russell, 2013; Russell et al., 2013

Russell et al., 1994; Russell and Hall, 1997, 2006

Russell and Hall, 1997, 2006; Ducluzeau et al., 2009; Nitschke and Russell, 2009; Barge et al., 2014

Huber and Wächtershäuser, 1997, 2003

Nitschke and Russell, 2009, 2011

Morse and Arakaki, 1993; Russell and Hall, 1997, 2006; McGlynn et al., 2009; Nitschke et al., 2013

Braun et al., 2003; Baaske et al., 2007; Mast and Braun, 2010; Mast et al., 2012, 2013

Ludwig et al., 2011 
a
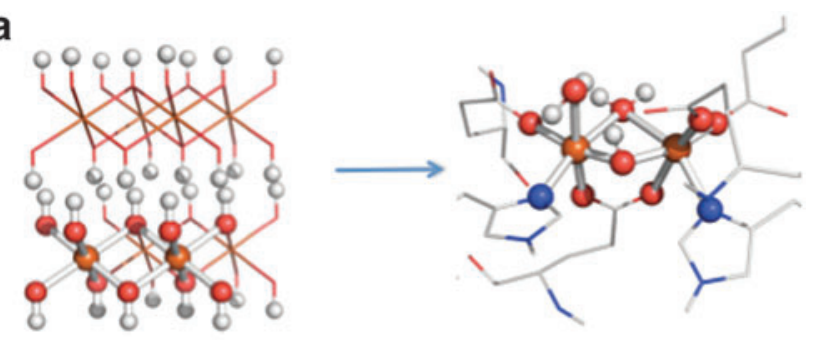

b

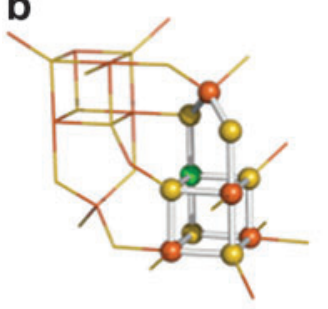

C
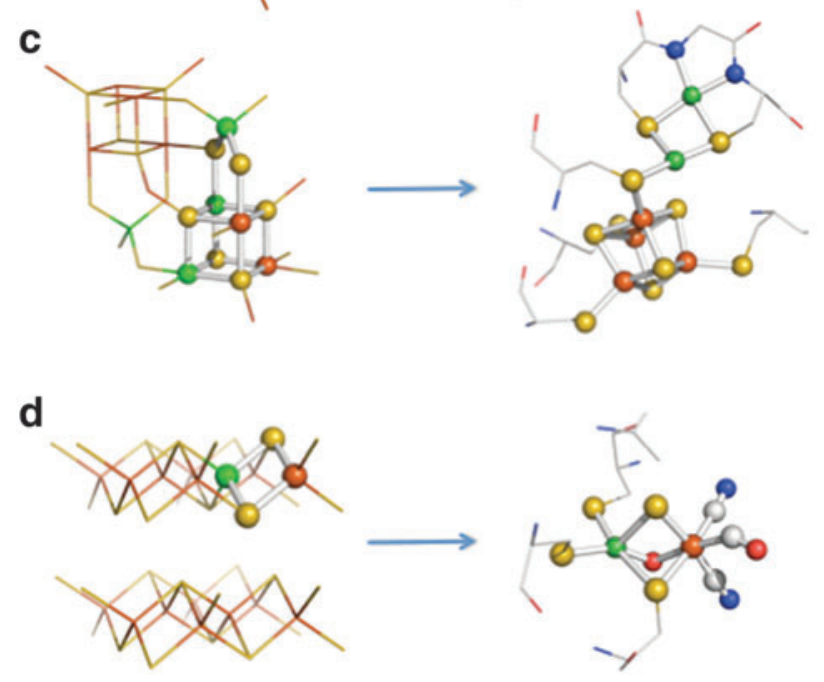

FIG. 4. Structural comparisons between transition element sulfides and oxides of the kind found in the precipitate membranes with the active sites of metalloenzymes present in the LUCA: (a) ferrous hydroxide $\left[\mathrm{Fe}(\mathrm{OH})_{2}\right]_{\mathrm{n}}$ (cf. brucite)prone to oxidation to $\sim \mathrm{Fe}_{2}(\mathrm{OH})_{5}$ (fougèrite) —with methane monooxygenase, (b) greigite and acetyl coenzyme-A synthase, (c) violarite and $\mathrm{CO}$ dehydrogenase, (d) nickelian mackinawite and [Ni-Fe] hydrogenase (Mielke et al., 2011; Nitschke et al., 2013).

operations of the particular biota elucidated there are equally encouraging, since one of the dominant microbiological processes as exploited by one type of Methanosarcinales reprises what we take to be the very first biochemical process-one that exploits both hydrogen and methane as fuel and sulfate as an electron acceptor (Fig. 6b) (Brazelton et al., 2011). (In our view the chief electron acceptor and provider of the oxygen to methanol in the first metabolist would have been nitrite rather than sulfate.) The aspect of the theory that calls upon methane as one carbon source is given further credence in principle through the identification of an archaeon, "Candidatus Methanoperedens nitroreducens," that oxidizes methane using nitrate as an electron acceptor through a complete reversal of the methanogenesis pathway (Haroon et al., 2013). Of course, we are not suggesting that these methanotrophs are in any way the direct descendants of those microbes that first emerged at the alkaline submarine mound, but merely that they facilitate a similar metabolism. Once these first, and steepest, of steps along pathways that lead to activated acetate were scaled, that is, $\mathrm{CO}_{2}$ reduction and $\mathrm{CH}_{4}$ oxidation, a gently undulating thermodynamic plateau was reached where subsequent reactions proved to be either exergonic in mildly alkaline solution or required a limited infusion of free energy (Table 2). Such reactions are considered next.

\section{Exergonic Reactions Favored by the Alkaline to Acid Hydrothermal Environment}

Hot springs in mafic and ultramafic environments all produce reduced molecules, and those alkaline springs exhaling at Lost City are no exception (Kelley et al., 2001; Douville et al., 2002). The Lost City alkaline solutions carry millimolar concentrations of hydrogen and methane, and micromolar amounts of formate and nanomolar concentrations of $\mathrm{C}_{2}-\mathrm{C}_{4}$ hydrocarbons (Proskurowski et al., 2006, 2008; Konn et al., 2009; Lang et al., 2010). Laboratory studies on organic molecules dissolved in alkaline solution were first pursued by Butlerov (1861). In experiments with some affinity to biochemical cycles, he demonstrated the synthesis of a variety of sugars from formaldehyde in solutions dosed with calcium hydroxide. Once trioses are formed in such experiments, more specific oligomerizations to tetrose and fructose ensue (Table 2). Indeed, Mellersh and Smith (2010) pointed out that "life uses a reaction very similar to that of Butlerov but controls it using phosphorylated substrates." In this regard, it is notable that glyceraldehyde, an early product, is easily phosphorylated to glyceraldehyde-3-phosphate (Kolb and Orgel, 1996). Huber and Wächtershäuser (1997) demonstrated the benefit of alkaline solutions in their production of activated acetatethe substrate for biosynthesis in the acetyl coenzyme A pathway-from methane thiol and $\mathrm{CO}$ with nickel as catalyst (and see Fig. 6a). A key reaction in the pathway is the non-enzymatic condensation of formaldehyde to methylene tetrahydrofolate (Friedkin, 1963), a vital step in the oxidative tributary to the proto-acetyl-CoA pathway as newly formulated by Nitschke and Russell (2013). Coenzyme A itself is a thiol, and life has taken full advantage of the fact that sulfur is equally at home ligated to the transition metals as it is bound to carbon and with itself (Beinert, 2000a, 2000b). Coenzyme B and coenzyme M, which are involved in methanotrophy and methanogenesis, are also thiols. The ability of sulfur to bind with itself is significant not only to catalysis and energetics but also to the early development of homeostasis; organic sulfides could have been directly converted to insoluble dithiols through the action of protons derived from the acidulous ocean through the membrane (Russell et al., 1994). Bracher et al. (2011) showed how thiol-thioester exchange of organic moieties is more rapid than hydrolysis at relatively high $\mathrm{pH}$ (and see Schouten et al., 1993; Schneckenburger et al., 1998), which suggests that sulfur-mediated exchange processes are more important than oxygen-mediated processes.

There are many other experimental examples of the synthesis of organic entities from the simplest of molecules in alkaline hydrothermal solutions of moderate temperature 
Table 2. Abiotic Reactions of Likely Relevance to Early Metabolism In Aqueous Alkaline Conditions $\left(\mathrm{PH}=12-6.1 ; T=4-100^{\circ} \mathrm{C}\right)$

\begin{tabular}{|c|c|c|}
\hline Reaction type and product & Conditions & References \\
\hline $\begin{array}{l}\mathrm{H}_{2} \text { generation } 2 \mathrm{H}_{2} \mathrm{O}+3 \mathrm{Fe}_{2} \mathrm{SiO}_{4} \\
\quad \rightarrow 2 \mathrm{H}_{2}+2 \mathrm{Fe}_{3} \mathrm{O}_{4}+3 \mathrm{SiO}_{2}\end{array}$ & $\begin{array}{c}\text { Actualistic (Lost City) } \\
\text { pH 9-11, } \leq 150^{\circ} \mathrm{C}, \leq 15 \mathrm{mM} / \mathrm{kg}\end{array}$ & Proskurowski et al., 2006 \\
\hline $\mathrm{C}$ hydride generation $4 \mathrm{H}_{2}+\mathrm{CO}_{2} \rightarrow \mathrm{CH}_{4}+2 \mathrm{H}_{2} \mathrm{O}$ & pH 9-11, $\leq 150^{\circ} \mathrm{C}, \leq 2 \mathrm{mM} / \mathrm{kg}$ & Proskurowski et al., 2008 \\
\hline Formate generation $\mathrm{H}_{2}+\mathrm{CO}_{2} \rightarrow \mathrm{HCOO}^{-}+\mathrm{H}^{+}$ & pH 9-11, $\leq 150^{\circ} \mathrm{C}, \leq 144 \mu M / \mathrm{kg}$ & Lang et al., 2010 \\
\hline Fructose $2 \mathrm{C}_{3} \mathrm{H}_{6} \mathrm{O}_{3} \rightarrow \mathrm{C}_{6} \mathrm{H}_{12} \mathrm{O}_{6}$ & $\begin{array}{l}\text { Experimental/Theoretical } \\
\mathbf{p H} \sim \mathbf{1 1 . 5}, 25^{\circ} \mathrm{C}\end{array}$ & Berl and Feazel, 1951 \\
\hline $\begin{array}{l}\text { Tetrose } 2 \mathrm{HOCH}_{2}-\mathrm{CH}=\mathrm{O}+\mathrm{Na}_{2} \mathrm{SiO}_{3} \rightarrow(2 \mathrm{HCl}) \\
\quad \rightarrow \mathrm{C}_{4} \mathrm{H}_{8} \mathrm{O}_{4}+\mathrm{SiO}_{2}\left(\text { and } \mathrm{H}_{2} \mathrm{O}+2 \mathrm{NaCl}\right)\end{array}$ & pH 9, $25^{\circ} \mathrm{C}$ & Lambert et al., 2010 \\
\hline $\begin{array}{l}\text { Ribose 5-phosphate (via acetyl-CoA?) } \\
\text { to glyceraldehyde 3-phosphate and DHAP }\end{array}$ & High pH, $25^{\circ} \mathrm{C}$ & $\begin{array}{l}\text { Mellersh and Smith, 2010; } \\
\text { Miljković, } 2009\end{array}$ \\
\hline $\begin{array}{l}2 \mathrm{CHO} \cdot \mathrm{CH}_{2} \mathrm{OH} \rightarrow\left(\mathrm{Na}_{2} \mathrm{SiO}_{3}\right) \rightarrow \mathrm{HO} \cdot \mathrm{SiO}_{4} \cdot\left(\mathrm{C}_{2} \mathrm{H}_{4} \mathrm{O}_{2}\right)_{2} \\
\quad \rightarrow\left(\mathrm{H}^{+}+\mathrm{H}_{2} \mathrm{O}\right)+\mathrm{C}_{4} \mathrm{H}_{8} \mathrm{O}_{4} \gg \sim \mathrm{C}_{6} \mathrm{H}_{12} \mathrm{O}_{5} \\
\quad \text { and } \mathrm{C} 2+\mathrm{C} 3 \text { sugars } \rightarrow \sim \mathrm{C} 5\end{array}$ & $\begin{array}{l}\text { High } \mathbf{p H}, 25^{\circ} \mathrm{C} \text {, Aldol reactions } \\
\text { between } \mathrm{C} 2 \text { and } \mathrm{C} 3 \text { sugar } \\
\text { silicates condense with } \mathbf{H}^{+}\end{array}$ & Lambert et al., 2010 \\
\hline $\mathrm{HCHO}+\mathrm{H}_{4}$ Folate $\rightarrow \mathrm{CH}_{2}-\mathrm{H}_{4}$ Folate & Moderately alkaline, $25^{\circ} \mathrm{C}$ & Friedkin, 1963 \\
\hline $\begin{array}{l}\text { Acetate } \mathrm{H}_{3} \mathrm{SH}+\mathrm{CO}+\mathrm{H}_{2} \mathrm{O} \rightarrow \mathrm{CH}_{3} \mathrm{COOH}+\mathrm{H}_{2} \mathrm{~S} \\
\quad \text { via } \mathrm{CH}_{3} \mathrm{SH}+\mathrm{CO}+\mathrm{NiX} \rightarrow \mathrm{CH}_{3} \mathrm{COS} \cdot \mathrm{NiX}\end{array}$ & $\begin{array}{l}\mathbf{p H}>\sim 7,100^{\circ} \mathrm{C}, \text { yield }>25 \% \\
\text { with } \mathrm{NiS} \text { or } \mathrm{NiSO}_{4}\end{array}$ & $\begin{array}{l}\text { Huber and Wächtershäuser, } \\
1997\end{array}$ \\
\hline $\begin{array}{l}\text { Ammonia } 6 \mathrm{Fe}^{2+}+7 \mathrm{H}^{+}+\mathrm{NO}_{2}^{-} \\
\rightarrow 6 \mathrm{Fe}^{\mathrm{III}}+2 \mathrm{H}_{2} \mathrm{O}+\mathrm{NH}_{3}\end{array}$ & pH 8, $>25^{\circ} \mathrm{C}$, yield $\sim 85 \%$ & Summers and Chang, 1993 \\
\hline $\begin{array}{l}\text { Ammonia } \mathrm{FeS}+5 \mathrm{H}_{2} \mathrm{O}+9 \mathrm{NO}^{2-} \\
\rightarrow \mathrm{Fe}^{3+}+\mathrm{SO}_{4}{ }^{2-}+9 \mathrm{NO}+10 \mathrm{OH}^{-} \\
\text {and } 16 \mathrm{H}_{2} \mathrm{O}+9 \mathrm{NO}+5 \mathrm{FeS}^{2-} \\
\rightarrow 9 \mathrm{NH}_{3}+5 \mathrm{Fe}^{3+}+5 \mathrm{SO}_{4}{ }^{2-}+5 \mathrm{OH}^{-}\end{array}$ & $\begin{array}{l}\text { pH } 10.3,70^{\circ} \mathrm{C} \text {, yield } \sim 2 \% \\
\quad\left(\sim 40 \% \text { at } 120^{\circ} \mathrm{C}\right)\end{array}$ & Gordon et al., 2013 \\
\hline $\begin{array}{l}\text { Ammonia } 4 \mathrm{Fe}_{4}^{\mathrm{II}} \mathrm{Fe}^{\mathrm{III}}{ }_{2}(\mathrm{OH})_{12} \mathrm{SO}_{4}+6 \mathrm{OH}^{-}+\mathrm{NO}_{3}{ }^{-} \\
\quad \rightarrow 8 \mathrm{Fe}_{3} \mathrm{O}_{4}+25 \mathrm{H}_{2} \mathrm{O}+4 \mathrm{SO}_{4}{ }^{2-}+\mathrm{NH}_{3}\end{array}$ & pH 8.25, $25^{\circ} \mathrm{C}$, high yield & Hansen et al., 1996 \\
\hline Ammonia $\mathrm{N}_{2}(\mathrm{aq})+3 \mathrm{H}_{2}(\mathrm{aq}) \rightarrow 2 \mathrm{NH}_{3}(\mathrm{aq})$ & $\begin{array}{c}\text { pH 6.1-9.8, } 70^{\circ} \mathrm{C} \\
\mathrm{Fe}^{0} \sim 1 \mathrm{~m} M / \mathrm{kg}\end{array}$ & Smirnov et al., 2008 \\
\hline $\begin{array}{l}\text { Amino acids } \mathrm{H}_{2}+\mathrm{R} \cdot \mathrm{CH}_{2} \cdot \mathrm{CO} \cdot \mathrm{COOH}+\mathrm{NH}_{4} \mathrm{Cl} \\
\quad \rightarrow \mathrm{R} \cdot \mathrm{CH}_{2}\left(\mathrm{NH}_{2}\right) \mathrm{COOH}(\mathrm{A}, \mathrm{E}, \mathrm{F}, \mathrm{Y})+\mathrm{H}_{2} \mathrm{O}+\mathrm{HCl}\end{array}$ & $\begin{array}{l}\text { pH 8.3-10.5, 50-100 } \\
\quad \mathrm{FeS}, \mathrm{Fe}(\mathrm{OH})_{2}\end{array}$ & $\begin{array}{l}\text { Huber and Wächtershäuser, } \\
2003\end{array}$ \\
\hline Thiol-thioester exchange $\mathrm{R}^{\prime} \mathrm{SH} \rightarrow \mathrm{R}^{\prime \prime} \mathrm{SH}$ & $\mathbf{p H}>\mathbf{8}-\mathbf{9}, 23^{\circ} \mathrm{C}$ & Bracher et al., 2011 \\
\hline $\mathrm{RSSR}+\mathrm{R}^{\prime} \mathrm{SH} \rightarrow \mathrm{RSSR}^{\prime}+\mathrm{RSH}$ & pH $\sim 9.2$ to $10.3,25^{\circ} \mathrm{C}$ & $\begin{array}{l}\text { Stricks et al., 1962; Leclaire } \\
\quad \text { et al., } 2005\end{array}$ \\
\hline $\mathrm{H}^{+}+2 \mathrm{HPO}_{4}{ }^{2-} \rightarrow \mathrm{HP}_{2} \mathrm{O}_{7}^{3-}+\mathrm{H}_{2} \mathrm{O}$ & $\mathbf{p H} \sim 8$ to $9, \mathrm{GWB}$ & Russell and Hall, 1997 \\
\hline $\begin{array}{l}\text { Dipeptide pyrophosphate }+\mathrm{G}+\mathrm{A} \rightarrow \mathrm{GA} \\
\text { polyphosphate }+\mathrm{G}+\mathrm{A} \rightarrow \mathrm{GA} \\
\text { trimetaphosphate }+2 \mathrm{G} \rightarrow \mathrm{G}_{2}\end{array}$ & $\begin{array}{l}\text { pH 7-8, } 70^{\circ} \mathrm{C} \text {, yield } 0.5 \% \\
\text { pH 7-11, } 70^{\circ} \mathrm{C} \text {, yield } 13 \% \\
\text { pH 8-7, } 70^{\circ} \mathrm{C} \text {, yield } 36 \% \\
\text { pH 9, } 38^{\circ} \mathrm{C}, \text { yield } \leq 25 \%\end{array}$ & $\begin{array}{l}\text { Rabinowitz et al., 1969; } \\
\text { Rabinowitz and Hampaï, } \\
\text { 1985; Gao et al., 2008; } \\
\text { Yamanaka et al., } 1988\end{array}$ \\
\hline $\begin{array}{l}\text { Ferredoxin analogue } \mathrm{HOCH}_{2} \mathrm{CH}_{2} \mathrm{SH} / \mathrm{FeCl}_{2} / \mathrm{HS}^{-} \\
\quad \rightarrow\left[\mathrm{Fe}_{4} \mathrm{~S}_{4}\left(\mathrm{SCH}_{2} \mathrm{CH}_{2} \mathrm{OH}\right)_{4}\right]^{2-/ 3-}\end{array}$ & $\mathbf{p H} \sim \mathbf{8}, \sim 25^{\circ} \mathrm{C}$ & Bonomi et al., 1985 \\
\hline $\begin{array}{l}\text { Nickel tetraglycine } \\
\mathrm{Ni}^{\mathrm{II}}\left[\mathrm{NH}_{2} \mathrm{CH}_{2} \mathrm{CONCH}_{2} \mathrm{CONCH}_{2} \mathrm{CONCH}_{2} \mathrm{COO}^{2-}\right.\end{array}$ & $\mathbf{p H} \sim \mathbf{8 . 1}, 25-37^{\circ} \mathrm{C}$ & $\begin{array}{l}\text { Martin et al., } 1960 \\
\text { Ma et al., } 1967\end{array}$ \\
\hline Cobalt tetraglycine $\mathrm{Co}^{\mathrm{II}} \mathrm{G}_{4}$ & $\mathbf{p H} \sim 9,25-37^{\circ} \mathrm{C}$ & Alipázaga et al., 2004 \\
\hline P-loop analogue Ser-Gly-Ala-Gly-Lys-Thr/HPO ${ }_{4}{ }^{2-}$ & $\mathbf{p H} \sim \mathbf{8 . 2}, 25^{\circ} \mathrm{C}$, yield $30 \%$ & Bianchi et al., 2012 \\
\hline Peptide P, Ser-Gly-Ala-Gly-Lys ${ }^{+}-\mathrm{HPO}_{4}{ }^{2}-\mathrm{Thr}$ & $\mathbf{p H} \sim \mathbf{1 0 . 4}, 25^{\circ} \mathrm{C}$, yield $65 \%$ & Bianchi et al., 2012 \\
\hline $\mathrm{Fe}^{2+}+2 \mathrm{HS}^{-} \rightarrow \mathrm{Fe}(\mathrm{HS})_{2} \rightarrow \mathrm{FeS}+\mathrm{H}_{2} \mathrm{~S}$ & pH 8, $\sim 25^{\circ} \mathrm{C}, 2 \mathrm{~nm}$ & Wolthers et al., 2003 \\
\hline Greigite $3 \mathrm{FeS}+\mathrm{H}_{2} \mathrm{~S} \rightarrow \mathrm{Fe}_{3} \mathrm{~S}_{4}+\mathrm{H}_{2}$ & $\mathbf{p H} \sim \mathbf{8 ?}, 70^{\circ} \mathrm{C}$ & Mielke et al., 2011 \\
\hline Selection of cis ribose with silica & pH $11.7,25^{\circ} \mathrm{C}$ & Lambert et al., 2004 \\
\hline Nucleic acids from formamide & $\begin{array}{l}\mathbf{p H}>7,110-160^{\circ} \mathrm{C} \text { mineral } \\
\text { catalyst }\end{array}$ & Saladino et al., 2012 \\
\hline Guanine oligomerization & $\mathbf{p H} \sim \mathbf{9}, 80^{\circ} \mathrm{C}$ & Norberg and Nilsson, 1995 \\
\hline Self-assembly of a triazine and a pyrimidine & pH 8, $25^{\circ} \mathrm{C}$ & Cafferty et al., 2013 \\
\hline RNA enzyme replication & pH 8.5, $42^{\circ} \mathrm{C} 1 \mathrm{~h}$ doubling time & Lincoln and Joyce, 2009 \\
\hline RNA polymerization & pH 8.4-(3.2), $40-90^{\circ} \mathrm{C}$ & Costanzo et al., 2009 \\
\hline $\begin{array}{l}\text { Convective polymerase chain reaction (cPCR) and } \\
\text { thermophoretic concentration of DNA }\end{array}$ & $\mathbf{p H} \sim \mathbf{8}, 50-95^{\circ} \mathrm{C}$ & $\begin{array}{l}\text { Saiki et al., 1988; } \\
\text { Braun et al., } 2003\end{array}$ \\
\hline Lipid vesicle formation & pH 8-10, $\sim 25^{\circ} \mathrm{C}$ & Hanczyc et al., 2003 \\
\hline Lipid vesicle concentration by thermophoresis & pH 8.5-11, $90-4^{\circ} \mathrm{C}$ & Budin et al., 2009 \\
\hline
\end{tabular}




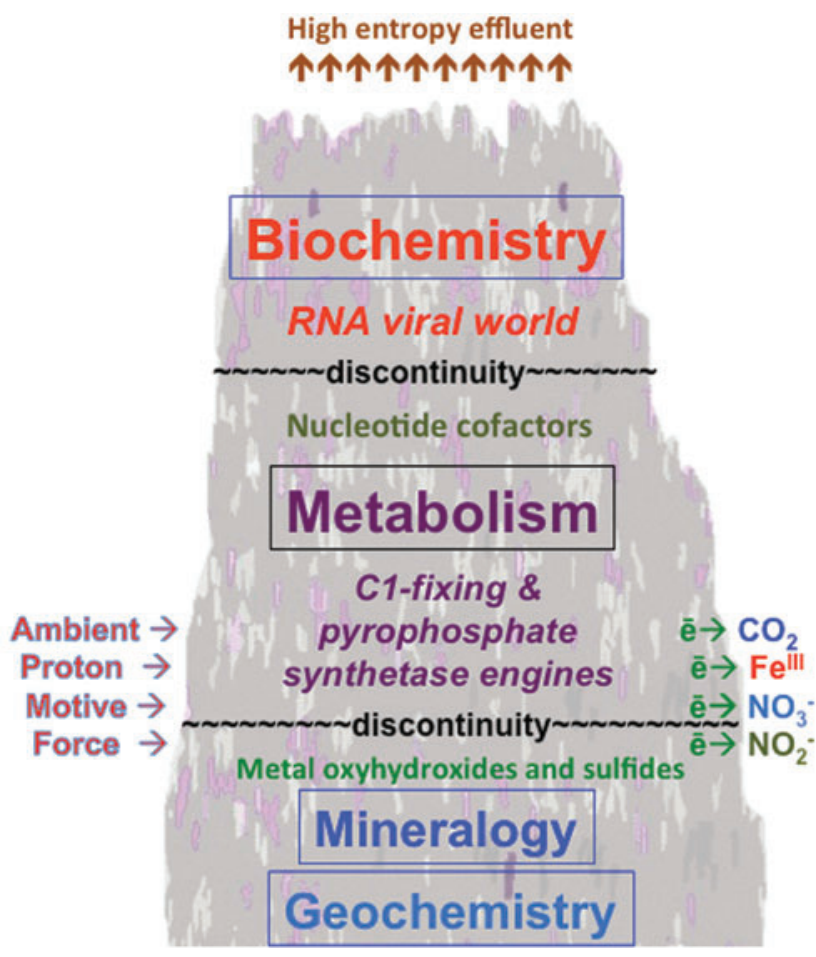

FIG. 5. This electro-geochemical hydrothermal system occupying a growing compartmentalized mound evolves through mineral recognition and propagation processes leading, through an amyloidal takeover, to a cofactor world which transforms through the stringing of bases along a peptide-like backbone into the RNA world capable of Darwinian evolution and the emergence of fully fledged autotrophic life (Russell et al., 1994; Milner-White and Russell, 2008; Yarus, 2011; Goodwin et al., 2012).

as would be expected from the alkaline hydrothermal theory. This is because alkaline conditions produce unprotonated organic anions, thiols, and phosphates that engender cascades of interactions and condensations. Table 2 lists a variety of reactions central to biosynthesis and proto-enzyme formation. Further examples are the synthesis of ammonia, and thence amino acids and peptides (Hansen et al., 1996; Huber and Wächtershäuser, 2003; Huber et al., 2003), the latter possibly generated on sphalerite or cleiophane (pristine $\mathrm{ZnS}$ ) (Ohara and Cody, 2010; cf. Boyce et al., 1983). At comparable $\mathrm{pH}$ values, two iron sulfides, mackinawite and its partial oxidation (or sulfidation) product greigite, are formed with structures similar to those in iron-sulfur proteins (Table 3, Fig. 4) (Russell and Hall, 1997, 2009; Rickard and Luther, 2007; Lin et al., 2009; CsákberényiMalasics et al., 2012; Nitschke et al., 2013). Indeed, the iron-sulfur cubane component of greigite can be thiolated to give a structure comparable to the cysteine-ligated ferredoxins (Bonomi et al., 1985). Milner-White and Russell $(2005,2011)$ suggested that the backbones to short (uncoded) peptides could act as the "nests" for both the $\mathrm{HPO}_{4}{ }^{2-}$ and the $\left[\mathrm{Fe}_{4} \mathrm{~S}_{4}\left(\mathrm{SC}_{6} \mathrm{H}_{5}\right)_{4}\right]^{2-}$ "eggs." The theoretical calculations of Hong Enriquez and Do (2012) indicate that peptides 8-10 residues long would even be capable of sequestering bare $\mathrm{Fe}_{4} \mathrm{~S}_{4}$ clusters, especially in the cooler reaches of the hydrothermal mound. Moreover, a soluble peptide involving a lysine, with a basic terminal amine residue, has been shown to sequester phosphate in a manner highly reminiscent of the P-loop motif found in all prokaryotes (Bianchi et al., 2012). Short peptides can also sequester the catalytic metal atoms nickel and cobalt (Martin et al., 1960; Ma et al., 1967). We can imagine a selection pressure that favors the sequestering of the smaller anions or cations by the longer peptides and thereby a positive feedback that improved rates of catalysis and proto-metabolism.

We note here that there are exceptions to the alkaline tendency to promote reactions. For example, glycylglycine (generated at high $\mathrm{pH}$ ) can be condensed through the activation of the carboxyl groups to tetraglycine with trimetaphosphate at $\mathrm{pH} 6.5$ (Yamanaka et al., 1988); and oligoglycines $\left(\mathrm{gly}_{4} \gg \mathrm{gly}_{6}\right.$ ) are generated, also with trimetaphosphate, optimally at $\mathrm{pH} 5$ and $38^{\circ} \mathrm{C}$ with $0.5 \mathrm{M} \mathrm{MgCl}_{2}$ as catalyst (Yamagata and Inomata, 1997) (Table 4). Pyrophosphate itself has also been produced from acetyl phosphate and orthophosphate at $\mathrm{pH} 6.5$ (de Zwart et al., 2004; Barge et al., 2014). These findings could be interpreted to favor the view that dipeptides were polymerized to tetrapeptides and beyond on the outer margins of the inorganic membrane. If so, one could imagine a peptide takeover of the inorganic membrane/wall in such a way that would not only improve its outer structure but also retain the inorganic centers vital to catalysis and electron transfer, thus improving their reactivities (Violante et al., 1995; Mielke et al. 2011; Milner-White and Russell, 2011; McGlynn et al. 2012). These conditions also favor reactions that play into stages or offshoots of the reverse (incomplete) tricarboxylic acid cycle (Fuchs and Stupperich, 1978; Wang et al., 2011). The iron sulfide catalysts of the type used by Wang and his coworkers should also be precipitated in a slightly more bulky form in the more acidic conditions that obtain at the outer periphery of the inorganic membranes (Rickard et al., 2001; Wolthers et al., 2003) (Table 3).

If these reactions were all there were to early life, we might ask what the problem is. It is those very first steps of carbon fixation and the ongoing requirement for condensations driven against water activity that are the challenge. We turn to these "uphill" entropy-reducing reactions next, bearing in mind that some of these could be coupled mechanistically to the exergonic reactions described above.

\section{Endergonic Reactions and the Need for Engines}

Once a metabolic system is established, many of the myriad of chemical reactions that take part in protobiochemical metabolic pathways, cycles, and networks are mildly exergonic, even in the absence of oxygen, as we have just detailed, and feed back positively to the organization (Amend and McCollom, 2009, Tables I, IV, and V; Amend et al., 2013). It is the entry points to the autotrophic pathways exacting a high free energy price that must first be assailed (Maden, 2000).

So what were the thermodynamic barriers that had to be climbed before life could get going from scratch? The first and most obvious is the fixation of carbon. It has been argued that, as the acetyl coenzyme A pathway is the simplest and probably the most ancient and cheapest energetically, and is used by certain autotrophs, all that has to be done is to find a way of copying it in an abiotic world in the lab (Wächtershäuser, 1990; Russell and Martin, 2004). It does look 


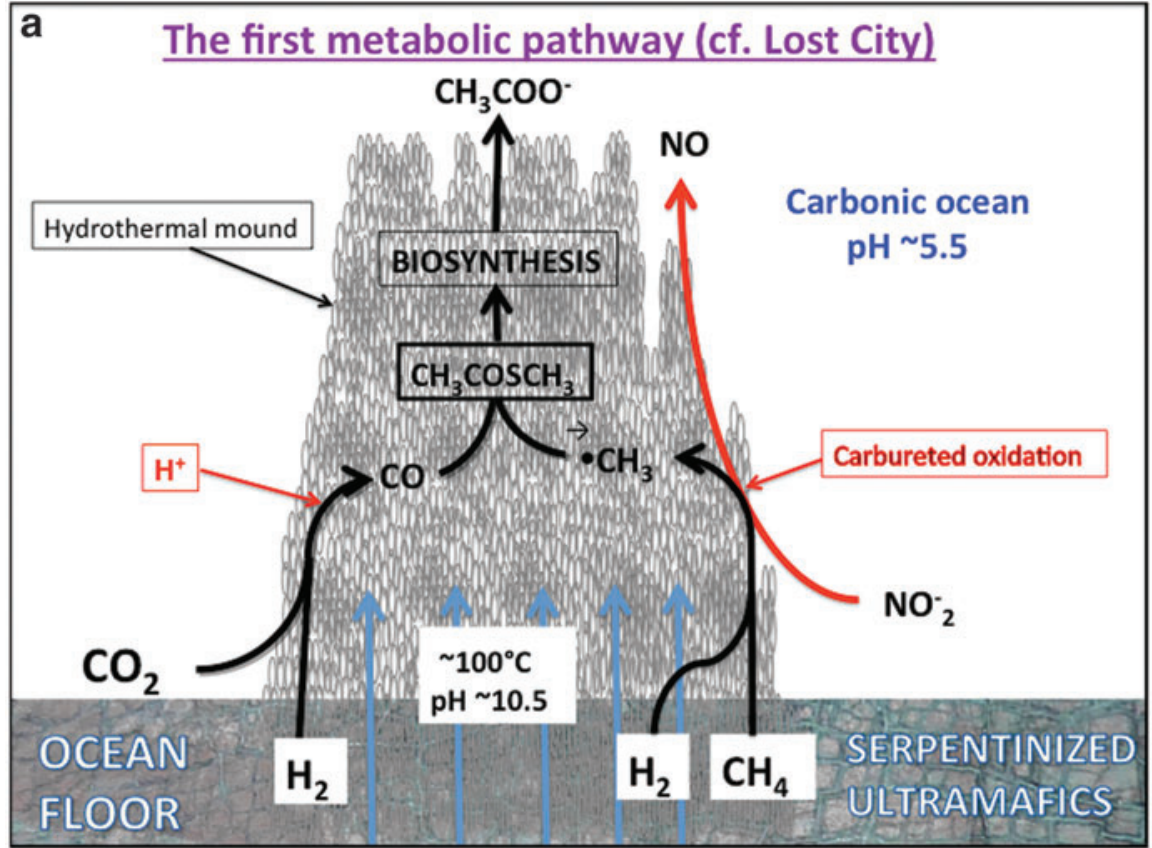

b

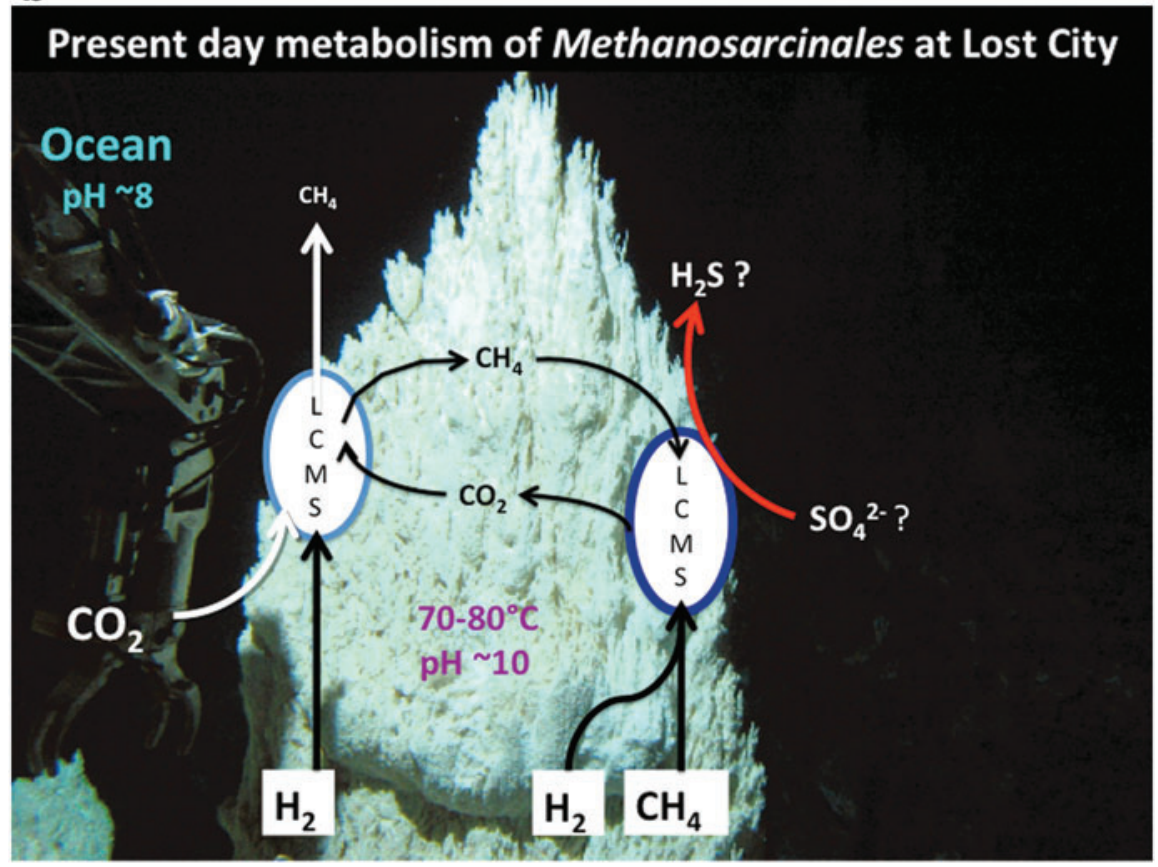

FIG. 6. (a) Schema to illustrate how the outer margins of a growing Hadean submarine hydrothermal alkaline mound could house carbon fixation engines. Electrons driving these engines are borne first by mass transfer in alkaline hydrothermal solution from the reduced crust as $\mathrm{H}_{2}$ and $\mathrm{CH}_{4}$ to the precipitate mound. Here they are split from $\mathrm{H}_{2}$ and $\mathrm{CH}_{4}$ at nickel sites in sulfides comprising the precipitate membranes and conducted via those sulfides and oxyhydroxides to interface high potential electron acceptors, especially nitrite and nitrate, while others reduce the low potential acceptor carbon dioxide aided by the proton gradient. (Just as convection requires a cold sink, emergent metabolism needs high potential electron sinks to operate.) The availability of these high potential acceptors nitrate and nitrite (dispersed cathodes) - although supplied continually through carburation and tidal currentsprobably limits the rate of protometabolism (Nitschke and Russell, 2009, 2013; Branscomb and Russell, 2013). (b) Diagram illustrating the similarities between the metabolic operations of Lost City Methanosarcinales (LCMS), as in the cell on the right, with the putative hatchery of life illustrated in Fig. 6a (Kelley et al., 2005). Acetate is also a possible waste product - a product consumed by another type of the same microbe, presumably in conditions of contrasting disequilibria (Hoehler and Alperin, 1996; Lang et al., 2010; Brazelton et al., 2011). straightforward, one $\mathrm{CO}_{2}$ molecule is reduced to $\mathrm{CO}$ while another is reduced to a methyl group, and the two are then condensed to an activated acetate. Yet only the last acetateforming step has been convincingly demonstrated (Huber and Wächtershäuser, 1997); the reduction of carbon dioxide at moderate temperatures beyond formate at significant yield has so far not been achieved in a laboratory setting. The abiotic reduction of $\mathrm{CO}_{2}$ to formaldehyde in aqueous solution is stymied by thermodynamic barriers so steep that even electrochemical efforts have failed the ascent (Maden, 2000; Vladimirov et al., 2004; Narayanan et al., 2011; cf. Schoonen et al., 1999). The second barrier is to condensation reactions in an aqueous environment, particularly the condensation of monophosphates and amino acids. Thus, because abiotic processes are not energetically conducive to carbon fixation and polymerizations, approaches that couple exergonic processes and steep gradients to these endergonic reactions by using a nanoengine are now considered.

\section{Searching for a Carbon-Fixation Nanoengine}

The oxidation of methane may offer a back door to the synthesis of activated acetate. Starokon and coworkers (2011) provided an indication of how this may have been facilitated. These authors oxidized methane to methanol even at room temperature through the $\alpha$-oxygen bonded to a 
Table 3. Likely Transition Metal Precipitates, Their Possible Chelators and Function, at a Sulfidic Alkaline Spring

\begin{tabular}{|c|c|c|c|}
\hline Mineral or cluster & Enzyme-protein & Chelator? & Reference \\
\hline $\begin{array}{l}\text { Mackinawite } \\
(\mathrm{Fe} \gg \mathrm{Ni}) \mathrm{S}\end{array}$ & $\begin{array}{l}\text { Ni-Fe hydrogenase } \\
\text { (Rieske protein) }\end{array}$ & $\begin{array}{l}\text { Thiolated egg in peptide } \\
\text { nests? }\end{array}$ & Bonomi et al., 1985 \\
\hline $\begin{array}{l}\text { Greigite as } \\
\quad \mathrm{FeSS}\left[\mathrm{Fe}_{4} \mathrm{~S}_{4}\right] \mathrm{SSFe}\end{array}$ & Ferredoxins & $\begin{array}{l}\text { Thiolated egg in peptide } \\
\text { nests? }\end{array}$ & Bonomi et al., 1985 \\
\hline $\begin{array}{l}\text { Greigite as } \\
\quad \mathrm{NiSS}\left[\mathrm{Fe}_{4} \mathrm{~S}_{4}\right] \mathrm{SSFe}\end{array}$ & $\begin{array}{l}\text { Carbon monoxide } \\
\text { dehydrogenase }\end{array}$ & $\begin{array}{l}\text { Thiolated egg in peptide } \\
\text { nests }\end{array}$ & Milner-White and Russell, 2011 \\
\hline $\begin{array}{l}\text { Violarite } \\
\sim \mathrm{NiSS}\left[\mathrm{Fe}_{2} \mathrm{Ni}_{2} \mathrm{~S}_{4}\right] \mathrm{SSNi}\end{array}$ & $\begin{array}{l}\text { Acetyl coenzyme A } \\
\text { synthase }\end{array}$ & $\begin{array}{l}\text { Ni-peptide and thiolated } \\
\text { egg in peptide nests }\end{array}$ & Milner-White and Russell, 2011 \\
\hline $\begin{array}{l}{\left[\mathrm{Fe}_{2} \mathrm{~S}_{2}\left(\mathrm{MoS}_{4}\right)_{2}\right]^{4-}} \\
\quad\left[\mathrm{Fe}_{2} \mathrm{~S}_{2}\left(\mathrm{MoO}_{2} \mathrm{~S}_{2}\right)_{2}\right]^{4-}\end{array}$ & {$\left[\mathrm{Fe}_{2} \mathrm{~S}_{2}\left(\mathrm{MoS}_{4}\right)_{2}\right]^{4-}$ (MorP) } & Not known & $\begin{array}{l}\text { Anglin et al., 1987; Helz et al., } \\
\text { 2013; Rivas et al., } 2009\end{array}$ \\
\hline $\begin{array}{l}\text { Fougèrite (green rust) } \\
\qquad \sim\left[\mathrm{Fe}^{\mathrm{II}} \mathrm{Fe} \mathrm{Fe}^{\text {III }}(\mathrm{OH})_{4}\right]^{+}[\mathrm{OH}]^{-}\end{array}$ & Methane monooxygenase & None known & $\begin{array}{l}\text { Trolard et al., 1997; Yoshizawa } \\
\quad \text { et al., } 2000\end{array}$ \\
\hline
\end{tabular}

cationic $\mathrm{Fe}^{2+}$ site standing proud within the cage of a manufactured synthetic iron-bearing pentasil zeolite, which acts too as an entropy trap (and see Panov et al., 2002; Kachurovskaya et al., 2004). However, it must be emphasized that the $\alpha$-oxygen-rich zeolite driving the reaction is prepared through endothermic oxidation of the synthetic zeolite by nitrous oxide at $200-250^{\circ} \mathrm{C}$ (Starokon et al., 2011, 2013; and see Schwarz, 2011; Sazama et al., 2013). Nevertheless, a further indication is afforded by known redox changes in ferrous hydroxides and fougèrite-clusters similar in structure to methane monooxygenase-that also facilitate aminations of carboxylic acids (Huber and Wächtershäuser, 2003; Nitschke et al., 2013) (Fig. 4). Microbiological support for a methanotrophic tributary to the acetyl-CoA pathway may be gleaned from the work of Ettwig and coworkers (2010). These authors showed that the oxidation of methane is achieved anaerobically by Methylomirabolis oxyfera through the concomitant reduction of nitrite. And Haroon and coworkers (2013) also demonstrated the biotic oxidation of methane with nitrate by the archaeon Methanoperedens nitroreducens. However, the process appears to be merely the reversal of methanogenesis, so it can hardly be considered primordial. We surmise that nitrite might drive a similar, though less efficient, partial oxidation of fougèrite, and that, given its structural similarity to the methane monooxygenase enzyme used by Methylomirabolis oxyfera, might have enabled the same reaction-an idea open to experimentation (Yoshizawa et al., 2000; Ettwig et al., 2010; Nitschke and Russell, 2013; Nitschke et al., 2013).

A pterin-molybdenum cofactor is required as part of the enzyme complex that facilitates oxidation of methane to a methyl group, a process which involves redox bifurcation with oxygen derived from NO (Ettwig et al., 2010). Martin and Russell (2007) pointed out that pterins and the like "might be more critical in getting an ancient but very complex biochemistry going than has traditionally been presumed," and this requirement appears ever more acute and remains unresolved (cf. Rebelo et al., 2003). Because of the easy passage between the oxidation states of molybdenum, the metal's involvement in redox bifurcation, its facility to bind sulfide (especially as $\mathrm{Mo}^{\mathrm{IV}}$ ) and oxygen (as $\mathrm{Mo}^{\mathrm{VI}}$ ), its proven wide use as an industrial catalyst, and its ubiquity throughout all life's domains, we assume that it acted in some form as a precursor to the pterins. Hence, our interest in the search for an abiotic locale for an active molybdenum atom prior to pterins becoming available, which would act as the redox bifurcation nanoengine (Branscomb and Russell, 2013). Inorganic cluster possibilities to be investigated in this regard include Mo atoms contained in sites in a mackinawite (FeS) cluster, linear tetranuclear clusters $\left[\left(\mathrm{MoO}_{2} \mathrm{~S}_{2}\right) \mathrm{Fe}_{2} \mathrm{~S}_{2}\right.$ $\left.\left(\mathrm{MoO}_{2} \mathrm{~S}_{2}\right)\right]^{4-},\left[\left(\mathrm{MoS}_{4}\right) \mathrm{Fe}_{2} \mathrm{~S}_{2}\left(\mathrm{MoS}_{4}\right)\right]^{4-}$, and $\left[\left(\mathrm{MoS}_{4}\right) \mathrm{FeO}(\mathrm{OH})\right.$ $\left.\left(\mathrm{MoS}_{4}\right)\right]^{3-}$, or as $\mathrm{Mo}(\mathrm{CN})_{8}^{4-/ 3-}$ in hydrotalcite, a layered double hydroxide comparable to fougèrite (Anglin et al.,

Table 4. Abiotic Condensations of Molecules/Precipitates, Some Previously Formed in Alkaline Conditions, Are Favored by Acidification Such as Could Be Construed to Occur in the Inorganic Membrane as Protons from the Ocean Diffuse through to the Alkaline Interior (Figure 6a)

\begin{tabular}{|c|c|c|}
\hline Reaction type & Theory/Experiment & References \\
\hline $2 \mathrm{gly}_{2}+$ trimetaphosphate $\rightarrow \mathrm{gly}_{4}$ & pH $6.5,38^{\circ} \mathrm{C}$ & Yamanaka et al., 1988 \\
\hline $2 \mathrm{gly}_{2} \rightarrow \mathrm{gly}_{4}$ & pH 5, $38^{\circ} \mathrm{C} / 0.5 \mathrm{M} \mathrm{Mg}^{2+} 12 \%$ yield & Yamagata and Inomata, 1997 \\
\hline $3 \mathrm{gly}_{2} \rightarrow$ gly $_{6}$ & pH $5,38^{\circ} \mathrm{C} / 0.5 \mathrm{M} \mathrm{Mg}^{2+} 1.4 \%$ yield & Yamagata and Inomata, 1997 \\
\hline $\begin{array}{c}\mathrm{CH}_{3} \mathrm{COPO}_{4}^{2-}+\mathrm{HPO}_{4}^{2-} \rightarrow \\
\mathrm{CH}_{3} \mathrm{COO}^{-}+\mathrm{HP}_{2} \mathrm{O}_{7}^{3-} \\
\text { substrate level to } \mathrm{PPi}\end{array}$ & $\mathbf{p H} \sim \mathbf{6 . 5}, \sim 35^{\circ} \mathrm{C}$ to $55^{\circ} \mathrm{C}$ catalyst $\mathrm{Fe}^{2+}$ & de Zwart et al., 2004 \\
\hline $\begin{array}{l}\text { Lactate } \rightarrow \text { pyruvate } \\
\text { malate } \rightarrow \text { oxaloacetate } \\
\text { glycolate } \rightarrow \text { glyoxylate }\end{array}$ & $\mathbf{p H} \leq \mathbf{7}, 100^{\circ} \mathrm{C} \mathrm{FeS} / \mathrm{S} / \mathrm{FeS}_{2}$ & Wang et al., 2011 \\
\hline $\mathrm{Fe}^{2+}+\mathrm{H}_{2} \mathrm{~S} \rightarrow \mathrm{FeS}+2 \mathrm{H}^{+}$ & pH 6, $\sim 25^{\circ} \mathrm{C}, 7 \mathrm{~nm}$ & Wolthers et al., 2003 \\
\hline $3 \mathrm{FeS}+4 \mathrm{H}_{2} \mathrm{~S} \rightarrow(\mathrm{HCHO}) \rightarrow \mathrm{Fe}_{3} \mathrm{~S}_{4}+8 \mathrm{H}_{2}$ & pH 6, $40-100^{\circ} \mathrm{C}$ & Rickard et al., 2001 \\
\hline
\end{tabular}


1987; Itaya et al., 1987; Nitschke and Russell, 2011; Geim and Grigorieva, 2013; Helz et al., 2013; Nicolosi et al., 2013) (Table 3). The linear sulfide clusters in particular may have been ligated non-covalently to a peptide (Burgmayer and Stiefel, 1985; Rivas et al., 2009; Nitschke and Russell, 2011; Schoepp-Cothenet et al., 2012). To be borne in mind when considering a possible precursor is the need for exposed sites for the molybdenum atom(s) and for protonation sites, perhaps afforded by the distal sulfurs (Nitschke and Russell, 2009; Jacques et al., 2014). Of course, once short peptides involving serine and cysteine became available, a scaffold for a peptide-coordinated molybdenum center might have emerged to act as an interim redox-bifurcating catalyst (Dutta et al., 2012; Jacques et al., 2014).

The other intermediate in the denitrifying methanotrophic acetogenic pathway is carbon monoxide, derived by the reduction of carbon dioxide in a reaction that is also thermodynamically uphill and therefore also requires a proton gradient and redox bifurcation (Maden, 2000; Nitschke and Russell 2009, 2013). In our hypothesis, the catalyst for this reaction is a nickel-bearing greigite cluster $\left(\mathrm{SNiS}\left[\mathrm{Fe}_{4} \mathrm{~S}_{4}\right]\right.$ $\mathrm{SFeS}$ ), the assumed precursor of carbon monoxide dehydrogenase ( $c f$. Vaughan and Craig, 1978; Dobbek et al., 2001) (Fig. 4). A single electron from a contiguous molybdenum site is presumed to reduce the greigite as the paired electron reduces fougèrite, which itself was previously oxidized by nitrite or nitrate ( $c f$. Ragsdale, 1997; Hansen and Koch, 1998). (In our view, both electrons are derived through the oxidation of hydrothermal hydrogen to protons on a nickel-bearing mackinawite and are, we imagine, attracted separately to the respective $\mathrm{Fe}^{\mathrm{III}}$ sitesone "uphill" to the greigite and one "downhill" to the fougèrite.) Once the $\mathrm{CO}$ is sited as a nickel-carbonyl entity on the greigite, ligand-accelerated autocatalysis promotes reaction with methane thiol to produce the activated acetate (Huber and Wächtershäuser, 1997; Wächtershäuser, 2007; Haydon et al., 2011).

In this formulation of the acetyl coenzyme A pathway, the two proto-tributaries - one reducing $\mathrm{CO}_{2}$ to $\mathrm{CO}$, the other oxidizing and sulfidizing $\mathrm{CH}_{4}$ to $\mathrm{CH}_{3} \mathrm{SH}$-are driven from either end of redox space to converge as the methyl thiol reacts with a $\mathrm{CO}$ group coordinated to a nickel atom, itself a constituent of a greigite cluster that was one occupant of the precipitate membrane and acted as a precursor to acetyl coenzyme A synthase (Fig. 4) ( $c f$. Huber and Wächtershäuser, 1997; Crabtree, 1997; Russell and Martin, 2004). The resulting acetyl methyl sulfide $\left(\mathrm{CH}_{3} \mathrm{COSCH}_{3}\right)$ - the supposed precursor of acetyl-CoA-is the key intermediate to further hydrogenations, carboxylations, phosphorylations, and aminations deriving from stages in the incomplete reverse tricarboxylic acid cycle terminating at succinate and glyoxylate (de Duve, 1991; Morowitz et al., 2000; Huber and Wächtershäuser, 2003; Huber et al., 2003; Smith and Morowitz, 2004; Martin and Russell, 2007; Srinivasan and Morowitz, 2009; Braakman and Smith, 2013).

With these further steps required, it is clear that carbon fixation is only half the battle at the very origin of metabolism. We also need a mechanism of free energy conversion that can produce a chemically appropriate and diffusible source of free energy, plausibly a strong disequilibrium between a polyphosphate and orthophosphate. This would enable further endergonic reactions, particularly dehydration condensations, to be driven within the precellular environment, which we take to be the nanometric laminar pore spaces within the inorganic membranes (Mielke et al., 2011; Nitschke and Russell, 2013; Russell et al., 2013). Before taking up this challenge, we need to remind ourselves of how present-day life deals with the problem.

\section{How Life Now Makes and Dissipates Proton Gradients}

Referring back in particular to Complex 1 and ATPasethe interdependent examples of just two of the biological nanoengines operating in our own bodies-we note that the primary fuels are electrons and protons, or sodium and even potassium ions in some other organisms (Mitchell, 1976; Martin, 1992; Mulkidjanian et al., 2008; Buckel and Thauer, 2013). It is the electrons attracted exergonically in Complexes I, III, and IV toward the cell's high potential exterior that force protons to follow suit. Once the protons are strongly out of equilibrium with the cell's interior, they stream back down an extremely steep gradient through ATP synthetase, in turn driving a massive disequilibrium between a high concentration of ATP as against the pool of orthophosphate and ADP. Complex 1 and ATP synthetase are, of course, extraordinarily complicated and hence highly evolved piston-like $\alpha$-helices and eccentric nanorotary engines, respectively (Abrahams et al., 1994; Yoshida et al., 2001; Efremov and Sazanov, 2011a). Do these free energy converters have ancestors that might help us identify possible missing entities occupying the first membrane that exploited exergonic geochemical gradients and reactions to drive endergonic reactions? If so, what were they built with, and how were they assembled and constructed (Branscomb and Russell, 2013)? While approximately two electrons are required to translocate four protons through Complex 1, the endergonic condensation of one molecule of ATP through ATP synthetase costs three to four protons when driven by a typical proton motive force of $\sim 180 \mathrm{mV}$ (Mitchell and Moyle, 1965; Davies et al., 2011; Efremov and Sazanov, 2011b). Hedderich (2004) speculated that the ion-pumping nickel-iron hydrogenases from archaea and extremophilic bacteria acted as the ancestors of archaeal Complex 1 through the "addition of alternative electron-input domains, replacement of the $[\mathrm{NiFe}]$ center by a quinone-binding site and the addition of further membrane subunits." Whatever its ultimate ancestry, this engine/enzyme would not have been required across the margins of the mound at the emergence of life as external protons were provided at a concentration of $\sim 10^{-5} \mathrm{M}$ in the ocean as against a $\mathrm{H}^{+}$concentration of $\sim 10^{-11} \mathrm{M}$ on the inner surface-one of the telling advantages of the submarine alkaline hydrothermal theory.

While the ambient $\mathrm{pH}$ gradient across the walls of the hydrothermal mound releases us from a search for precursors to Complexes I, III, and IV, we do need to find precursors to what is the extraordinarily sophisticated rotary mechanism of ATP synthetase. Baltscheffsky (1971) suggested that something like a pyrophosphatase might have played a part in energizing proto-biosynthesis, an idea given experimental support by Moyle et al. (1972) (and see Baltscheffsky et al., 1999). A proton pyrophosphatase has now been characterized by Lin et al. (2012) and a sodium pyrophosphatase by Kellosalo et al. (2012). They are rather similar in structure, 
each consisting of 16 transmembrane helices, six of these comprising an inner flexible passageway surrounded by the remaining 10 that constitute the outer wall. It is likely that at least some pyrophosphatases can use either $\mathrm{H}^{+}$or $\mathrm{Na}^{+}$indiscriminately (Luoto et al., 2013). In most organisms, these pyrophosphatases are located in the membrane or in intracellular vacuoles. The entrance or exit funnels to these enzymes are around $1.5 \AA(0.15 \mathrm{~nm})$ across. While described as a proton and sodium transporter, respectively, these enzymes are probably reversible (Façanha and de Meis, 1998; Maeshima, 2000). In other words, with ion flow running downgradient, they could act as pyrophosphate synthetases. If so, we expect two orthophosphates $\left(2 \times \mathrm{HPO}_{4}{ }^{2-}\right)$ to be driven into the vacuole by the proton (or sodium) disequilibria where they would condense to the diphosphate $\left(\mathrm{HP}_{2} \mathrm{O}_{7}{ }^{3-}\right)$. During the condensation, the protein undergoes an allosteric transition so that the cavity is now open to the cytoplasm, causing release of the diphosphate where it is in strong disequilibrium with respect to the two orthophosphates. Because the proton gradient would have stretched to 5 orders of magnitude while the sodium gradient was zero, we argue_pace Mulkidjanian et al. (2008) — that the ancestral ion gradient was based on protons and not sodium ions (Russell and Hall, 1997; Martin et al., 2008; Ducluzeau et al., 2014; and see Kelley et al., 2001, Table 1). Moreover, Baltscheffsky and Persson (2014) showed from genomic studies of the archaeon "Candidatus Korarchaeum cryptofilum" that the pre-LUCA evolutionary form of the membrane-integral inorganic pyrophosphatase was a proton pump (and see Elkins et al., 2008). Baltscheffsky and Persson (2014) tentatively suggested that sodium pumping was post-LUCA. The challenge before us then is to imagine a primitive functional equivalent of $\mathrm{H}^{+}$-pyrophosphatase. Thus, we consider next whether the kind of mineral structures implicated in coupling primitive carbon fixation to the ambient redox potentials could also serve as the engine for coupling the mound's proton gradient to the maintenance of an internal pyrophosphate disequilibrium.

\section{Proto-Pyrophosphate Synthetase Nanoengines}

As we noted above, the second great "disequilibrium conversion" challenge is to find a primitive functional equivalent of $\mathrm{H}^{+}$pyrophosphatase. There, we made a case for metal hydroxides having contributed to the earliest inorganic membranes developed at submarine alkaline springs. The main contributors to such membranes would have been layered double hydroxides such as the hydrotalcite pyroaurite $\left[\sim \mathrm{Mg}_{6} \mathrm{Fe}_{2}\left(\mathrm{CO}_{3}\right)(\mathrm{OH})_{16} \cdot 4\left(\mathrm{H}_{2} \mathrm{O}\right)\right]$ and the mixed-valence green rust or fougèrite $\sim\left[\left(\mathrm{Fe}^{\mathrm{II}}, \mathrm{Mg}\right)_{2}\right.$ $\mathrm{Fe}^{\mathrm{III}}\left(\mathrm{OH}^{-}\right)_{5} \cdot \mathrm{CO}_{3}{ }^{2-}$ ] (Cairns-Smith, 1982; Trolard et al., 1997; Feder et al., 2005; Trolard and Bourrié, 2012). Other likely precipitates are montmorillonites, smectites, and other expandable cationic clays with comparable properties to fougèrite. Ever since Bernal's suggestion that clays would have adsorbed organic molecules on early Earth (1951, 1960, 1967), many origin-of-life researchers have considered such layered minerals and mineral clusters as being central to life's emergence (Cairns-Smith, 1982, 2008; Ponnamperuma et al., 1982; Cairns-Smith et al., 1992; Ertem and Ferris, 1998, 2000; Hill et al., 1998; Ferris, 2002, 2005; Aldersley et al., 2011; Adraa et al., 2012; Feuillie et al., 2013). In particular, Arrhenius (1986, 2003) has long championed a role for the mixed-valence iron hydroxides and other layered double hydroxides in the synthesis of prebiotic molecules, albeit from cyanide and formaldehyde. In our opinion, molecules such as cyanide are inimical to the redox state of the early atmosphere. Instead, cyanide along with carbon monoxide could have been produced in the inorganic membrane in a way similar to cleavage of tyrosine catalyzed by $\mathrm{Fe}-\mathrm{S}$ cluster-mediated radical chemistry, and glycine decomposed to cyanide (along with $\mathrm{CO}$ ) also by an iron sulfur cluster-containing enzyme (Driesener et al., 2010; McGlynn et al., 2010; cf. Peters et al., 2006; MilnerWhite and Russell, 2011; Kuchenreuther et al., 2013). Arrhenius and his colleagues also experimented with the potential role of anion-selective minerals as concentrators and catalysts in the chemistry of the organic phosphates (Kuma et al., 1989; Arrhenius et al., 1993, 1997; Pitsch et al., 1995; Krishnamurthy et al., 1999; and see Baliarsingh et al., 2013) (Table 2). For example, hydrotalcite catalyzes the selective condensation of aldol phosphate, a reaction along a path to the nucleic acids (Pitsch et al., 1995). Organic phosphates are also strongly adsorbed and concentrated on layered double hydroxides (Kolb et al., 1997).

Greenwell and Coveney added substantially to the knowledge base with their simulations of processes involving the intercalation of organic anions in the layered double hydroxides (Greenwell and Coveney, 2006; Greenwell, 2010; Coveney et al., 2012; Ma et al., 2012). In particular, they showed how the double layers are likely to flex and even engage in peristaltic behavior to drive diffusion of organic intercalates (Thyveetil et al., 2008; Coveney et al., 2012). Following these leads, we have suggested that fougèrite could have operated as a pyrophosphatase engine (Russell et al., 2013). Comprising the precipitates at the outer margin of an alkaline mound, ferrous hydroxide may have been oxidized to fougèrite by the nitrate and nitrite in the ocean. Opposing ferric ions in fougèrite proximal to the acidulous ocean would repel each other, opening the interlayer up to invasion by anions such as nitrate (Arrhenius, 2003). Having invaded the interlayer, nitrate would "pillar" a microgallery $\sim 4 \AA$ ( $0.4 \mathrm{~nm})$ high (Choy et al. 2000), leading to polaron formation, perhaps giving an opportunity to orthophosphate (diameter $=4.8 \AA$ ) dissolved in the Hadean Ocean and adsorbed onto the outer faces of green rust, to be driven into the layered double hydroxide by the steep proton gradient (Ookubo et al., 1993; Arrhenius et al., 1997; Hagan et al., 2007; Yan et al., 2010; Zhou et al., 2011; Barthélémy et al., 2012; Russell et al., 2013; cf. Baikousi et al., 2013). In our model, a positive redox polaron wave propagates along the layered double hydroxide from the oxidized acidic ocean exterior toward the reduced alkaline interior, locally distorting the brucite-like layers and inducing, through charge conservation, the migration of doubly charged orthophosphates $\left(\mathrm{HPO}_{4}{ }^{2-}\right.$ ) ( $c f$. Wander et al., 2007; Katz et al., 2012). The peristaltic drive is vectorially augmented by the direction of the proton gradient ( $c f$. Horváth et al., 2011). The protons would be driven down-gradient by the Grotthuss mechanism (covalent transfer of a proton from one molecule to another) in a process that could extend within the membrane through interlayers in mackinawite (Agmon, 1995; Muñoz-Santiburcio et al., 2013; cf. Kellosalo et al., 2012). In these confined low-entropy two-dimensional 
spaces, where water activity is low, $\mathrm{Mg}^{2+}$, also from the ocean, acts to offset the charge repulsion between two monophosphates (perhaps as $\mathrm{KPO}_{4}{ }^{2-}$ or $\mathrm{HPO}_{4}{ }^{2-}$ ), which are forced to condense to $\mathrm{HP}_{2} \mathrm{O}_{7}{ }^{3-}$. The pyrophosphate is then driven peristaltically into the interior. Electrons derived from hydrothermal hydrogen at a nickel-iron sulfide center within the membrane re-reduce the fougèrite (Fig. 7). But whether phosphates can be driven by the steep proton gradient to displace interlayer carbonate requires experimental validation in light of the research by Bocher et al. (2004).
So the question remains: can transmembrane redox and $\mathrm{pH}$ gradients totaling around $1 \mathrm{~V}$ abiotically drive the formation of a strong pyrophosphate versus orthophosphate disequilibrium via the endergonic condensation of mono- to pyrophosphate ( $c f$. Paulo and Tavares, 2011)?

\section{The Putative Hybrid Nanoengine}

A model isolating and integrating the suggested mechanisms - the carbon-fixing and pyrophosphate synthetase

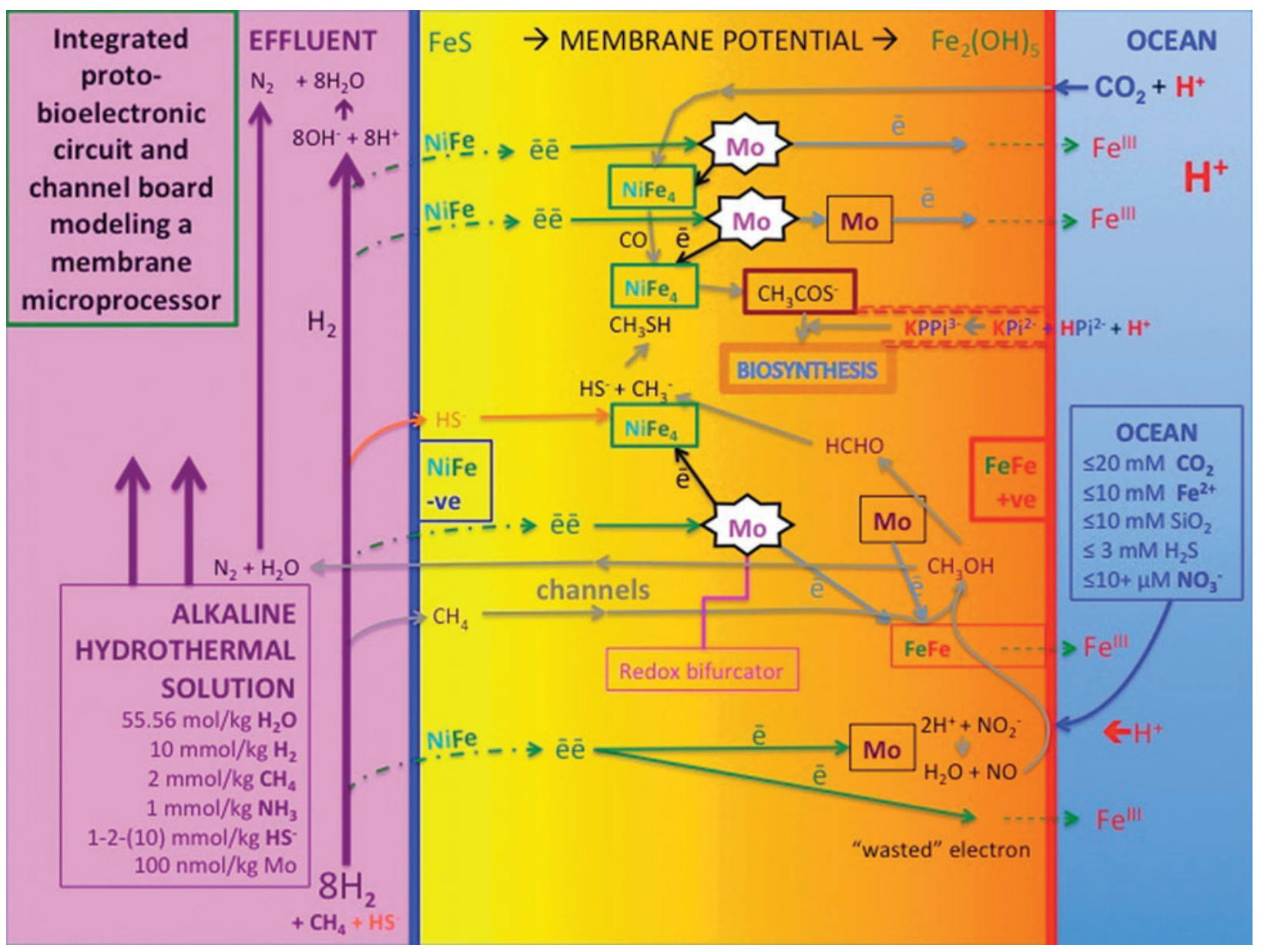

FIG. 7. The engines that put metabolism on the road. Highly idealized deconstruction of Fig. 6a to reveal the hypothetical proto-bioelectronic and proto-bioprotonic circuitry and channels in the inorganic membrane that feed the redox and proton disequilibria to the putative carbon-fixing and pyrophosphatase nanoengines ( $c f$. Szent-Györgyi, 1968a, 1968b; Poinsignon, 1997; Nitschke and Russell, 2013). Nickel sites in the FeS comprising the innermost zone of the inorganic membrane oxidize the hydrothermal $\mathrm{H}_{2}$, sending waves of electrons through the semiconducting iron minerals toward the oxidants bathing the membrane exterior. The resulting protons react with the hydroxyls in the hydrothermal fluid to produce more water. Some of the electrons reduce nitrate and nitrite to highly active $\mathrm{NO}$ and $\mathrm{N}_{2} \mathrm{O}$ at a molybdenum site stabilized by protons [e.g., $\left[\mathrm{Fe}_{2} \mathrm{~S}_{2}\left(\mathrm{MoS}_{4}\right)_{2}\right]^{4-}$ and/or $\left[\mathrm{FeO}(\mathrm{OH})\left(\mathrm{MoS}_{4}\right)_{2}\right]^{3-}$ (Itaya et al., 1987; Helz et al., 2013)], which in turn are hypothesized to oxidize methane to methanol on green rust [fougèrite, $\mathrm{Fe}_{2}(\mathrm{OH})_{5}$, cf. Martinez-Espinosa et al., 2007; Starokon et al., 2011]. Two more electrons reduce $\mathrm{Mo}^{\mathrm{VI}}$ atoms to $\mathrm{Mo}^{\mathrm{IV}}$, which then bifurcate; one electron is drawn along a large entropy-increasing path to $\mathrm{Fe}^{\mathrm{III}}$ in fougèrite comprising the membrane exterior, while the other takes the entropydecreasing path against membrane potential and reduces the low potential nickel iron sulfide $\left(e . g\right.$., $\left.\mathrm{Fe}_{5} \mathrm{NiS}_{8}\right)$. These reduced $\mathrm{NiFe}_{4}$ clusters then feed electrons to $\mathrm{CO}_{2}$ and formaldehyde in preparation for the assembly of CO and a methyl group to activated acetate, the entry point to putative carbon-fixing denitrifying methanotrophic acetogenesis. Fougèrite may also act as a proton pyrophosphatase. Note that while the characteristics of the alkaline $\sim 10 \mathrm{~m} M$ hydrothermal feed of electron donors remain stable for $\geq 10^{17} \mu$ s (i.e., $\geq 32,000$ years, Ludwig et al., 2011), the concentrations of the oxidants are likely to vary widely in time and be the limiting entities in completing the circuit. The ocean may also have supplied many $\mathrm{m} M$ of $\mathrm{SiO}_{2}$ and a few $\mathrm{mM}$ of $\mathrm{H}_{2} \mathrm{~S}$ to the alkaline hydrothermal chimneys (Mielke et al., 2010; Shibuya et al., 2010). Based on Nitschke and Russell (2013) and Russell, Nitschke and Branscomb (2013). 
nanoengines-imagined and invoked to resolve the disequilibria acting across the first inorganic membrane is presented in Fig. 7. Here, in the spirit of Szent-Györgyi (1968a, 1968b), we seek to combine electron conduction and redox bifurcation/confurcation with vectorial chemical transport in fluid channels such that the putative mechanocatalytic nanoengines at their confluence drive the "hard" reactions of carbon fixation and subsequent organic condensations ( $c f$. Mitchell, 1975; Huang et al., 2012). The aim of this protobioelectronic and proto-bioprotonic circuit diagram is to provide a basis for experimental investigations. The system combines the mechanisms of a fuel cell directly with the two hypothesized engines of proto-metabolism, all situated within the membrane (Russell, 2007; Branscomb and Russell, 2013; Russell et al., 2013; Barge et al., 2014).

\section{The Organic Takeover}

Assuming we are on the right track, it must be admitted that a fougèrite $\mathrm{H}^{+}$-pyrophosphatase does not resemble the bundle of transmembrane helices comprising $\mathrm{H}^{+} / \mathrm{Na}^{+}$pyrophosphatases as elucidated by Lin et al. (2012) and Kellosalo et al. (2012). So what could have been the natural intermediate step between the mineral motor and the protein? Milner-White and Russell $(2005,2011)$ suggested that the organic takeover involved just those molecules that are most exergonic to produce - the amino acids and uncoded peptides (Fig. 8) (Amend and Shock, 1998; Amend and McCollom, 2009). In this light, it is not so surprising that Ferris and his collaborators (1996) have generated long peptides on the layered mineral illite. They imagine mineral surfaces covered

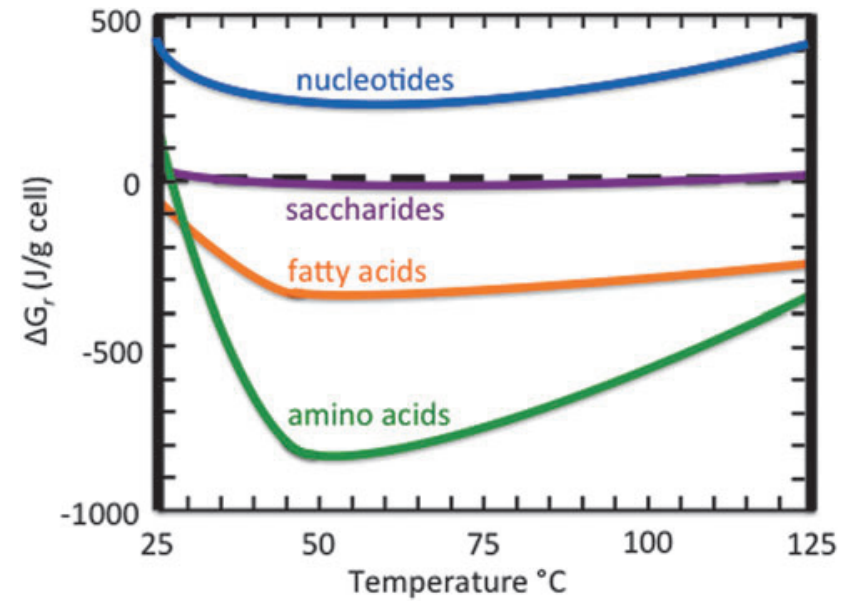

FIG. 8. Calculated Gibbs energies of reaction for total cellular constituents assumed to be generated on mixing of Hadean seawater with a Lost City-like hydrothermal fluid as a function of temperature (Amend and McCollom, 2009). Fatty acid synthesis is exergonic at all temperatures, whereas amino acid synthesis is exergonic above $\sim 27^{\circ} \mathrm{C}$, and strongly so between $30^{\circ} \mathrm{C}$ and $\sim 90^{\circ} \mathrm{C}$. Amines and saccharides are potential products close to equilibrium. The synthesis of nucleotides, in strong contrast, is endergonic at all temperatures for all mixtures (Amend and McCollom, 2009, Tables I, IV, and V). This is why life does not live on RNA/DNA alone, could not have begun relying on these molecules in these conditions, and why these polymers could never clog up the cell. Redrawn from Fig. 2 in Amend and McCollom (2009), with permission. by polymers 50 residues long or more on early Earth. Spontaneously precipitated layered minerals, such as mackinawite $(\sim \mathrm{FeS})$, fougèrite $\left(\sim \mathrm{Fe}_{2}(\mathrm{OH})_{5}\right)$, and perhaps tochilinite $\left(6 \mathrm{FeS}_{0.9} \cdot 5(\mathrm{Mg}, \mathrm{Fe})(\mathrm{OH})_{2}\right)$, would seemingly offer attractive surfaces and interlayers for ligation of such multidentate ligands that comprise the backbones and side chains of peptides (Zolensky, 1984; Beard, 2000; Mielke et al., 2011; McGlynn et al., 2012; Kang et al., 2013; cf. Shanker et al. 2013). Indeed, McGlynn et al. (2012) demonstrated that the addition of peptides or RNA to the alkaline solution modifies the elemental stoichiometry of the chimney precipitates to the effect of increasing the oxygen-to-iron ratio and likely that of the hydroxide proportions of the membrane. Membrane stability is also increased in proportion to polymer length (Bormashenko et al., 2006). It is also likely that spontaneously precipitated mackinawite $(\mathrm{FeS})$ and fougèrite $\left(\sim \mathrm{Fe}_{2}(\mathrm{OH})_{5}\right)$, the assumed "objets trouvés" for engine components, may have had some templating control over subsequent precipitation as the inorganic compartments were forced to grow during hydrothermal inflation (Russell et al., 1994; Baymann et al., 2003; Cairns-Smith, 2008; Greenwald and Riek, 2012; Branscomb and Russell, 2013; Kang et al., 2013; Nitschke et al., 2013).

With increase in proportion of peptide to layered double hydroxide and sulfide, we imagine an organic takeover of the membrane by amyloid in an evolving process of what might be called "minerobiolization" (Russell, 1991; Milner-White and Russell, 2005). Minerobiolization with amyloidal peptide templated upon these mineral clusters would markedly improve the membrane structure, durability, and discrimination (Zhang et al., 1993; Chernoff, 2004; Carny and Gazit, 2005; Russell and Hall, 2006; MilnerWhite and Russell, 2008; McGlynn et al., 2012). Indeed, such uncoded peptides are known to be self-recognizing and thereby to arrange themselves as parallel $\alpha$-sheets (Armen et al., 2004; Milner-White et al., 2006; Hayward and Milner-White, 2008). The $\alpha$-sheet can spontaneously convert into the somewhat more stable and nontoxic $\beta$-sheet of insoluble proteins known as amyloid by the process of peptide plane flipping (Milner-White et al., 2006; Hayward and Milner-White, 2008). As either $\alpha$ - or $\beta$-sheets, they would have been rapidly self-propagating and temperatureresistant and could have comprised the first organic membranes and cell walls (Zhang et al., 1993; Milner-White and Russell, 2005; Childers et al., 2009, 2010; Maury 2009; Greenwald and Riek, 2010; Goodwin et al., 2012). As remarked by Greenwald and Riek (2012), amyloidal peptide may therefore be said to propagate information in the form of conformation (and see Maury, 2009; Li et al., 2010; Goodwin et al., 2012), and amyloid-like fibrils have been shown to replicate (Takahashi and Mihara, 2004). Moreover, peptides are much more versatile with respect to the requirements of basic metabolism than any other of the biotic molecules, comprising, as they do, the main structures of the enzymes, proteins, and even the cofactors as well as much of the membrane. They are much stronger than lipids as evidenced by their role in cell walls-in weblike structures strong enough to contain turgor pressures (Kandler and König, 1998; Desvaux et al., 2006). Thus, they have the potential to act at the emergence of life in such roles as cell membrane/cell walls, and their backbones can sequester metals and phosphate without reliance on side-chain order; 
that is, they operate as nests for the inorganic active centers of enzymes comparable to the P-loop without the requirement for coding (Table 2) (Milner-White and Russell, 2005, 2011; Childers et al., 2009; Bianchi et al., 2012; Hong Enriquez and Do, 2012). However, various short peptides with particular sequences useful as binding nests may have afforded reproducible protein structures, some of them oligomeric, through self-assembly (Lupas et al., 2001).

Given a reservoir of amino acids, amyloid grows exceedingly rapidly (Collins et al., 2004; Goodwin et al., 2012). Many of the amino acid residues comprising amyloid proteins are "nitrogen-rich," for example, asparagine, glutamine, and arginine, although serine is also common. The sequences in which they occur are largely immaterial to amyloid growth (Ross and Poirier, 2005). Indeed, the amyloid structure can maintain dynamic contact even as the sequences of these particular amino acids are shuffled, thus giving opportunities for selection and survival based on function. Such analog behavior may be thought of as Lamarckian molecular evolution guided by attractor states (Kuhn, 1972; Corliss, 1986; Hengeveld, 2007; Halfmann and Lindquist, 2010; Goodwin et al., 2012). At this stage, it is the main-chain $\mathrm{CONH}$ atoms, rather than the side chains, that dominate function. Were the main chains at the edges of blocks to be juxtaposed to blocks of similar charge, the membrane would remain semipermeable, and channels composed of $\alpha$-sheet peptides could encourage the transport of protons across the membrane (Milner-White and Russell, 2008). Whether such transport could be gated and coupled to pyrophosphate synthesis is ripe for research (e.g., Hansen and Poulsen, 1999; Dong, et al., 2006; Childers et al., 2009).

\section{The Second Transition across the Darwinian Threshold-the Guidance System}

As explained by Goodwin et al. (2012), the kind of thermodynamically driven evolutionary process described in the last section falls short of digital Darwinism. So how might the Darwinian threshold be crossed (Woese, 2002)? What are the steps leading toward and across this threshold toward a nucleotide guidance system? First, there is the problem of synthesis (Fig. 5). While cyanide has often been appealed to as explanation for the facile production of certain nucleic acid bases (Sanchez et al., 1967), abiotic HCN has not been recorded in moderate-temperature alkaline submarine springs (e.g., Lang et al., 2010). And while it is also true that nucleotides have been generated in the laboratory (Powner et al., 2009), the various conditions imposed are particular, discontinuous, and result in complex mixtures, and eventually face the "asphalt problem" (Benner et al., 2012). Instead, given that the substrates for the biosyntheses of the nucleobases are aspartate, glutamine, and glycine, with contributions too of carbon dioxide, ammonia, formyl phosphate, and glyceraldehyde-3-phosphate (Berg et al., 2006)-all molecules that are likely to have been present or generated in the hydrothermal mound-it seems that this is an occasion for "top-down" inference to be entertained (Martin and Russell, 2007). Add to this observation that effective phosphorylation mechanisms and rapid mineral-assisted condensation of aldehyde phosphates have been demonstrated to form tetrose and pentose phosphates in high yield, the emergence of the simple nucleic acid enzymes may be more facile than generally assumed (Pitsch et al., 1995; Krishnamurthy et al., 1999; Martin and Russell, 2007).

Supposing this to be the case, we follow White's (1976) suggestion that the first nucleic acid enzymes involved in intermediary metabolism had limited substrate specificity and would catalyze classes of reactions rather than specific metabolic reactions. Yarus (2011) suggested that such early cofactors could take part in their own replication. In particular, nicotinamide adenine dinucleotide phosphate (NADP) and flavin adenine dinucleotide (FAD) might replicate through base pairings with adenine and uracil. Yarus portrays a collective of these molecules as the "initial Darwinian ancestor." Strung together with other nucleic acid bases, the RNA polymers could behave like viruses living off metabolic energies, though partially paying back the system with some catalytic activity (Koonin and Martin, 2005). However, the synthesis of a negatively charged phosphoribose backbone on which to hang a variety of nucleobases is beyond the limits of spontaneous unguided self-organization. Considering the work of Goodwin et al. (2012), one possibility is that the first nucleobase backbones were produced through the condensation of amine and aldehyde to produce cationic alkyl iminium backbones. This is a process more easily imagined in the amyloidal milieu. On this tack, Braun et al. (2011) suggested that the earliest replicating entities were amyloid-nucleic acid fibers produced through electrostatic interactions between nucleic acids and peptides. The fibers would grow rapidly through the addition of monomers, generally alternating between hydrophobic and hydrophilic residues as influenced by replicating nucleic acids (Collins et al., 2004; Braun et al., 2011).

Perhaps the Yarus mechanism evolved from these first putative amyloidal peptides and membranes (Zhang et al., 1993). ATP drives all these condensations today (Goodwin and Lynn, 1992; Benner, 2004), but at the emergence of life, pyrophosphate-presumed to have been produced in proto$\mathrm{H}^{+}$pyrophosphatases-may have fulfilled the same role (Yamanaka et al. 1988; Russell and Hall, 1997; Yamagata and Inomata, 1997; Baltscheffsky et al., 1999; Baltscheffsky and Persson, 2014). Moreover, there was likely a surplus of just the right stuff in the vicinity of amyloidal membrane growth. For example, it may be that ammonia could have been generated on site through the reduction of nitrate and nitrite by fougèrite to add to the $\mathrm{CO}_{2}$ from the ocean and formyl phosphate synthesized within the membrane (Hansen and Koch, 1998; Martin and Russell, 2007).

Once "invented," the major achievement of the RNA world was the development of a pocketlike primitive ribosome-another entropy trap-with the peptidyl transfer center at its heart (Sievers et al., 2004; Hsiao et al., 2009; Fox et al., 2012). This ribosome could generate short uncoded peptides more effectively than those probably generated on the mineral surfaces and interlayers comprising the compartment walls of the mound. And once generated, these peptides could further stabilize and protect the primitive ribosome from which they emerged-the kind of positive feedback behavior required of emergent life. That peptides preceded a nucleic acid-based world is suggested too by the presence of an 18-mer unstructured glycine-rich peptide in the modern peptidyl transfer site where it carries out the same function: the stabilization of ribosomal RNA (Nissen et al., 2000; Hsiao and Williams, 2009; Hsiao et al., 
2009; Belousoff et al., 2010). Indeed, Hsiao et al. (2009) suggested that the peptide is a molecular fossil and an ancestor of the ribosomal proteins.

The plausibility of this sketch of how the evolutionary transition was effected might seem to face the same problem as the organic soup hypothesis, that is, concentrations of polymers way below a required critical mass for interaction and recombination. However, research by the Braun group illustrates how nucleic acids might be concentrated in such a complex system (Mast et al., 2013). Though in their experiments they used DNA rather than the less stable RNA, these authors demonstrated how a thermal gradient across inorganic compartments of a dimension expected in a hydrothermal mound could drive a convective polymerase chain reaction to produce longer polymers, and how once formed these are driven to, and concentrated in, the coolest region of the compartment through thermal diffusion (Baaske et al., 2007; Mast and Braun, 2010; Mast et al., 2012).

\section{Discussion}

In the present discussion, we have concentrated on how metabolism might have begun from scratch and outlined our reformulated transdisciplinary theory for an autotrophic emergence of life in a submarine alkaline mound. This theory abides by the rules of thermodynamics, pays due consideration to initial conditions on wet rocky worlds, and looks to the Last Universal Common Ancestor (LUCA) for correspondence. It explains the polarity of the cell, alkaline and reducing inside, acidulous and oxidizing outside; the vector of the proton motive force and the universality of its use; the similarity of mineral and active protein center structure; and the commonalities of certain "proto-biochemical" reactions and metabolic pathways and syntheses (Nitschke and Russell, 2013).

Under this view, life emerged quickly in the confines of the founding mound within the duration of the vitalizing low-entropy hydrothermal feed. The first steps were the steepest: reduction of carbon dioxide, oxidation of methane, and the production of pyrophosphate very far from equilibrium with its orthophosphate source. These steps necessitated close physicochemical couplings to exergonic reactions (Branscomb and Russell, 2013). This is where we find ourselves converging with another well-established origin-of-life research field, one that championed mechanistic roles for layered double hydroxides and smectites (expandable clays) at the emergence of life, but with the difference of placing them in, and as components of, the inorganic membrane (Arrhenius, 2003; Meunier et al., 2010). After all, the affinities are now well established between the structures of certain mineral clusters comprising the precipitate membranes-mackinawite, greigite, violarite, and fougèrite-with the most ancient metalloenzymes involved in autotrophy (Fig. 4) (Nitschke et al., 2013). What is not so clear is how the flexible motions of the transmembrane bundles of $\alpha$-helices involved in so many of life's nanoengines that couple exergonic with endergonic reactions functioned in a mineral world before the emergence of proteins (Childers et al., 2012; Branscomb and Russell, 2013). Here, appeal is made to the layered double hydroxide fougèrite (green rust) - a likely precipitate on the outer margins of an alkaline hydrothermal Hadean mound — to act in this capacity, albeit inefficiently (Mielke et al., 2011; McGlynn et al., 2012; Russell et al., 2013). Of course, it is true that their haphazard architecture would have made them unreliable at best. Nevertheless, presuming that these materials engineered the first steep steps to metabolism, their inherent autocatalytic behavior would have seen to their improvement through a rapid organic takeover. Once the initial steep carbon fixation steps were overcome, the synthesis of carboxylic, amino, and fatty acids as reduced hydrothermal solutions met Hadean Ocean in a precipitate mound, was generally exergonic, so much so as to suggest basins of attraction to particular metabolic pathways and, eventually, cycles where evolution was largely "analog" in nature (e.g., Corliss, 1986; Amend and McCollom, 2009; Goodwin et al., 2012). Even so, catalysts and enzymes, initially inorganic but eventually protein-based, were required to expedite and control the rates of reactions.

The phase transition from aqueous geochemistry to metabolism through prebiotic physicochemical reactions, like all symmetry-breaking and irreversible events, would have been so rapid as to call into question the idea-rooted in the "organic soup" concept-that prebiotic organic molecules be considered as targets for "pre- or proto-life" detection (Lane et al., 2010; Russell and Kanik, 2010). Indeed, as we have argued here and previously, the main prebiotic molecules were $\mathrm{CO}_{2}, \mathrm{CH}_{4}, \mathrm{H}_{2}, \mathrm{HPO}_{4}^{2-}, \mathrm{P}_{4} \mathrm{O}_{10}, \mathrm{NH}_{3}, \mathrm{NO}, \mathrm{FeS}$, $\mathrm{Fe}_{3} \mathrm{~S}_{4}, \mathrm{Ni}, \mathrm{Co}, \mathrm{Mg}, \mathrm{Mo}, \mathrm{W}$, and the like (Nitschke and Russell, 2009). Evidence for this is provided by the fact that the biosphere is overall autotrophic and appears to have been so from life's onset (Fuchs 1989, 2011; Berg et al., 2010; Schoepp-Cothenet et al., 2013). Efficiencies of inorganic precipitates as catalysts and nanoengines were likely improved significantly when replaced by amyloidal peptide.

The next step on the way from metabolism to life is the sorting out of a muddle of possible reaction manifolds (Cabello et al., 2004) - the taming, constraining, and guiding of reactions involved in various possible natural attractor states, for example, those otherwise controlled by physicochemical thermodynamics such as the reduction of nitrate to nitrite, nitric, and nitrous oxides through to ammonia. This is when the RNA world begins to make a contribution. Heterocyclic nitrogen compounds formed in an amyloidal milieu are an imperative even for an uncoded early metabolism (Nissenbaum et al., 1975; Martin and Russell, 2007). Strung together on a peptide-like backbone, the metabolism involved in the cell's free energy economy could be guided and evolve. Once an RNA world and eventually a ribosomal world kicked in, favorable reactions would be sorted out in metabolic networks more responsive to the environment (Fig. 3) (Berthoumieux et al., 2013; de Lorenzo, 2014). An intriguing aspect of the onset of coding is the demonstration by Amend and McCollom (2009) of the relatively high thermodynamic costs of nucleotide synthesis in submarine hydrothermal conditions (Fig. 8). Not only is it now evident from energetic considerations that metabolism had to have preceded coding, it is also clear that the first protocells must have been more than sacks of RNA - that once introduced, RNA and DNA could never increase to the point that they would clog up the internal workings of protocells. Indeed, polynucleotides had to pay their way through reciprocal arrangements and collaboration with amino acids to produce the first coded proteins, and in so doing, cross the Darwinian 
threshold to cellular life (Woese, 2002). Of course, this "thermodynamic cost" refers to unavoidably endergonic reactions. Indeed, it seems clear that no replicative and/or "coding" system could operate based only on exergonic reactions and quasi-equilibrium chemistry. Even such a strong advocate of "replication first" as Addy Pross has argued "the replication reaction must be effectively irreversible. That condition, in turn, means the system must be maintained in a far-from-equilibrium state" (Pross and Pascal, 2013). Here, the key point is that by the second law endergonic reactions can only take place-and non-equilibrium states thereby be maintained-if they are mechanistically coupled to stronger exergonic reactions so that the coupled pair, acting thermodynamically as a single, unitary process, is itself exergonic. This conclusion raises the question: what were the necessary sources of driving free energy, what would it take to produce and maintain them, and very nontrivially, how could they be thermodynamically coupled to the needed endergonic reactions? Our position is that some primitive prebiotic metabolism, roughly of the type here proposed, must have been in place to meet these fundamental and inescapable thermodynamic requirements. It is in this rather limited sense, and for this reason, that we prefer a "metabolism first" model of the emergence of life.

Although the disequilibria that drove life into being are easily imagined, the nature and operations of the first engines assumed to have negotiated the steep endergonic barriers to autotrophic metabolism are not. Moreover, it is to be expected that any such engines, and their housings, would have been inefficient and unreliable at best. Had it not been for the large numbers of alkaline hydrothermal systems likely operating on early Earth, each with billions of inorganic membranous compartments, we might be tempted to entertain Monod's pessimistic surmise that life is an accident and we are alone in the Universe (Monod, 1972). But with this redundancy of opportunity-that there were so many chemical systems in so many dispositions in so many hydrothermal mounds over so much time-life's emergence appears inevitable. We imagine that the proto-metabolic free energy converters approximating the ones described here would easily ratchet up to the next level of complexity, that is, to a coded world guided by RNA. Once RNA-guided evolution began to make its contribution, such entities would be capable of taking the many steps, through the LUCA, to the complex life that constituted our biosphere as it was 3.8 billion years ago (Rosing, 1999).

Evolutionary retrodictions and postdictions addressing life's emergence restrict history-based inquiry to surviving prokaryotes, their constituents, their particular phylogenies, and the "calculated" geophysical and geochemical conditions that occurred around 4 billion years ago on our own planet. Much information on the initial conditions that drove life into being has been lost to tectonic process and biochemical weathering, while the progress of earliest life has been lost to extinctions as well as to the absence of evolutionary information before the evolution of the ribosome. However much we surmise over the mechanisms that enabled life to emerge, and how it spread to environments where appropriate disequilibria obtained and obtain here on Earth, astrobiological research has the potential to add dimension to our understanding of how, and under what conditions, life emerged from a low-entropy feed to play its part in increasing the overall entropy of the Universe (Boltzmann, 1886; cf. England, 2013). It is possible that different physicochemical disequilibria, different high potential electron acceptors, and environmental challenges on other worlds might have called for somewhat different metabolic pathways and strategies to be entertained by emergent life elsewhere. For example, in the absence of high potential electron acceptors, life may have eventually emerged via the reductive acetyl coenzyme A pathway after all (Russell and Martin, 2004). Whatever the possibilities, the various interdependent physical and chemical conditions to be revealed by the exploration of, for example, Mars, and eventually of Europa and Enceladus and the exoplanets, can only help our general understanding and perhaps force a rethinking of how life might have emerged here on Earth. Supposing life did begin in an alkaline submarine mound, we may surmise that on our own planet, needing surfaces as substrate, it would have expanded into, or been carried along and just below, the ocean bottom, eventually to inaugurate the deep biosphere (Roussel et al., 2008; Suzuki et al., 2013). Starved of electron acceptors, microbes may then have been forced to adopt methanogenesis as a means of losing electrons. Geochemical conditions in the mafic and ultramafic crust hosting the present deep biosphere, even when obducted, can have hardly changed in the last 4 billion years and thus might provide indications of what the oldest inhabitants of the planet were like (Thauer et al., 1977; Morrill et al., 2013).

However, the immediate and mutually dependent experimental challenges are (i) to recreate the putative denitrifying methanotrophic acetogenic pathway and its extension toward the reductive, though incomplete, version of a citric acid cycle, presumably necessitating electron bifurcation involving molybdenum, and (ii) to demonstrate that a steep proton gradient across a fougèrite-bearing membrane will drive a strong pyrophosphate disequilibrium (Smith and Morowitz, 2004; Martin and Russell, 2007; Branscomb and Russell, 2013; Nitschke and Russell, 2013; Russell et al., 2013). Both these challenges require experimentation in sterile conditions under the kind of high pressures that would be met at depth in the Hadean Ocean.

\section{Unresolved Issues}

The recognition (i) that all life absolutely and fundamentally depends on driving strongly endergonic, thermodynamically "uphill" reactions; (ii) that, by the second law, this in turn requires that each such reaction be "coupled," as the driven partner, to a (stronger) exergonic reaction, acting as the driving partner; and (iii) that such reaction coupling may require the mediation of a molecular "mechanocatalyst engine" specific to the reactions being coupled has forced the realization that some simpler mechanocatalysts might have been on hand to engineer life's origin. We have alighted on green rust (fougèrite) as one of the most plausible mineral precipitates at the membrane that, within its interlayers, is potentially capable of the kind of physical articulation allied to redox and ionic gradients likely to result in particular products and their transport (Arrhenius, 2003). The demonstration by Hansen and Koch (1998) of the reduction of nitrite to ammonia through the partial oxidation of fougèrite prompts the question whether that same mineral, suitably doped, could concomitantly oxidize methane to methanol and 
formaldehyde. To date, such abiotic oxidation has only been achieved with surface oxygen on an $\alpha$-cationic $\mathrm{Fe}^{2+}$ site within the cage of a synthetic zeolite (see Kachurovskaya et al., 2004, Fig. 4). Experiments at high pressure interacting fougèrite with methane, hydrogen, and nitrite across an inorganic membrane are called for. The aim in this case would be to test whether fougèrite could act as the inorganic analogue of the methane monooxygenase enzyme and, at the same time, act as a proton-pyrophosphate synthetase (Huang et al., 2013; Russell et al., 2013).

We are also lacking a good model for the first redox bifurcation engine that we hold to be vital for entry to $\mathrm{C} 1$ metabolism. A difficulty is that it is not entirely clear how two-electron bifurcating engines work in metabolism today. Nitschke and Russell (2011) invoked strongly crossed-over individual redox potentials dependent on local $\mathrm{pH}$ gradients involving a molybdenum atom (or tungsten at high temperature). However, the detailed molecular properties of the mechanism by which these shifts would be produced mechanistically to ensure that the exergonic (i.e., driving) one-electron reduction only takes place if, "at the same time," the endergonic (i.e., driven) one-electron reduction takes place remain to be worked out. Mitchell (1975) involved the concept of electron bifurcation (Wikström and Berden, 1972; Wikström and Saari, 1977) in his chemiosmotic theory, and we are alert to the interdependency of redox bifurcations and protonations (and see Buckel and Thauer, 2013). Jacques et al. (2014) offered models of how protons are involved in the activation of nitrate reductase, a di-pterin with a molybdenum cofactor. The molybdenum is invariably situated in an exposed position at the axis of a symmetrical di-pterin and is reduced as the pterin proximal to an $[4 \mathrm{Fe}-4 \mathrm{~S}]$ center is protonated. The onus is on us to suggest an inorganic cluster that might be protonated as molybdenum is reduced. In an inorganic membrane, molybdenum could be present in sulfide or oxide clusters. By reference to operations of ferredoxin (FdL), we tentatively speculate that of all known entities, linear clusters such as $\left[\mathrm{Fe}_{2} \mathrm{~S}_{2}\left(\mathrm{MoS}_{4}\right)_{2}\right]^{2-/ 4-}$ or $\left[\mathrm{FeO}(\mathrm{OH})\left(\mathrm{MoS}_{4}\right)_{2}\right]^{1-/ 3-}$ might be reduced and protonated as hydrogen is oxidized on a nickelbearing mackinawite (Helz et al., 2013). Molybdenum can also occur as iron-Mo ${ }^{\mathrm{IV}}$-oxide domains within green rust (Boucherit et al., 1991). However, such an association has not been observed in modern metalloenzymes. In theory, the entropy gained as one electron from a molybdenum cluster reduces nitrate to nitrite more than offsets the reduction of entropy entailed in the second electron's loss to the recalcitrant $\mathrm{CO}_{2}$. This potentially might be made possible by a reorientation of a putative molybdenum cluster as the two protons are drawn one by one to the alkaline interior. In any case, the challenge is to realize an abiotic system in which the inherently exergonic one-electron substrate oxidation serves to gate the one-electron endergonic one and which at the same time prevents both electrons from taking the easy exergonic ride downhill. Whether this can be achieved through sterical (mechanocatalytic) or purely electrochemical means is controversial even among the authors of this article.

\section{Conclusions}

(1) Immediately prior to the onset of life, icy wet rocky worlds would have the same electrochemical polarity as do cells, that is, a reduced and basic interior (cf. cytoplasm) and a relatively oxidized and slightly acidic exterior ( $c f$. periplasm). Both are electrochemical cells with outputs or inputs of up to $\sim 1 \mathrm{~V}$ (Russell and Hall, 1997; Nitschke and Russell, 2013). The likely factor limiting the first metabolizing system is the proximal availability of high potential electron acceptors such as nitrite, nitrate, and ferric iron.

(2) Hydrothermal mounds at submarine alkaline springs produced through serpentinization would have focused and miniaturized Earth's polarity and configuration, presenting hydrothermal hydrogen, methane, ammonia, and hydrogen bisulfide to nitrate/nitrite, carbon dioxide, and ferric iron in the metal-bearing acidulous carbonic ocean for their controlled irreversible interactions across the spontaneously precipitated inorganic membranes (Russell and Hall, 1997; Nitschke and Russell, 2009). This would have set the table with strong redox disequilibria to drive $\mathrm{C}$ fixation and a strong and correctly oriented proton gradient disequilibrium to drive the generation of an ATP-like diffusible source of free energy in the form of pyrophosphate versus orthophosphate.

(3) The first steps to carbon fixation, one reductive and one oxidative, are the very steepest-fixing $\mathrm{C} 1$ carbon from $\mathrm{CO}_{2}$ pumped out of volcanoes and dissolved in the ocean, and $\mathrm{CH}_{4}$ carried by the alkaline hydrothermal solution. Both processes involve free energy converting catalysts to perform redox bifurcations and exploit the proton motive force (Nitschke and Russell, 2013; Russell et al., 2013). The "organic soup" concept fails to account for the presence of these mechanisms in the LUCA (Lane et al., 2010).

(4) The first free energy-converting nanoengines or mechanocatalysts that enable and drive $\mathrm{C} 1$ metabolism up these steep steps are argued to involve (i) iron nickel sulfides as hydrogenases and dehydrogenases, (ii) layered double ferrous/ferric oxyhydroxides (fougèrite) as methane monooxygenase and as a proto-pyrophosphatase, (iii) redox bifurcation agents involving individual atoms of molybdenum complexed in the sulfides and/or fougèrite constituting the first membranes (Boucherit et al., 1991; Helz et al., 2013). With the involvement of these inherent catalysts, emergent life transcends mere chemistry and geochemistry as well as mere catalysis (Nitschke et al., 2013). Activated acetate is the first product (Huber and Wächtershäuser, 1997), and the revised pathway is denoted by the descriptor denitrifying methanotrophic acetogenesis (Nitschke and Russell, 2013). The pathway is assumed to eventually extend to succinate and glyoxalate through hydrogenations, carboxylations, and condensations driven by ATP. Aminations and further condensations produce amino acids, peptides, and ultimately nucleic acids and polymers (Martin and Russell, 2007).

(5) The organic takeover from the mineral precursors is facilitated by the surface structure of amyloidal peptides between 6 and 10 amino acids long that behave as nests for inorganic clusters. Together these do the work of proto-enzymes (Milner-White and Russell, 2008, 2011; Bianchi et al., 2012; Hong 
Enriquez and Do, 2012). Propagating rapidly, amyloid can substitute for the inorganic membrane (Zhang et al., 1993). The amino acids might interact with ammonia, formyl phosphate, and carbon dioxide to produce the nucleobases that initially function as coenzymes (Berg et al., 2006; Martin and Russell, 2007). Strung together on a peptide-like backbone, these RNAs could act as the first transportable genes (Koonin and Martin, 2005; Goodwin et al., 2012).

(6) We argue that, once the initial hard steps of free energy conversion were scaled by the available free energy-converting engines, further biosynthetic pathways involving thiolations, condensations, phosphorylations, and aminations are all exergonic and relatively straightforward. The same goes for the pathways and cycles themselves, each becoming more cost-effective as enzyme efficiencies and peptide and protein motors are incorporated into the individuated systems or cells and gifted, through horizontal gene transfer, to their neighbors.

(7) The only opportunity of egress from the mound was to the ocean bottom and crust where, although concentrations of nutrients and fluxes of electron donors' and acceptors' energy were lower, they were otherwise similar (Takai et al., 2004; Russell and Hall, 2006; Preston et al., 2011; Brazelton et al., 2012; Ménez et al., 2012; Takami et al., 2012; Orcutt et al., 2013). And while in these reduced circumstances carbon turnover was likely orders of magnitude slower than at the vent, the unsurpassed economy of the acetyl coenzyme A pathway would have been adequate to support acetogenic bacteria (Russell and Martin, 2004; Martin and Russell, 2007; cf. Lever, 2012; Hoehler and Jørgensen, 2013). The loss of electron acceptors at the base of this deep biosphere may have forced the emergence of methanogenesis as the mechanism of electron loss.

(8) The evolutionary path from the hydrothermal hatchery to the complex biochemical world of today transcended geochemical and analog operations such that it attained the heterarchical metabolic and digital processing that is life as we know it (Goodwin et al., 2012; Nitschke and Russell, 2013). The effects were to (i) access hitherto untapped but metabolically commensurate and appropriate free energies, including solar free energies, which allowed leaps to higher levels of complexity (Baltscheffsky, 1997; Mulkidjanian and Junge, 1997; Ferry and House, 2006; Russell, 2007; Russell et al., 2008; de Lorenzo, 2014); (ii) find ways of increasing the efficiencies of free energy conversion to the ultimate consequence of increasing the overall rate of entropy production, for example, by endosymbiosis of mitochondria and chloroplasts (Allen, 2003; Lane and Martin, 2010).

(9) Evolution subsequent to the LUCA operated as a search engine for free energies and materials fundamentally related to those that got life going in the first place, though at lower flux until photosynthesis emerged: life forms that, notwithstanding their diversity, maintain deep and common characteristics as their shared inheritance from how-and in what context-metabolism began. In fundamental terms, how it was done in the beginning is how it has ever thereafter been done over the succeeding 4.4billion-year journey from that inanimate geochemical world (Russell, 2007).

(10) Hydrogen from water-released geochemically and subsequently photosynthetically through mineral-like $\mathrm{Fe} \pm \mathrm{Ni}$ and $\mathrm{Mn}_{4} \mathrm{Ca}$ active centers, respectivelycontinued as the dominant source of electrons, while carbon dioxide became the main primary source of carbon and oxygen the dominant electron sink (Russell and Hall, 2006; Russell et al., 2008).

(11) Although the synthesis of most biomolecules is exergonic, the fact that the biosynthesis of the nucleotides is highly endergonic is fortuitous in that there is no tendency for them to clog up the early cytoplasm-RNA and DNA always have to pay their way (Amend and McCollom, 2009).

(12) In considering habitability and the potential for life elsewhere in the Solar System and beyond, the physical and chemical disequilibria that obtain on wet icy rocky worlds, and the various processes that might relieve them, need to be established (Lovelock, 1965; McCollom, 1999; Zolotov and Shock, 2003; Hand et al., 2009; Stüeken et al., 2013). If life's origin is ultimately coupled to geophysical convection in a particular geochemical context, one should be able to make predictions about life's likelihood on a planet or moon of interest from application of coupled chemical and fluid/geodynamical modeling, and from the availability of key feedstocks, thus accounting for other planetary energetic drivers, for example, tidal and radiogenic heating, solar wind interactions, magnetic dynamos - appropriate to the object in question. In this way, it might be possible to predict whether the required gravitational, thermal, and chemical gradients are likely to have been forced, or are being forced still, beyond the critical values needed for the drive to life.

\section{Acknowledgments}

We thank John Allen, Ariel Anbar, Jean Bédard, Billy Brazelton, John Callas, Ivria Doloboff, Kevin Hand, Mickey Honchell, Michael Malaska, Randall Mielke, Ken Nealson, Yuk Yung, and the Thermodynamics, Disequilibrium and Evolution (TDE) NAI Focus Group for discussions, and two anonymous reviewers for their suggestions. The research described in this publication was carried out at the Jet Propulsion Laboratory, California Institute of Technology, under a contract with the National Aeronautics and Space Administration, with support by a NASA Exobiology and Evolutionary Biology award (NNH06ZDA001N) and supported by the NASA Astrobiology Institute (Icy Worlds). E.B. is supported by the NASA Astrobiology Institute (Universal Biology).

\section{Abbreviations}

ADP, adenosine diphosphate; ATP, adenosine triphosphate; LUCA, Last Universal Common Ancestor.

\section{References}

Abrahams, J.P., Leslie, A.G., Lutter, R., and Walker, J.E. (1994) Structure at $2.8 \AA$ resolution of F1-ATPase from bovine heart mitochondria. Nature 370:621-628. 
Abramov, O. and Mojzsis, S.J. (2009) Microbial habitability of the Hadean Earth during the Late Heavy Bombardment. Nature 459:419-422.

Adraa, K.E., Timon, V., Lambert, J.F., Al-Rabaa, A.R., Jaber, F., Jaber, M., and Tielens, F. (2012) Adsorption of 1-DOPA intercalated in hydrated Na-saponite clay: a combined experimental and theoretical study. J Phys Chem C 116:2641426421.

Agmon, N. (1995) The Grotthuss mechanism. Chem Phys Lett 244:456-462.

Aldersley, M.F., Joshi, P.C., Price, J.D., and Ferris, J.P. (2011) The role of montmorillonite in its catalysis of RNA synthesis. Appl Clay Sci 54:1-14.

Alexander, C.O.D., Bowden, R., Fogel, M.L., Howard, K.T., Herd, C.D.K., and Nittler, L.R. (2012) The provenances of asteroids, and their contributions to the volatile inventories of the terrestrial planets. Science 337:721-723.

Alipázaga, M.V., Lowinsohn, D., Bertotti, M., and Coichev, N. (2004) Sulfite induced autoxidation of $\mathrm{Ni}(\mathrm{II})$ and $\mathrm{Co}(\mathrm{II})$ tetraglycine complexes. Spectrophotometric and rotating ringdisc voltametric studies. Dalton Trans 2004:267-272.

Allen, J.F. (2003) The function of genomes in bioenergetic organelles. Philos Trans R Soc Lond B Biol Sci 358:19-38.

Amend, J.P. and McCollom, T.M. (2009) Energetics of biomolecule synthesis on early earth. In Chemical Evolution II: From the Origins of Life to Modern Society, edited by L. Zaikowski, J.M. Friedrich, and S.R. Seidel, American Chemical Society, Washington, DC, pp 63-94.

Amend, J.P. and Shock, E.L. (1998) Energetics of amino acid synthesis in hydrothermal ecosystems. Science 281:16591662.

Amend, J.P., LaRowe, D., McCollom, T., and Shock, E.L. (2013) The energetics of organic synthesis inside and outside the cell. Philos Trans $R$ Soc Lond B Biol Sci 368, doi:10.1098/rstb.2012.0255.

Anglin, R.J., Kurtz, D.M., Jr., Kim, S., and Jacobson, R.A. (1987) Synthesis and structure of the "linear" tetranuclear cluster $\left[\left(\mathrm{MoO}_{2} \mathrm{~S}_{2}\right)_{2} \mathrm{Fe}_{2} \mathrm{~S}_{2}\right]^{4-}$ : implications for aqueous Mo-FeS chemistry. Inorg Chem 26:1470-1472.

Antony, H., Legrand, L., and Chaussé, A. (2008) Carbonate and sulphate green rusts-mechanisms of oxidation and reduction. Electrochim Acta 53:7146-7156.

Armen, R.S., DeMarco, M.L., Alonso, D.O., and Daggett, V. (2004) Pauling and Corey's $\alpha$-pleated sheet structure may define the prefibrillar amyloidogenic intermediate in amyloid disease. Proc Natl Acad Sci USA 101:11622-11627.

Arndt, N. and Nisbet, E. (2012) Processes on the young Earth and the habitats of early life. Annu Rev Earth Planet Sci 40:521-549.

Arrhenius, G. (1986) Dysoxic environments as models for primordial mineralisation. In Clay Minerals and the Origin of Life, Cambridge University Press, Cambridge, UK, pp 97104.

Arrhenius, G., Gedulin, B., and Mojzsis, S. (1993) Phosphate in models for chemical evolution. In Chemical Evolution and Origin of Life, edited by C. Ponnamperuma, and J. ChelaFlores, Harpers Brothers, New York, pp 23-40.

Arrhenius, G., Sales, B., Mojzsis, S., and Lee, T. (1997) Entropy and charge in molecular evolution-the case of phosphate. J Theor Biol 187:503-522.

Arrhenius, G.O. (2003) Crystals and life. Helv Chim Acta 86:1569-1586.

Atri, D. and Melott, A.L. (2012) Cosmic rays and terrestrial life: a brief review. arXiv:1211.3962.
Baade, W. and Zwicky, F. (1934) Supernovae and cosmic rays. Physical Review 45:138.

Baaske, P., Weinert, F., Duhr, S., Lemke, K., Russell, M.J., and Braun, D. (2007) Extreme accumulation of nucleotides in simulated hydrothermal pore systems. Proc Natl Acad Sci USA 104:9346-9351.

Baikousi, M., Stamatis, A., Louloudi, M., and Karakassides, M.A. (2013) Thiamine pyrophosphate intercalation in layered double hydroxides (LDHs): an active bio-hybrid catalyst for pyruvate decarboxylation. Appl Clay Sci 75-76: 126-133.

Baliarsingh, N., Parida, K.M., and Pradhan, G.C. (2013) Influence of the nature and concentration of precursor metal ions in the brucite layer of LDHs for phosphate adsorption-a review. RSC Adv 2013:23865-23878.

Baltscheffsky, H. (1971) Inorganic pyrophosphate and the origin and evolution of biological energy transformation (biological energy transformation origin and evolution, discussing inorganic pyrophosphates precursor to adenosine phosphates as energy carriers). In Chemical Evolution and the Origin of Life, edited by R. Buvet and C. Ponnamperuma, North-Holland Pub. Cy., Amsterdam, pp 466-474.

Baltscheffsky, H. (1997) Major "anastrophes" in the origin and early evolution of biological energy conversion. $J$ Theor Biol 187:495-501.

Baltscheffsky, H. and Persson, B. (2014) On an early gene for membrane-integral inorganic pyrophosphatase in the genome of an apparently pre-LUCA extremophile, the archaeon Candidatus Korarchaeum cryptofilum. J Mol Evol 78:140147.

Baltscheffsky, M., Schultz, A., and Baltscheffsky, H. (1999) $\mathrm{H}^{+}$-PPases: a tightly membrane-bound family. FEBS Lett 457:527-533.

Baradaran, R., Berrisford, J.M., Minhas, G.S., and Sazanov, L.A. (2013) Crystal structure of the entire respiratory complex I. Nature 494:443-448.

Barge, L.M., Doloboff, I.J., Russell, M.J., VanderVelde, D., White, L.M., Stucky, G.D., Baum, M.M., Zeytounian, J., Kidd, R., and Kanik, I. (2014) Pyrophosphate synthesis in iron mineral films and membranes simulating prebiotic submarine hydrothermal precipitates. Geochim Cosmochim Acta 128:1-12.

Baross, J.A. and Hoffman, S.E. (1985) Submarine hydrothermal vents and associated gradient environments as sites for the origin and evolution of life. Orig Life Evol Biosph 15:327345.

Barthélémy, K., Naille S., Despas, C., Ruby, C., and Mallet, M. (2012) Carbonated ferric green rust as a new material for efficient phosphate removal. J Colloid Interface Sci 384:121127.

Baymann, F., Lebrun, E., Brugna, M., Schoepp-Cothenet, B., Giudici-Orticoni, M.T., and Nitschke, W. (2003) The redox protein construction kit: pre last universal common ancestor evolution of energy-conserving enzymes. Philos Trans $R$ Soc Lond B Biol Sci 358:267-274.

Beard, J.S. (2000) Occurrence and composition of tochilinite and related minerals in Site 1068 serpentinites. In Proceedings of the Ocean Drilling Program Scientific Results, Vol. 173, edited by M.-O. Beslier, R.B. Whitmarsh, P.J. Wallace, and J. Girardeau, Ocean Drilling Program, College Station, TX, pp 1-9.

Bédard, J.H. (2006) A catalytic delamination-driven model for coupled genesis of Archaean crust and sub-continental lithospheric mantle. Geochim Cosmochim Acta 70:1188-1214. 
Beinert, H. (2000a) Iron-sulfur proteins: ancient structures, still full of surprises. J Biol Inorg Chem 5:2-15.

Beinert, H. (2000b) A tribute to sulfur. Eur $J$ Biochem 267:5657-5664.

Belousoff, M.J., Davidovich, C., Zimmerman, E., Caspi, Y., Wekselman, I., Rozenszajn, L., Shapira, T., Sade-Falk, O., Taha, R., Bashan, A., Weiss, M.S., and Yonath, A. (2010) Ancient machinery embedded in the contemporary ribosome. Biochem Soc Trans 38:422-427.

Benner, S.A. (2004) Understanding nucleic acids using synthetic chemistry. Acc Chem Res 37:784-797.

Benner, S.A., Kim, H.-J., and Carrigan, M.A. (2012) Asphalt, water, and the prebiotic synthesis of ribose, ribonucleosides, and RNA. Acc Chem Res 45:2025-2034.

Berg, I.A., Kockelkorn, D., Ramos-Vera, W.H., Say, R.F., Zarzycki, J., Hügler, M., Alber, B.E., and Fuchs, G. (2010) Autotrophic carbon fixation in archaea. Nat Rev Microbiol 8:447-460.

Berg, J.M., Tymoczko, J.L., and Stryer, L. (2006) Biochemistry, International Edition, WH Freeman \& Co., New York.

Berl, W.G. and Feazel, C.E. (1951) The kinetics of hexose formation from trioses in alkaline solution. J Am Chem Soc 73:2054-2057.

Bernal, J.D. (1951) The Physical Basis of Life, Routledge and Kegan Paul, London.

Bernal, J.D. (1960) The problem of stages in biopoesis. In Aspects of the Origin of Life, edited by M. Florkin, Pergamon Press, New York, pp 30-45.

Bernal, J.D. (1967) The Origin of Life, World Publishing Co., Cleveland, $\mathrm{OH}$.

Berthoumieux, S., De Jong, H., Baptist, G., Pinel, C., Ranquet, C., Ropers, D., and Geiselmann, J. (2013) Shared control of gene expression in bacteria by transcription factors and global physiology of the cell. Mol Syst Biol 9, doi:10.1038/msb .2012.70.

Bianchi, A., Giorgi, C., Ruzza, P., Toniolo, C., and MilnerWhite, E.J. (2012) A synthetic hexapeptide designed to resemble a proteinaceous P-loop nest is shown to bind inorganic phosphate. Proteins 80, doi:10.1002/prot.24038.

Bieber, J.W., Cane, H., Evenson, P., Pyle, R., and Richardson, I. (1999) Energetic particle flow near CME shocks and ejecta. In Solar Wind Nine, Proceedings of the $9^{\text {th }}$ International Solar Wind Conference, AIP Conference Proceedings 471, edited by S.R. Habbal, R. Esser, and J.V. Hollweg, American Institute of Physics, Melville, NY, pp 137-140.

Bocher, F., Géhin, A., Ruby, C., Ghanbaja, J., Abdelmoula, M., and Génin, J.-M.R. (2004) Coprecipitation of Fe(II-III) hydroxycarbonate green rust stabilised by phosphate adsorption. Solid State Sciences 6:117-124.

Boltzmann, L. (1886) The second law of thermodynamics. In Ludwig Boltzmann: Theoretical Physics and Philosophical Problems: Selected Writings, Vienna Circle collection, edited by B.F. McGuinness, Reidel (reprint), Dordrecht, the Netherlands, pp 13-32.

Bonatti, E., Simmons, E.C., Breger, D., Hamlyn, P.R., and Lawrence, J. (1983) Ultramafic rock/seawater interaction in the oceanic crust: Mg-silicate (sepiolite) deposit from the Indian Ocean floor. Earth Planet Sci Lett 62:229-238.

Bonomi, F., Werth, M.T., and Kurtz, D.M. (1985) Assembly of $\mathrm{Fe}_{n} \mathrm{~S}_{n}(\mathrm{SR})^{2-}(n=2,4)$ in aqueous media from iron salts, thiols, and sulfur, sulfide, or thiosulfate plus rhodonase. Inorg Chem 24:4331-4335.

Booth, I.R. (1985) Regulation of cytoplasmic pH in bacteria. Microbiol Rev 49:359-378.
Bormashenko, E., Bormashenko, Y., Stanevsky, O., and Pogreb, R. (2006) Evolution of chemical gardens in aqueous solutions of polymers. Chem Phys Lett 417:341-344.

Botcharnikov, R.E., Shmulovicha, K.I., Tkachenkoa, S.I., Korzhinskya, M.A., and Rybin, A.V. (2003) Hydrogen isotope geochemistry and heat balance of a fumarolic system: Kudriavy Volcano, Kuriles. Journal of Volcanology and Geothermal Research 124:45-66.

Boucherit, N., Hugot-Le Goff, A., and Joiret, S. (1991) Raman studies of corrosion films grown on $\mathrm{Fe}$ and $\mathrm{Fe}-6 \mathrm{Mo}$ in pitting conditions. Corros Sci 32:497-507.

Bounama, C., Franck, S., and von Bloh, W. (2001) The fate of the Earth's ocean. Hydrology and Earth System Sciences 5:569-575.

Boyce, A.J., Coleman, M.L., and Russell, M.J. (1983) Formation of fossil hydrothermal chimneys and mounds from Silvermines, Ireland. Nature 306:545-550.

Boyer, P.D. (1975) A model for conformational coupling of membrane potential and proton translocation to ATP synthesis and to active transport. FEBS Lett 58:1-6.

Boyer, P.D. (1997) The ATP synthase-a splendid molecular machine. Аnnu Rev Biochem 66:717-749.

Braakman, R. and Smith, E. (2013) The compositional and evolutionary logic of metabolism. Phys Biol 10, doi:10.1088/ 1478-3975/10/1/011001.

Bracher, P.J., Snyder, P.W., Bohall, B.R., and Whitesides, G.M. (2011) The relative rates of thiol-thioester exchange and hydrolysis for alkyl and aryl thioalkanoates in water. Orig Life Evol Biosph 41:399-412.

Branscomb, E. and Russell, M.J. (2013) Turnstiles and bifurcators: the disequilibrium converting engines that put metabolism on the road. Biochim Biophys Acta Bioenergetics 1827:62-78.

Braterman, P.S., Xu, Z.P., and Yarberry, F. (2004) Layered double hydroxides (LDHs). In Handbook of Layered Materials, edited by S.M. Auerbach, K.A. Carrado, and P.K. Dutta, Dekker, New York, pp 373-474.

Braun, D., Goddard, N.L., and Libchaber, A. (2003) Exponential DNA replication by laminar convection. Phys Rev Lett 91, doi:10.1103/PhysRevLett.91.158103.

Braun, S., Humphreys, C., Fraser, E., Brancale, A., Bochtler, M., and Dale, T.C. (2011) Amyloid-associated nucleic acid hybridisation. PLoS One 6, doi:10.1371/journal.pone .0019125 .

Brazelton, W.J., Mehta, M.P., Kelley, D.S., and Baross, J.A. (2011) Physiological differentiation within a single-species biofilm fueled by serpentinization. Biology 2, doi:10.1128/ mBio.00127-11.

Brazelton, W.J., Nelson, B., and Schrenk, M.O. (2012) Metagenomic evidence for $\mathrm{H}_{2}$ oxidation and $\mathrm{H}_{2}$ production by serpentinite-hosted subsurface microbial communities. Front Microbiol 2, doi:10.3389/fmicb.2011.00268.

Buckel, W. and Thauer, R.K. (2013) Energy conservation via electron bifurcating ferredoxin reduction and proton $/ \mathrm{Na}^{+}$ translocating ferredoxin oxidation. Biochim Biophys Acta Bioenergetics 1827:94-113.

Budin, I., Bruckner, R.J., and Szostak, J.W. (2009) Formation of protocell-like vesicles in a thermal diffusion column. $J$ Am Chem Soc 131:9628-9629.

Burgmayer, S.J.N. and Stiefel, E.I. (1985) Molybdenum enzymes, cofactors, and systems: the chemical uniqueness of molybdenum. J Chem Educ 62:943-953.

Butlerov, A.M. (1861) Einiges über die chemische Structur der Körper. Zeitschrift für Chemie 4:549-560. 
Cabello, P., Roldán, M.D., and Moreno-Vivián, C. (2004) Nitrate reduction and the nitrogen cycle in archaea. Microbiology 150:3527-3546.

Cafferty, B.J., Gllego, I., Chen, M.C., Farley, K.I., Eritja, R., and Hud, N.V. (2013) Efficient self-assembly in water of long noncovalent polymers by nucleobase analogues. J Am Chem Soc 135:2447-2450.

Cairns-Smith, A.G. (1982) Genetic Takeover and the Mineral Origins of Life, Cambridge University Press, Cambridge, UK.

Cairns-Smith, A.G. (2008) Chemistry and the missing era of evolution. Chemistry-A European Journal 14:3830-3839.

Cairns-Smith, A.G., Hall, A.J., and Russell, M.J. (1992) Mineral theories of the origin of life and an iron sulphide example. Orig Life Evol Biosph 22:161-180.

Carlson, R., Johnson, R.E., and Anderson, M.S. (1999) Sulfuric acid on Europa and the radiolytic sulfur cycle. Science 286:97-99.

Carny, O. and Gazit, E. (2005) A model for the role of short self-assembed peptides in the very early stages of the origin of life. FASEB J 19:1051-1055.

Catling, D.C. (2006) Comment on "A hydrogen-rich early Earth atmosphere." Science 311:38a.

Charlou, J.L., Donval, J.P., Fouquet, Y., Jean-Baptiste, P., and Holm, N. (2002) Geochemistry of high $\mathrm{H}_{2}$ and $\mathrm{CH}_{4}$ vent fluids issuing from ultramafic rocks at the Rainbow hydrothermal field ( $\left.36^{\circ} 14^{\prime} \mathrm{N}, \mathrm{MAR}\right)$. Chem Geol 191:345-359.

Chernoff, Y.O. (2004) Amyloidogenic domains, prions and structural inheritance: rudiments of early life or recent acquisition? Curr Opin Chem Biol 8:665-671.

Childers, W.S., Ni, R., Mehta, A.K., and Lynn, D.G. (2009) Peptide membranes in chemical evolution. Curr Opin Chem Biol 13:652-659.

Childers, W.S., Mehta, A.K., Ni, R., Taylor, J.V., and Lynn, D.G. (2010) Peptides organized as bilayer membranes. Angew Chem Int Ed 49:4104-4107.

Childers, W.S., Mehta, A.K., Bui, T.Q., Liang, Y., and Lynn, D.G. (2012) Toward intelligent materials. In Molecular Self-Assembly: Advances and Applications, edited by A.D.Q. Li, Pan Stanford Publishing Pte Ltd, Singapore/SG, pp 1-36.

Choy, J.H., Kwak, S.Y., Jeong, Y.J., and Park, J.S. (2000) Inorganic layered double hydroxides as nonviral vectors. Angew Chem Int Ed 39:4041-4045.

Cockell, C.S. (2006) The origin and emergence of life under impact bombardment. Philos Trans $R$ Soc Lond B Biol Sci 361:1845-1856.

Cody, G.D. and Alexander, C.M.D. (2005) NMR studies of chemical structural variation of insoluble organic matter from different carbonaceous chondrite groups. Geochim Cosmochim Acta 69:1085-1097.

Cody, G.D., Mysen, B., Sághi-Szabó, G., and Tossell, J.A. (2001) Silicate-phosphate interactions in silicate glasses and melts: I. A multinuclear $\left.{ }^{27} \mathrm{Al},{ }^{29} \mathrm{Si},{ }^{31} \mathrm{P}\right) \mathrm{MAS}$ NMR and $a b$ initio chemical shielding $\left({ }^{31} \mathrm{P}\right)$ study of phosphorous speciation in silicate glasses. Geochim Cosmochim Acta 65:2395-2411.

Cohen, O., Drake, J.J., and Kota, J. (2012) The cosmic ray intensity near the Archean Earth. Astrophys J 760, doi:10.1088/ 0004-637X/760/1/85.

Collins, S.R., Douglass, A., Vale, R.D., and Weissman, J.S. (2004) Mechanism of prion propagation: amyloid growth occurs by monomer addition. PLoS Biol 2:e321.

Corliss, J.B. (1986) On the creation of living cells in submarine hot spring flow reactors: attractors and bifurcations in the natural hierarchy of dissipative systems. Orig Life Evol Biosph 16:381-382.
Costanzo, G., Pino, S., Ciciriello, F., and Di Mauro, E. (2009) Generation of long RNA chains in water. $\mathrm{J}$ Biol Chem 284:33206-33216.

Cottrell, A. (1979) The natural philosophy of engines. Contemp Phys 20:1-10.

Coveney, P.V., Swadling, J.B., Wattis, J.A., and Greenwell, H.C. (2012) Theory, modelling and simulation in origins of life studies. Chem Soc Rev 41:5430-5446.

Crabtree, R.H. (1997) Where smokers rule. Science 276:222.

Csákberényi-Malasics, D., Rodriguez-Blanco, J.D., Kis, V.K., Rečnik, A., Benning, L.G., and Pósfai, M. (2012) Structural properties and transformations of precipitated FeS. Chem Geol 294:249-258.

Darrouzet, E., Issartel, J.P., Lunardi, J., and Dupuis, A. (1998) The 49-kDa subunit of NADH-ubiquinone oxidoreductase (complex I) is involved in the binding of piericidin and rotenone, two quinone-related inhibitors. FEBS Lett 431: 34-38.

Dasgupta, R. (2013) Ingassing, storage, and outgassing of terrestrial carbon through geologic time. Reviews in Mineralogy and Geochemistry 75:183-229.

Dauphas, N., Cates, N.L., Mojzsis, S.J., and Busigny, V. (2007) Identification of chemical sedimentary protoliths using iron isotopes in the $>3750 \mathrm{Ma}$ Nuvvuagittuq supracrustal belt, Canada. Earth Planet Sci Lett 254:358-376.

Davies, K.M., Strauss, M., Daum, B., Kief, J.H., Osiewacz, H.D., Rycovska, A., Zickermann, V., and Kühlbrandt, W. (2011) Macromolecular organization of ATP synthase and complex I in whole mitochondria. Proc Natl Acad Sci USA 108:14121-14126.

de Duve, C. (1991) Blueprint for a Cell: The Nature and Origin of Life, Neil Patterson Publishers, Burlington, NC.

de Lorenzo, V. (2014) From the selfish gene to selfish metabolism: revisiting the central dogma. BioEssays 36:226-235.

de Zwart, I.I., Meade, S.J., and Pratt, A.J. (2004) Biomimetic phosphoryl transfer catalysed by iron(II)-mineral precipitates. Geochim Cosmochim Acta 68:4093-4098.

Denis, C., Rybicki, K.R., Schreider, A.A., Tomecka-Suchoń, S., and Varga, P. (2011) Length of the day and evolution of the Earth's core in the geological past. Astronomische $\mathrm{Na}$ chrichten 332:24-35.

Desvaux, M., Dumas, E., Chafsey, I., and Hébraud, M. (2006) Protein cell surface display in Gram-positive bacteria: from single protein to macromolecular protein structure. FEMS Microbiol Lett 256:1-15.

Dobbek, H., Svetlitchnyi, V., Gremer, L., Huber, R., and Meyer, O. (2001) Crystal structure of a carbon monoxide dehydrogenase reveals a [Ni-4Fe-5S] cluster. Science 293:1281-1285.

Dong, J., Lu, K., Lakdawala, A., Mehta, A.K., and Lynn, D.G. (2006) Controlling amyloid growth in multiple dimensions. Amyloid 13:206-215.

Doolittle, W.F. (1999) Phylogenetic classification and the universal tree. Science 284:2124-2128.

Douville, E., Charlou, J.L., Oelkers, E.H., Bienvenu, P., Colon, C.F.J., Donval, J.P., Fouquet, Y., Prieur, D., and Appriou, P. (2002) The Rainbow vent fluids ( $36^{\circ} 14^{\prime} \mathrm{N}$, MAR): the influence of ultramafic rocks and phase separation on trace metal content in Mid-Atlantic Ridge hydrothermal fluids. Chem Geol 184:37-48.

Driesener, R.C., Challand, M.R., McGlynn, S.E., Shepard, E.M., Boyd, E.S., Broderick, J.B., Peters, J.W., and Roach, P.L. (2010) [FeFe]-Hydrogenase cyanide ligands derived from $S$-adenosylmethionine-dependent cleavage of tyrosine. Angew Chem Int Ed 49:1687-1690. 
Ducluzeau, A.-L., van Lis, R., Duval, S., Schoepp-Cothenet, B., Russell, M.J., and Nitschke, W. (2009) Was nitric oxide the first strongly oxidizing terminal electron sink? Trends Biochem Sci 34:9-15.

Ducluzeau, A.-L., Schoepp-Cothenet, B., Baymann, F., Russell, M.J., and Nitschke, W. (2014) Free energy conversion in the LUCA: quo vadis? Biochim Biophys Acta, in press, doi:10.1016/j.bbabio.2013.12.005.

Dutta, A., Hamilton, G.A., Hartnett, H.E., and Jones, A.K. (2012) Construction of heterometallic clusters in a small peptide scaffold as [NiFe]-hydrogenase models: development of a synthetic methodology. Inorg Chem 51:9580-9588.

Efremov, R.G. and Sazanov, L.A. (2011a) Structure of the membrane domain of respiratory complex I. Nature 476: 414-420.

Efremov, R.G. and Sazanov, L.A. (2011b) Respiratory complex I: "steam engine" of the cell? Curr Opin Struct Biol 21:532-540.

Efremov, R.G., Baradaran, R., and Sazanov, L.A. (2010) The architecture of respiratory complex I. Nature 465:441-447.

Ehrenfreund, P. and Charnley, S.B. (2000) Organic molecules in the interstellar medium, comets, and meteorites: a voyage from dark clouds to the early Earth. Annu Rev Astron Astrophys 38:427-483.

Elkins, J.G., Podar, M., Graham, D.E., Makarova, K.S., Wolf, Y., Randau, L., Hedlund, B.P., Brochier-Armanet, C., Kunin, V., Anderson, I., Lapidus, A., Goltsman, E., Barry, K., Koonin, E.V., Hugenholtz, P., Kyrpides, N., Wanner, G., Richardson, P., Keller, M., and Stetter, K.O. (2008) A korarchaeal genome reveals insights into the evolution of the archaea. Proc Natl Acad Sci USA 105:8102-8107.

Elkins-Tanton, L.T. (2008) Linked magma ocean solidification and atmospheric growth for Earth and Mars. Earth Planet Sci Lett 271:181-191.

England, J. (2013) Statistical physics of self-replication. J Chem Phys 139, doi:10.1063/1.4818538.

Erickson, B.E. and Helz, G.R. (2000) Molybdenum (VI) speciation in sulfidic waters: stability and lability of thiomolybdates. Geochim Cosmochim Acta 64:1149-1158.

Erlykin, A.D. and Wolfendale, A.W. (2010) Long term time variability of cosmic rays and possible relevance to the development of life on Earth. Surveys in Geophysics 31:383-398.

Ertem, G. and Ferris, J.P. (1998) Formation of RNA oligomers on montmorillonite: site of catalysis. Orig Life Evol Biosph 28:485-499.

Ertem, G. and Ferris, J.P. (2000) Sequence- and regio-selectivity in the montmorillonite-catalyzed synthesis of RNA. Orig Life Evol Biosph 30:411-422.

Etiope, G. and Sherwood Lollar, B. (2013) Abiotic methane on Earth. Rev Geophys 51:276-299.

Etiope, G., Vance, S., Christensen, L.E., Marques, J.M., and Ribeiro da Costa, I. (2013) Methane in serpentinized ultramafic rocks in mainland Portugal. Marine and Petroleum Geology 45:12-16.

Ettwig, K.F., Butler, M.K., Le Paslier, D., Pelletier, E., Mangenot, S., Kuypers, M.M.M., Schreiber, F., Dutilh, B.E., Zedelius, J., de Beer, D., Gloerich, J., Wessels, H.J.C.T. van Alen, T., Luesken, F., Wu, M.L., van de Pas-Schoonen, K.T., Op den Camp, H.J.M., Janssen-Megens, E.M., Francoijs, K.J., Stunnenberg, H., Weissenbach, J., Jetten, M.S.M., and Strous, M. (2010) Nitrite-driven anaerobic methane oxidation by oxygenic bacteria. Nature 464:543-548.

Façanha, A.R. and de Meis, L. (1998) Reversibility of $\mathrm{H}^{+}$ATPase and $\mathrm{H}^{+}$-pyrophosphatase in tonoplast vesicles from maize coleoptiles and seeds. Plant Physiol 116:1487-1495.
Feder, F., Trolard, F., Klingelhofer, G., and Bourrie, G. (2005) In situ Mössbauer spectroscopy: evidence for green rust (fougerite) in a gleysol and its mineralogical transformations with time and depth. Geochim Cosmochim Acta 69:44634483.

Ferris, J.P. (2002) Montmorillonite catalysis of 30-50 mer oligonucleotides: laboratory demonstration of potential steps in the origin of the RNA world. Orig Life Evol Biosph 32: 311-332.

Ferris, J.P. (2005) Mineral catalysis and prebiotic synthesis: montmorillonite-catalyzed formation of RNA. Elements 1: 145-149.

Ferris, J.P., Hill, A.R., Liu, R.H., and Orgel, L.E. (1996) Synthesis of long prebiotic oligomers on mineral surfaces. Nature 381:59-61.

Ferry, J.G. and House, C.H. (2006) The step-wise evolution of early life driven by energy conservation. Mol Biol Evol 23: 1286-1292.

Feuillie, C., Daniel, I., Michot, L.J., and Pedreira-Segade, U. (2013) Adsorption of nucleotides onto Fe-Mg-Al rich swelling clays. Geochim Cosmochim Acta 120:97-108.

Fox, G.E., Tran, Q., and Yonath, A. (2012) An exit cavity was crucial to the polymerase activity of the early ribosome. Astrobiology 12:57-60.

Friedkin, M. (1963) Enzymatic aspects of folic acid. Annu Rev Biochem 32:185-214.

Frost, B.R. and Beard, J.S. (2007) On silica activity and serpentinization. Journal of Petrology 48:1351-1368.

Fuchs, G. (1989) Alternative pathways of autotrophic $\mathrm{CO}_{2}$ fixation. In Autotrophic Bacteria, edited by H.G. Schlegel and B. Bowen, Science Technology, Madison, WI, pp 365-382.

Fuchs, G. (2011) Alternative pathways of carbon dioxide fixation: insights into the early evolution of life. Апnи Rev Microbiol 65:631-658.

Fuchs, G. and Stupperich, E. (1978) Evidence for an incomplete reductive carboxylic acid cycle in Methanobacterium thermoautotrophicum. Arch Microbiol 118:121-125.

Gaidos, E.J. (2000) A cosmochemical determinism in the formation of Earth-like planets. Icarus 145:637-640.

Gao, X, Liu, Y., Cai, Y.M., and Zhao, Y.F. (2008) Alpha-amino acid behaves differently from beta- or gamma-amino acids as treated by metaphosphate. Amino Acids 34:47-53.

Gargaud, M., Martin, H., López-García, P., Montmerle, T., and Pascal, R. (2012) Formation and early infancy of the Earth. In Young Sun, Early Earth and the Origins of Life, Springer, Berlin Heidelberg, pp 37-59.

Geim, A.K. and Grigorieva, I.V. (2013) Van der Waals heterostructures. Nature 499:419-425.

Génin, J.-M.R., Abdelmoula, M., Aissa, R., and Ruby, C. (2005) Ordering in $\mathrm{Fe}^{\mathrm{II}-\mathrm{III}}$ hydroxysalt green rusts from XRD and Mössbauer analysis (chloride, carbonate, sulphate, oxalate ... ); about the structure of hydrotalcite-like compounds. Hyperfine Interact 166:391-396.

Génin, J.-M.R., Ruby, C., Géhin, A., and Refait, Ph. (2006) Synthesis of green rust by oxidation of $\mathrm{Fe}(\mathrm{OH})_{2}$, their products of oxidation and reduction of ferric oxyhydroxides; EhpH Pourbaix diagrams. Comptes Rendus Geoscience 338: 433-446.

Goldblatt, C., Claire, M.W., Lenton, T.M., Matthews, A.J., Watson, A.J., and Zahnle, K.J. (2009) Nitrogen-enhanced greenhouse warming on early Earth. Nat Geosci 2:891-896.

Goodwin, J.T. and Lynn, D.G. (1992) Template-directed synthesis: use of a reversible reaction. J Am Chem Soc 114:91979198. 
Goodwin, J.T., Mehta, A.K., and Lynn, D.G. (2012) Digital and analog chemical evolution. Acc Chem Res 45:2189-2199.

Gordon, A.D., Smirnov, A., Shumlas, S.L., Singireddy, S., DeCesare, M., Schoonen, M.A., and Strongin, D.R. (2013) Reduction of nitrite and nitrate on nano-dimensioned FeS. Orig Life Evol Biosph 43:1-18.

Greenwald, J. and Riek, R. (2010) Biology of amyloid: structure, function, and regulation. Structure 18:1244-1260.

Greenwald, J. and Riek, R. (2012) On the possible amyloid origin of protein folds. $J$ Mol Biol 421:417-426.

Greenwell, H.C. (2010) Modeling layered-mineral organic interactions. In Ideas in Chemistry and Molecular Sciences: Advances in Nanotechnology, Materials and Devices, edited by B. Pignataro, Wiley VCH Verlag GmbH, Weinheim, pp 255-279.

Greenwell, H.C. and Coveney, P.V. (2006) Layered double hydroxide minerals as possible prebiotic information storage and transfer compounds. Orig Life Evol Biosph 36:13-37.

Grenfell, J.L., Grießmeier, J.M., von Paris, P., Patzer, A.B.C., Lammer, H., Stracke, B., Gebauer, S., Schreier, F., and Rauer, H. (2012) Response of atmospheric biomarkers to $\mathrm{NO}_{x}$-induced photochemistry generated by stellar cosmic rays for Earth-like planets in the habitable zone of $\mathrm{M}$ dwarf stars. Astrobiology 12:1109-1122.

Griffin, W.L., Belousova, E.A., O’Neil, C., O'Reilly, S.Y., Malkovets, V., Pearson, N.J., Spetsius, S., and Wilde, S.A. (2014) The world turns over: Hadean-Archean crust-mantle evolution. Lithos 189:2-15.

Gurevich, A.V. and Karashtin, A.N. (2013) Runaway breakdown and hydrometeors in lightning initiation. Phys Rev Lett 110, doi:10.1103/PhysRevLett.110.185005.

Gurevich, A.V., Zybin, K.P., and Roussel-Dupré, R.A. (1999) Lightning initiation by simultaneous effect of runaway breakdown and cosmic ray showers. Phys Lett A 254:79-87.

Hagan, W.J., Parker, A., Steuerwald, A., and Hathaway, M. (2007) Phosphate solubility and the cyanate-mediated synthesis of pyrophosphate. Orig Life Evol Biosph 37:113-122.

Halevy, I., Zuber, M.T., and Schrag, D.P. (2007) A sulfur dioxide climate feedback on early Mars. Science 318:19031907.

Halfmann, R. and Lindquist, S. (2010) Epigenetics in the extreme: prions and the inheritance of environmentally acquired traits. Science 330:629-632.

Halliday, A.N. (2004) Mixing, volatile loss and compositional change during impact-driven accretion of the Earth. Nature 427:505-509.

Hanczyc, M.M., Fujikawa, S.M., and Szostak, J.W. (2003) Experimental models of primitive cellular compartments: encapsulation, growth and division. Science 302:618-622.

Hand, K.P., Carlson, R.W., and Chyba, C.F. (2007) Energy, chemical disequilibrium, and geological constraints on Europa. Astrobiology 7:1-18.

Hand, K.P., Chyba, C.F., Priscu, J.C., Carlson, R.W., and Nealson, K.H. (2009) Astrobiology and the potential for life on Europa. In Europa, edited by R.T. Pappalardo, W.B. McKinnon, and K.K. Khurana, University of Arizona Press, Tucson, AZ, pp 589-630.

Hand, K.P., McKay, C.P., and Pilcher, C. (2010) Spectroscopic and spectrometric differentiation between abiotic and biogenic material on icy worlds. Proceedings of the International Astronomical Union 6:165-176.

Hansen, H.C.B. and Koch, C.B. (1998) Reduction of nitrate to ammonium by sulphate green rust: activation energy and reaction mechanism. Clay Miner 33:87-101.
Hansen, H.C.B. and Poulsen, I.F. (1999) Interaction of synthetic sulphate "green rust" with phosphate and the crystallization of vivianite. Clays Clay Miner 47:312-318.

Hansen, H.C.B., Koch, C.B., Nancke-Krogh, H., Borggaard, O.K., and Sørensen, J. (1996) Abiotic nitrate reduction to ammonium: key role of green rust. Environ Sci Technol 30:2053-2056.

Haroon, M.F., Hu, S. Shi, Y., Imelfort, M., Keller, J., Hugenholtz, P., Yuan, Z., and Tyson, G.W. (2013) Anaerobic oxidation of methane coupled to nitrate reduction in a novel archaeal lineage. Nature 500:567-570.

Harris, J.K., Kelley, S.T., Spiegelman, G.B., and Pace, N.R. (2003) The genetic core of the universal ancestor. Genome Res 13:407-412.

Harris, L.B. and Bédard, J.H. (2014) Crustal evolution and deformation in a non-plate-tectonic Archaean Earth: comparisons with Venus. In Evolution of Archean Crust and Early Life, edited by Y. Dilek and H. Furnes, Springer, Dordrecht, the Netherlands, pp 215-291.

Harrison, T.M. (2009) The Hadean crust: evidence from $>4 \mathrm{Ga}$ zircons. Annu Rev Earth Planet Sci 37:479-505.

Haydon, N., McGlynn, S.E., and Robus, O. (2011) Speculation on quantum mechanics and the operation of life giving catalysts. Orig Life Evol Biosph 41:35-50.

Hayward, S. and Milner-White, E.J. (2008) The geometry of $\alpha$-sheet: implications for its possible function as amyloid precursor in proteins. Proteins 71:415-425.

He, X., Aizenberg, M., Kuksenok, O., Zarzar, L.D., Shastri, A., Balazs, A.C., and Aizenberg, J. (2012) Synthetic homeostatic materials with chemo-mechano-chemical self-regulation. Nature 487:214-218.

Heck, P.R., Huberty, J.M., Kita, N.T., Ushikubo, T., Kozdon, R., and Valley, J.W. (2011) SIMS analyses of silicon and oxygen isotope ratios for quartz from Archean and Paleoproterozoic banded iron formations. Geochim Cosmochim Acta 75:5879-5891.

Hedderich, R. (2004) Energy-converting [NiFe] hydrogenases from archaea and extremophiles: ancestors of complex I. $J$ Bioenerg Biomembr 36:65-75.

Helz, G.R., Erickson, B.E., and Vorlicek, T.P. (2013) Stabilities of thiomolybdate complexes of iron: implications for retention of essential trace elements $(\mathrm{Fe}, \mathrm{Cu}, \mathrm{Mo})$ in sulfidic waters. Metallomics, doi:10.1039/C3MT00217A.

Hengeveld, R. (2007) Two approaches to the study of the origin of life. Acta Biotheor 55:97-131.

Herrmann, G., Jayamani, E., Mai, G., and Buckel, W. (2008) Energy conservation via electron-transferring flavoprotein in anaerobic bacteria. J Bacteriol 190:784-791.

Hill, A.R., Böhler, C., and Orgel, L.E. (1998) Polymerization on the rocks: negatively charged $\alpha$-amino acids. Orig Life Evol Biosph 28:235-243.

Hoehler, T.M. and Alperin, M.J. (1996) Anaerobic methane oxidation by a methanogen-sulfate reducer consortium: geochemical evidence and biochemical considerations. In $\mathrm{Mi}$ crobial Growth on C-1 Compounds, edited by M.E. Lidstrom and R.F. Tabita, Kluwer Academic Publishing, Dordrecht, the Netherlands, pp 326-333.

Hoehler, T.M. and Jørgensen, B.B. (2013) Microbial life under extreme energy limitation. Nat Rev Microbiol 11:83-94.

Hoffmann, P.M. (2012) Life's Ratchet: How Molecular Machines Extract Order from Chaos, Basic Books, New York.

Holmes, A. (1931) Radioactivity and Earth movements. Transactions of the Geological Society of Glasgow 18:559606. 
Hong Enriquez, R.P. and Do, T.N. (2012) Interactions of ironsulfur clusters with small peptides: insights into early evolution. Computational Biology and Chemistry 41:58-61.

Hopkinson, L., Beard, J.S., and Boulter, C.A. (2004) The hydrothermal plumbing of a serpentinite-hosted detachment: evidence from the West Iberia non-volcanic rifted continental margin. Mar Geol 204:301-315.

Horváth, J., Szalai, I., Boissonade, J., and De Kepper, P. (2011) Oscillatory dynamics induced in a gel by a non-oscillatory chemical reaction: experimental evidence. Soft Matter 7:8462-8472.

Hsiao, C. and Williams, L.D. (2009) A recurrent magnesiumbinding motif provides a framework for the ribosomal peptidyl transferase center. Nucleic Acids Res 37:3134-3142.

Hsiao, C., Mohan, S., Kalahar, B.K., and Williams, L.D. (2009) Peeling the onion: ribosomes are ancient molecular fossils. Mol Biol Evol 26:2415-2425.

Huang, H., Wang, S., Moll, J., and Thauer, R.K. (2012) Electron bifurcation involved in the energy metabolism of the acetogenic bacterium Moorella thermoacetica growing on glucose or $\mathrm{H}_{2}$ plus $\mathrm{CO}_{2}$. J Bacteriol 194:3689-3699.

Huang, S.P., Shiota, Y., and Yoshizawa, K. (2013) DFT study of the mechanism for methane hydroxylation by soluble methane monooxygenase (sMMO): effects of oxidation state, spin state, and coordination number. Dalton Trans 42:10111023.

Huber, C. and Wächtershäuser, G. (1997) Activated acetic acid by carbon fixation on $(\mathrm{Fe}, \mathrm{Ni}) \mathrm{S}$ under primordial conditions. Science 276:245-247.

Huber, C. and Wächtershäuser, G. (2003) Primordial reductive amination revisited. Tetrahedron Lett 44:1695-1697.

Huber, C., Eisenreich, W., Hecht, S., and Wächtershäuser, G. (2003) A possible primordial peptide cycle. Science 301:938940.

Huss, G.R., Meyer, B.S., Srinivasan, G., Goswami, J.N., and Sahijpal, S. (2009) Stellar sources of the short-lived radionuclides in the early Solar System. Geochim Cosmochim Acta 73:4922-4945.

Itaya, K., Chang, H.C., and Uchida, I. (1987) Anion-exchanged clay (hydrotalcite-like compounds) modified electrodes. Inorg Chem 26:624-626.

Jacques, J.G.J., Fourmond, V., Arnoux, P., Sabaty, M., Etienne, E., Grosse, S., Biaso, F., Bertrand, P., Pignol, D., Léger, C., Guigliarelli, B., and Burlat, B., (2014) Reductive activation in periplasmic nitrate reductase involves chemical modifications of the Mo-cofactor beyond the first coordination sphere of the metal ion. Biochim Biophys Acta 1837:277-286.

Johnson, T.E., Brown, M., Kaus, B.J., and VanTongeren, J.A. (2013) Delamination and recycling of Archaean crust caused by gravitational instabilities. Nat Geosci 7:47-52.

Kachurovskaya, N.A., Zhidomirov, G.M., and van Santen, R.A. (2004) Computational study of benzene-to-phenol oxidation catalyzed by $\mathrm{N}_{2} \mathrm{O}$ on iron-exchanged ferrierite. J Phys Chem $B$ 108:5944-5950.

Kandler, O. and König, H. (1998) Cell wall polymers in Archaea (Archaebacteria). Cell Mol Life Sci 54:305-308.

Kang, S.G., Huynh, T., Xia, Z., Zhang, Y., Fang, H., Wei, G., and Zhou, R. (2013) Hydrophobic interaction drives surfaceassisted epitaxial assembly of amyloid-like peptides. $J$ Am Chem Soc 135:3150-3157.

Kargel, J.S., Kaye, J.Z., Head, J.W., Marion, G.M., Sassen, R., Crowley, J.K., Ballesteros, O.P., Grant, S.A., and Hogenboom, D.L. (2000) Europa's crust and ocean: origin, composition, and the prospects for life. Icarus 148:226-265.
Kaster, A.-K., Moll, J., Parey, K., and Thauer, R.K. (2011) Coupling of ferredoxin and heterodisulfide reduction via electron bifurcation in hydrogenotrophic methanogenic Archaea. Proc Natl Acad Sci USA 108:2981-2986.

Kasting, J.F. (1990) Bolide impacts and the oxidation state of carbon in the Earth's early atmosphere. Orig Life Evol Biosph 20:199-231.

Katz, J.E., Zhang, X., Attenkofer, K., Chapman, K.W., Frandsen, C., Zarzycki, P., Rosso, K.M., Falcone, R.W., Waychunas, G.A., and Gilbert, B. (2012) Electron small polarons and their mobility in iron (oxyhydr)oxide nanoparticles. Science 337:1200-1203.

Kebukawa, Y., Alexander, C.M.D., and Cody, G.D. (2011) Compositional diversity in insoluble organic matter in type 1, 2 and 3 chondrites as detected by infrared spectroscopy. Geochim Cosmochim Acta 75:3530-3541.

Kell, D.B. (1988) Protonmotive energy-transducing mechanisms: some physical principles and experimental approaches. In Bacterial Energy Transduction, edited by C. Anthony, Academic Press, London, pp 429-490.

Kelley, D.S. (1996) Methane-rich fluids in the oceanic crust. J Geophys Res 101:2943-2962.

Kelley, D.S., Karson, J.A., Blackman, D.K., Früh-Green, G.L., Butterfield, D.A., Lilley, M.D., Olson, E.J., Schrenk, M.O., Roe, K.K., Lebon, G.T., Rivizzigno, P., and the AT360 Shipboard Party. (2001) An off-axis hydrothermal vent field near the Mid-Atlantic Ridge at $30^{\circ}$ N. Nature 412:145149.

Kelley, D.S., Karson, J.A., Früh-Green, G.L., Yoerger, D.R., Shank, T.M., Butterfield, D.A., Hayes, J.M., Schrenk, M.O., Olson, E.J., Proskurowski, G., Jakuba, M., Bradley, A., Larson, B., Ludwig, K., Glickson, D., Buckman, K., Bradley, A.S., Brazelton, W.J., Roe, K., Elend, M.J., Delacour, A., Bernasconi, S.M., Lilley, M.D., Baross, J.A., Summons, R.E., and Sylva, S.P. (2005) A serpentinite-hosted ecosystem: the Lost City hydrothermal field. Science 307:1428-1434.

Kellosalo, J., Kajander, T., Kogan, K., Pokharel, K., and Goldman, A. (2012) The structure and catalytic cycle of a sodium-pumping pyrophosphatase. Science 337:473-476.

Kellum, J.A. (2005) Clinical review: reunification of acid-base physiology. Crit Care 9:500-507.

Kemp, A.I.S., Wilde, S.A., Hawkesworth, C.J., Coath, C.D., Nemchin, A., Pidgeon, R.T., Vervoort, J.D., and DuFrane, S.A. (2010) Hadean crustal evolution revisited: new constraints from $\mathrm{Pb}-\mathrm{Hf}$ isotope systematics of the Jack Hills zircons. Earth Planet Sci Lett 296:45-56.

Klein, F., Bach, W., and McCollom, T.M. (2013) Compositional controls on hydrogen generation during serpentinization of ultramafic rocks. Lithos 178:55-69.

Kolb, V. and Orgel, L.E. (1996) Phosphorylation of glyceric acid in aqueous solution using trimetaphosphate. Orig Life Evol Biosph 26:7-13.

Kolb, V., Zhang, S., Xu, Y., and Arrhenius, G. (1997) Mineral induced phosphorylation of glycolate ion-a metaphor in chemical evolution. Orig Life Evol Biosph 27:485-503.

Konn, C., Charlou, J.L., Donval, J.P., Holm, N.G., Dehairs, F., and Bouillon, S. (2009) Hydrocarbons and oxidized organic compounds in hydrothermal fluids from Rainbow and Lost City ultramafic-hosted vents. Chem Geol 258:299-314.

Koonin, E.V. and Martin, W. (2005) On the origin of genomes and cells within inorganic compartments. Trends Genet 21: 647-654.

Kopf, S.H., Henny, C., and Newman, D.K. (2013) Ligandenhanced abiotic iron oxidation and the effects of chemical 
versus biological iron cycling in anoxic environments. Environ Sci Technol 47:2602-2611.

Korenaga, J. (2008) Plate tectonics, flood basalts and the evolution of Earth's oceans. Terra Nova 20:419-439.

Korenaga, J. (2013) Initiation and evolution of plate tectonics on Earth: theories and observations. Annu Rev Earth Planet Sci 41:7.1-7.35

Koschinsky, A., Garbe-Schonberg, D., Sander, S., Schmidt, K., Gennerich, H., and Strauss, H. (2008) Hydrothermal venting at pressure-temperature conditions above the critical point of seawater, 58S on the mid-Atlantic ridge. Geology 36:615618.

Kotwicki, V. (2009) Water balance of Earth/Bilan hydrologique de la Terre. Hydrological Sciences Journal 54:829-840.

Krasnopolsky, V.A. (2006) A sensitive search for nitric oxide in the lower atmospheres of Venus and Mars: detection on Venus and upper limit for Mars. Icarus 182:80-91.

Krishnamurthy, R., Pitsch, S., and Arrhenius. G. (1999) Mineral induced formation of pentose-2,4-bisphosphates. Orig Life Evol Biosph 29:139-152.

Kuchenreuther, J.M., Myers, W.K., Stich, T.A., George, S.J., NejatyJahromy, Y., Swartz, J.R., and Britt, R.D. (2013) A radical intermediate in tyrosine scission to the $\mathrm{CO}$ and $\mathrm{CN}^{-}$ ligands of FeFe hydrogenase. Science 342:472-475.

Kuhn, H. (1972) Self-organization of molecular systems and evolution of the genetic apparatus. Angew Chem Int Ed 11: 798-820.

Kuma, K., Paplawsky, W., Gedulin, B., and Arrhenius, G. (1989) Mixed-valence hydroxides as bioorganic host minerals. Orig Life Evol Biosph 19:573-601.

Labrosse, S., Hernlund, J.W., and Coltice, N. (2007) A crystallizing dense magma ocean at the base of the Earth's mantle. Nature 450:866-869.

Lambert, J.B., Lu, G., Singer, S.R., and Kolb, V.M. (2004) Silicate complexes of sugars in aqueous solution. J Am Chem Soc 126:9611-9625.

Lambert, J.B., Gurusamy-Thangavelu, S.A., and Ma, M. (2010) The silicate-mediated formose reaction: bottom-up synthesis of sugar silicates. Science 327:984-986.

Lane, N. (2010) Why are cells powered by proton gradients? Nature Ed 3:18.

Lane, N. and Martin, W. (2010) The energetics of genome complexity. Nature 467:929-934.

Lane, N., Allen, J.F., and Martin, W. (2010) How did LUCA make a living? Chemiosmosis in the origin of life. Bioessays 32:271-280.

Lang, S.Q., Butterfield, D.A., Schulte, M., Kelley, D.S., and Lilley, M.D. (2010) Elevated concentrations of formate, acetate and dissolved organic carbon found at the Lost City hydrothermal field. Geochim Cosmochim Acta 74: 941-952.

Lang, S.Q., Früh-Green, G.L., Bernasconi, S.M., Lilley, M.D., Proskurowski, G., Méhay, S., and Butterfield, D.A. (2012) Microbial utilization of abiogenic carbon and hydrogen in a serpentinite-hosted system. Geochim Cosmochim Acta 92: 82-99.

Leclaire, J., Vial, L., Otto, S., and Sanders, J.K.M. (2005) Expanding diversity in dynamic combinatorial libraries: simultaneous exchange of disulfide and thioester linkages. Chem Commun 2005:1959-1961.

Leduc, S. (1911) The Mechanism of Life, Rebman Ltd., London. Lever, M.A. (2012) Acetogenesis in the energy starved deep biosphere-a paradox? Front Microbiol 2:1-14.
Li, J., Browning, S., Mahal, S.P., Oelschlegel, A.M., and Weissmann, C. (2010) Darwinian evolution of prions in cell culture. Science 327:869-872.

Lin, S., Krause, F., and Voordouw, G. (2009) Transformation of iron sulfide to greigite by nitrite produced by oil field bacteria. Appl Microbiol Biotechnol 83:369-376.

Lin, S.M., Tsai, J.Y., Hsiao, C.D., Huang, Y.T., Chiu, C.L., Liu, M.H., Tung, J.Y., Liu, T.H., Pan, R.L., and Sun, Y.J. (2012) Crystal structure of a membrane-embedded $\mathrm{H}^{+}$-translocating pyrophosphatase. Nature 484:399-403.

Lincoln, T.A. and Joyce, G.F. (2009) Self-sustained replication of an RNA enzyme. Science 323:1229-1232.

Liu, Z., Tian, G., Zhu, S., He, C., Yue, H., and Feng, S. (2013) Ready hydrothermal reactions from carbon dioxide to methane. ACS Sustain Chem Eng 1:313-315.

Lovelock, J.E. (1965) A physical basis for life detection experiments. Nature 207:568-570.

Lowell, R.P. and Rona, P.A. (2002) Seafloor hydrothermal systems driven by the serpentinization of peridotite. Geophys Res Lett 29, doi:10.1029/2001GL014411.

Ludwig, K.A., Kelley, D.S., Butterfield, D.A., Nelson, B.K., and Früh-Green, G.L. (2006) Formation and evolution of carbonate chimneys at the Lost City Hydrothermal Field. Geochim Cosmochim Acta 70:3625-3645.

Ludwig, K.A., Shen, C.-C., Kelley, D.S., Cheng, H., and Edwards, R.L. (2011) U-Th systematics and ${ }^{230} \mathrm{Th}$ ages of carbonate chimneys at the Lost City hydrothermal field. Geochim Cosmochim Acta 75:1869-1888.

Luoto, H.H., Baykov, A.A., Lahti, R., and Malinen, A.M. (2013) Membrane-integral pyrophosphatase subfamily capable of translocating both $\mathrm{Na}^{+}$and $\mathrm{H}^{+}$. Proc Natl Acad Sci USA 110:1255-1260.

Lupas, A.N., Ponting, C.P., and Russell, R.B. (2001) On the evolution of protein folds: are similar motifs the result of convergence, insertion or relics of an ancient peptide world? J Struct Biol 134:191-203.

Ma, N.W.H., White, D.A., and Martin, R.B. (1967) Metal ion exchange of square-planar nickel(II) tetraglycine with polydentate amines. Inorg Chem 6:1632-1636.

Ma, S., Wang, J., Du, L., Sun, Y., Gu, Q., Sun, G., and Yang, X. (2012) A new method for fast intercalation of bulk crown ether guest into LDH. J Colloid Interface Sci 393: 29-35

Macleod, G., Mckeown, C., Hall, A.J., and Russell, M.J. (1994) Hydrothermal and oceanic $\mathrm{pH}$ conditions at $4 \mathrm{Ga}$ relevant to the origin of life. Orig Life Evol Biosph 24:19-41.

Maden, B.E.H. (2000) Tetrahydrofolate and tetrahydromethanopterin compared: functionally distinct carriers in $\mathrm{C} 1$ metabolism. Biochem J 350:609-629.

Maeshima, M. (2000) Vacuolar $\mathrm{H}^{+}$-pyrophosphatase. Biochim Biophys Acta Biomembranes 1465:37-51.

Mahaffy, P.R., Webster, C.R., Atreya, S.K., Franz, H., Wong, M., Conrad, P.G., Harpold, D., Jones, J.J., Leshin, L.A., Manning, H., Owen, T., Pepin, R.O., Squyres, S., Trainer, M., and the MSL Science Team. (2013) Abundance and isotopic composition of gases in the martian atmosphere from the Curiosity Rover. Science 341:263-266.

Martin, F.G. (1992) Circuit analysis of transmembrane voltage relationships in V-ATPase-coupled ion movements. $J$ Exp Biol 172:387-402.

Martin, H., Albarède, F., Claeys, P., Gargaud, M., Marty, B., Morbidelli, A., and Pinti, D.L. (2006) Building of a habitable planet. Earth Moon Planets 98:97-151. 
Martin, R.B., Chamberlin, M., and Edsal, J.T. (1960) The association of nickel(II) ion with peptides. J Am Chem Soc 82:495-498.

Martin, R.S., Mather, T.A., and Pyle, D.M. (2007) Volcanic emissions and the early Earth atmosphere. Geochim Cosmochim Acta 71:3673-3685.

Martin, W. and Russell M.J. (2007) On the origin of biochemistry at an alkaline hydrothermal vent. Philos Trans $R$ Soc Lond B Biol Sci 362:1887-1925.

Martin, W., Baross, J., Kelley, D., and Russell M.J. (2008) Hydrothermal vents and the origin of life. Nat Rev Microbiol 6:806-814.

Martinez-Espinosa, R.M., Dridge, E.J., Bonete, M.J., Butt, J.N., Butler, C.S., Sargent, F., and Richardson, D.J. (2007) Look on the positive side! The orientation, identification and bioenergetics of 'Archaeal' membrane-bound nitrate reductases. FEMS Microbiol Lett 276:129-139.

Marty, B. (2012) The origins and concentrations of water, carbon, nitrogen and noble gases on Earth. Earth Planet Sci Lett 313-314:56-66.

Maruyama, S., Ikoma, M., Genda, H., Hirose, K., Yokoyama, T., and Santosh, M. (2013) The naked planet Earth: most essential pre-requisite for the origin and evolution of life. Geoscience Frontiers 4:141-165.

Mast, C.B. and Braun, D. (2010) Thermal trap for DNA replication. Phys Rev Lett 104, doi:10.1103/PhysRevLett.104 .188102.

Mast, C.B., Osterman, N., and Braun, D. (2012) Thermal solutions for molecular evolution. International Journal of Modern Physics B 26, doi:10.1142/S0217979212300174.

Mast, C.B., Schink, S., Gerland, U., and Braun, D. (2013) Escalation of polymerization in a thermal gradient. Proc Natl Acad Sci USA 110:8030-8035.

Maury, C.P.J. (2009) Self-propagating $\beta$-sheet polypeptide structures as prebiotic informational molecular entities: the amyloid world. Orig Life Evol Biosph 39:141-150.

McCollom, T.M. (1999) Methanogenesis as a potential source of chemical energy for primary production by autotrophic organisms in hydrothermal systems on Europa. J Geophys Res 104:30729-30742.

McGlynn, S.E., Mulder, D.W., Shepard, E.M., Broderick, J.B., and Peters, J.W. (2009) Hydrogenase cluster biosynthesis: organometallic chemistry nature's way. Dalton Trans 2009: 4274-4285.

McGlynn, S.E., Beard, T.E., Broderick, J.B., and Peters, J.W. (2010) Life's origins: potential for radical mediated cyanide production on the early Earth. The Journal of Cosmology 10:3315-3324.

McGlynn, S.E., Kanik, I., and Russell, M.J. (2012) Modification of simulated hydrothermal iron sulfide chimneys by RNA and peptides. Philos Transact A Math Phys Eng Sci 370:30073022.

McLaughlin, G.C., Wijers, R.A.M.J., Brown, G.E., and Bethe, H.A. (2008) Broad and shifted iron-group emission lines in gamma-ray bursts as tests of the hypernova scenario. Astrophys $J$ 567:454-462.

McMahon, S., Parnell, J., and Blamey, N.J. (2013) Sampling methane in basalt on Earth and Mars. International Journal of Astrobiology 12:1-10.

Meier, D.L. (2012) Black Hole Astrophysics: The Engine Paradigm, Springer, Heidelberg.

Mellersh, A.R. and Smith, P.M. (2010) The alkaline world and the origin of life. The Journal of Cosmology 10:3230 3242 .
Melott, A.L. and Thomas, B.C. (2011) Astrophysical ionizing radiation and Earth: a brief review and census of intermittent intense sources. Astrobiology 11:343-361.

Ménez, B., Pasini, V., and Brunelli, D. (2012) Life in the hydrated suboceanic mantle. Nat Geosci 5:133-137.

Meunier, A., Petit, S., Cockell, C.S., El Albani, A., and Beaufort, D. (2010) The Fe-rich clay microsystems in basaltkomatiite lavas: importance of $\mathrm{Fe}$-smectites for pre-biotic molecule catalysis during the Hadean Eon. Orig Life Evol Biosph 40:253-272.

Michalski, J.R., Cuadros, J., Niles, P.B., Parnell, J., Rogers, A.D., and Wright, S.P. (2013) Groundwater activity on Mars and implications for a deep biosphere. Nat Geosci 6:133-138.

Mielke, R.E., Russell, M.J., Wilson, P.R., McGlynn, S., Coleman, M., Kidd, R., and Kanik, I. (2010) Design, fabrication and test of a hydrothermal reactor for origin-of-life experiments. Astrobiology 10:799-810.

Mielke, R.E., Robinson, K.J., White, L.M., McGlynn, S.E., McEachern, K., Bhartia, R., Kanik, I., and Russell, M.J. (2011) Iron-sulfide-bearing chimneys as potential catalytic energy traps at life's emergence. Astrobiology 11:933-950.

Miljković, M. (2009) Carbohydrates: Synthesis, Mechanisms, and Stereoelectronic Effects, Springer, New York.

Milner-White, E.J. and Russell, M.J. (2005) Nests as sites for phosphates and iron-sulfur thiolates in the first membranes: 3 to 6 residue anion-binding motifs. Orig Life Evol Biosph 35:19-27.

Milner-White, E.J. and Russell, M.J. (2008) Predicting peptide and protein conformations in early evolution. Biol Direct 3, doi:10.1186/1745-6150-3-3.

Milner-White, E.J. and Russell, M.J. (2011) Functional capabilities of the earliest peptides and the emergence of life. Genes 2:671-688.

Milner-White, E.J., Watson, J.D., Qi, G., and Hayward, S. (2006) Amyloid formation may involve $\alpha$ - to $\beta$-sheet interconversion via peptide plane flipping. Structure 14:13691376.

Mitchell, P. (1959) The origin of life and the formation and organizing functions of natural membranes. In Proceedings of the First International Symposium on the Origin of Life on the Earth, edited by A.I. Oparin, A.G. Pasynskiu, A.E. Brauntstein, and T.E. Pavlovskaya, House Academy of Science, Moscow, USSR, 1957; English edition edited by F. Clark and R.L.M. Synge, Pergamon Press, New York, 1959, pp 437-443.

Mitchell, P. (1961) Coupling of phosphorylation to electron and hydrogen transfer by a chemiosmotic type of mechanism. Nature 191:144-148.

Mitchell, P. (1975) The protonmotive Q cycle: a general formulation. FEBS Lett 59:137-139.

Mitchell, P. (1976) Vectorial chemistry and the molecular mechanics of chemiosmotic coupling: power transmission by proticity. Biochem Soc Trans 4:399-430.

Mitchell, P. (1979a) Compartmentation and communication in living systems. Ligand conduction: a general catalytic principle in chemical, osmotic, and chemiosmotic reaction systems. Eur J Biochem 95:1-20.

Mitchell, P. (1979b) Keilin's respiratory chain concept and its chemiosmotic consequences. Science 206:1148-1159.

Mitchell, P. and Moyle, J. (1965) Stoichiometry of proton translocation through the respiratory chain and adenosine triphosphatase systems of rat liver mitochondria. Nature 208:147-151. Mloszewska, A.M., Pecoits, E., Cates, N.L., Mojzsis, S.J., O’Neil, J., Robbins, L.J., and Konhauser, K.O. (2012) The composition of Earth's oldest iron formations: the Nuvvuagittuq Supra- 
crustal Belt (Québec, Canada). Earth Planet Sci Lett 317318:331-342.

Moeller, A. and Hansen, U. (2013) Influence of rotation on the metal rain in a Hadean magma ocean. Geochemistry, Geophysics, Geosystems 14, doi:10.1002/ggge.20087.

Monod, J. (1972) Chance and Necessity: An Essay on the Natural Philosophy of Modern Biology, Vintage Books, New York, p 111.

Montmerle, T., Augereau, J.C., Chaussidon, M., Gounelle, M., Marty, B., and Morbidelli, A. (2006) Solar System formation and early evolution: the first 100 million years. In From Suns to Life: A Chronological Approach to the History of Life on Earth, Springer, New York, pp 39-95.

Morowitz, H.J., Kostelnik, J.D., Yang, J., and Cody, G.D. (2000) The origin of intermediary metabolism. Proc Natl Acad Sci USA 97:7704-7708.

Morrill, P.L., Kuenen, J.G., Johnson, O.J., Suzuki, S., Rietze, A., Sessions, A.L., Fogel, M.L., and Nealson, K.H. (2013) Geochemistry and geobiology of a present-day serpentinization site in California: The Cedars. Geochim Cosmochim Acta 109:222-240.

Morse, J.W. and Arakaki, T. (1993) Adsorption and coprecipitation of divalent metals with mackinawite (FeS). Geochim Cosmochim Acta 57:3635-3640.

Moyle, J., Mitchell, R., and Mitchell, P. (1972) Proton-translocating pyrophosphatase of Rhodospirillum rubrum. FEBS Lett 23:233-236.

Mulkidjanian, A.Y. and Junge, W. (1997) On the origin of photosynthesis as inferred from sequence analysis-a primordial UV-protector as common ancestor of reaction centers and antenna proteins. Photosynth Res 51:27-42.

Mulkidjanian, A.Y., Dibrov, P., and Galperin, M.Y. (2008) The past and present of sodium energetics: may the sodiummotive force be with you. Biochim Biophys Acta Bioenergetics 1777:985-992.

Muñoz-Santiburcio, D., Wittekindt, C., and Marx, D. (2013) Nanoconfinement effects on hydrated excess protons in layered materials. Nature Commun 4, doi:10.1038/ncomms3349.

Narayanan, S.R., Haines, B., Soler, J., and Valdez, T.I. (2011) Electrochemical conversion of carbon dioxide to formate in alkaline polymer electrolyte membrane cells. $J$ Electrochem Soc 158:A167-A173.

Nealson, K.H. and Saffarini, D. (1994) Iron and manganese in anaerobic respiration: environmental significance, physiology, and regulation. Annu Rev Microbiol 48:311-343.

Newman, M.J. and Rood, R.T. (1977) Implications of solar evolution for the Earth's early atmosphere. Science 198:1035-1037.

Ni, H. and Keppler, H. (2013) Carbon in silicate melts. Reviews in Mineralogy and Geochemistry 75:251-287.

Nicolosi, V., Chhowalla, M., Kanatzidis, M.G., Strano, M.S., and Coleman, J.N. (2013) Liquid exfoliation of layered materials. Science 340, doi:10.1126/science.1226419.

Nissen, P., Hansen, J., Ban, N., Moore, P.B., and Steitz, T.A. (2000) The structural basis of ribosome activity in peptide bond synthesis. Science 289:920-930.

Nissenbaum, A., Kenyon, D.H., and Oró, J. (1975) On the possible role of organic melanoidin polymers as matrices for prebiotic activity. J Mol Evol 6:253-270.

Nitschke, W. and Russell, M.J. (2009) Hydrothermal focusing of chemical and chemiosmotic energy, supported by delivery of catalytic $\mathrm{Fe}, \mathrm{Ni}, \mathrm{Mo} / \mathrm{W}, \mathrm{Co}, \mathrm{S}$ and $\mathrm{Se}$, forced life to emerge. J Mol Evol 69:481-496.

Nitschke, W. and Russell, M.J. (2010) Just like the Universe the emergence of life had high enthalpy and low entropy beginnings. The Journal of Cosmology 10:3200-3216.
Nitschke, W. and Russell, M.J. (2011) Redox bifurcations; how they work and what they mean to extant life and (potentially) to its inorganic roots. BioEssays 34:106-109.

Nitschke, W. and Russell, M.J. (2013) Beating the acetyl coenzyme-A pathway to the origin of life. Philos Trans $R$ Soc Lond B Biol Sci 368, doi:10.1098/rstb.2012.0258.

Nitschke, W., McGlynn, S.E., Milner-White, J.E., and Russell, M.J. (2013) On the antiquity of metalloenzymes and their substrates in bioenergetics. Biochim Biophys Acta Bioenergetics 1827:871-881.

Norberg, J. and Nilsson, L. (1995) Stacking free energy profiles for all 16 natural ribodinucleoside monophosphates in aqueous solution. J Am Chem Soc 117:10832-10840.

Ohara, S. and Cody, G.D. (2010) Surface-catalyzed peptide formation on sulfide minerals [abstract 5309]. In Astrobiology Science Conference 2010: Evolution and Life: Surviving Catastrophes and Extremes on Earth and Beyond, Lunar and Planetary Institute, Houston.

Ookubo, A., Ooi, K., and Hayashi, H. (1993) Preparation and phosphate ion-exchange properties of a hydrotalcite-like compound. Langmuir 9:1418-1422.

Open University Course Team. (1993) Ocean Circulation, Pergamon Press, Oxford.

Orcutt, B.N., LaRowe, D.E., Biddle, J.F., Colwell, F.S., Glazer, B.T., Reese, B.K., Kirkpatrick, J.B., Lapham, L.L., Mills, H.J., Sylvan, J.B., Wankel, S.D., and Wheat, C.G. (2013) Microbial activity in the marine deep biosphere: progress and prospects. Front Microbiol 4, doi:10.3389/fmicb.2013.00189.

Orgel, L.E. (1999) Are you serious, Dr Mitchell? Nature 402:17.

Orthous-Daunay, F.R., Quirico, E., Lemelle, L., Beck, P., deAndrade, V., Simionovici, A., and Derenne, S. (2010) Speciation of sulfur in the insoluble organic matter from carbonaceous chondrites by XANES spectroscopy. Earth Planet Sci Lett 300:321-328.

Ozima, M., Seki, K., Terada, N., Miura, Y.N., Podosek, F.A., and Shinagawa, H. (2005) Terrestrial nitrogen and noble gases in lunar soils. Nature 436:655-659.

Page, M.I. and Jencks, W.P. (1971) Entropic contributions to rate accelerations in enzymic and intramolecular reactions and the chelate effect. Proc Natl Acad Sci USA 68:16781683.

Panov, G.I., Dubkov, K.A., Starokon, E.V., and Parmon V.N. (2002) Non-catalytic liquid phase oxidation of alkenes with nitrous oxide. 1. Oxidation of cyclohexene to cyclohexanone. Reaction Kinetics and Catalysis Letters 76:401-406.

Pascal, R., Pross, A., and Sutherland, J.D. (2013) Towards an evolutionary theory of the origin of life based on kinetics and thermodynamics. Open Biol 3, doi:10.1098/rsob.130156.

Pasek, M.A. and Greenberg, R. (2012) Acidification of Europa's subsurface ocean as a consequence of oxidant delivery. Astrobiology 12:151-159.

Pasek, M.A., Harnmeijer, J.P., Buick, R., Gull, M., and Atlas, Z. (2013) Evidence for reactive reduced phosphorus species in the early Archean ocean. Proc Natl Acad Sci USA 110: 10089-10094.

Paulo, M.J.V.R. and Tavares, A. (2011) Novel hydrotalcite composites membranes for alkaline fuel cells. ECS Trans 35:21-28.

Penrose, R. (2005) The Road to Reality: A Complete Guide to the Laws of the Universe, Knopf, New York.

Peters, J.W., Szilagyi, R.K., Naumov, A., and Douglas, T. (2006) A radical solution for the biosynthesis of the H-cluster of hydrogenase. FEBS Lett 580:363-367. 
Pitsch, S., Eschenmoser, A., Gedulin, B., Hui, S., and Arrhenius, G. (1995) Mineral induced formation of sugar phosphates. Orig Life Evol Biosph 25:297-334.

Poinsignon, C. (1997) Protonic conductivity and water dynamics in swelling clays. Solid State Ionics 97:399-407.

Ponnamperuma, C., Shimoyama, A., and Friebele, E. (1982) Clay and the origin of life. Orig Life 12:9-40.

Powner, M.W., Gerland, B., and Sutherland, J.D. (2009) Synthesis of activated pyrimidine ribonucleotides in prebiotically plausible conditions. Nature 459:239-242.

Prebble, J. (2002) Peter Mitchell and the ox phos wars. Trends Biochem Sci 27:209-212.

Preston, L.J., Izawa, M.R.M., and Banerjee, N.R. (2011) Infrared spectroscopic characterization of organic matter associated with microbial bioalteration textures in basaltic glass. Astrobiology 11:585-599.

Prigogine, I. (1978) Time, structure, and fluctuations. Science 201:777-785.

Proskurowski, G., Lilley, M.D., Kelley, D.S., and Olson, E.J. (2006) Low temperature volatile production at the Lost City hydrothermal field, evidence from a hydrogen stable isotope geothermometer. Chem Geol 229:331-343.

Proskurowski, G., Lilley, M.D., Seewald, J.S., Früh-Green, G.L., Olson, E.J., Lupton, J.E., Sylva, S.P., and Kelley, D.S. (2008) Abiogenic hydrocarbon production at Lost City hydrothermal field. Science 319:604-607.

Pross, A., and Pascal, R. (2013) The origin of life: what we know, what we can know and what we will never know. Open Biol 3, doi:10.1098/rsob.120190.

Rabinowitz, J. and Hampaï, A. (1985) Quantitative polyphosphate-induced "prebiotic" peptide formation in $\mathrm{H}_{2} \mathrm{O}$ by addition of certain azoles and ions. J Mol Evol 21:199-201.

Rabinowitz, J., Flores, R., Krebsback, R., and Rogers, G. (1969) Peptide formation in the presence of linear or cyclic polyphosphates. Nature 224:795-796.

Ragsdale, S.W. (1997) The Eastern and Western branches of the Wood/Ljungdahl pathway: how the East and West were won. BioFactors 6:3-11.

Rebelo, J., Auerbach, G., Bader, G., Bracher, A., Nar, H., Hösl, C., Schramek, N., Kaiser, J., Bacher, A., Huber, R., and Fischer, M. (2003) Biosynthesis of pteridines. Reaction mechanism of GTP cyclohydrolase I. J Mol Biol 326:503516.

Reeves, G.D., Cayton, T.E., Gary, S.P., and Belian, R.D. (1992) The great solar energetic particle events of 1989 observed from geosynchronous orbit. J Geophys Res 97: 6219-6226.

Reeves, E.P., Seewald, J.S., Saccocia, P., Bach, W., Craddock, P.R., Shanks, W.C., Sylva, S.P., Walsh, E., Pichler, T., and Rosner, M. (2011) Geochemistry of hydrothermal fluids from the PACMANUS, Northeast Pual and Vienna Woods hydrothermal fields, Manus Basin, Papua New Guinea. Geochim Cosmochim Acta 75:1088-1123.

Rickard, D. and Luther, G.W. (2007) Chemistry of iron sulfides. Chem Rev 107:514-562.

Rickard, D., Butler, I.B., and Olroyd, A. (2001) A novel iron sulphide switch and its implications for Earth and planetary science. Earth Planet Sci Lett 189:85-91.

Rivas, M.G., Carepo, M.S., Mota, C.S., Korbas, M., Durand, M.C., Lopes, A.T., Brondino, C.D., Pereira, A.S., George, G.N., Dolla, A., Moura, J.J.G., and Moura, I. (2009) Molybdenum induces the expression of a protein containing a new heterometallic Mo-Fe cluster in Desulfovibrio alaskensis. Biochem 48:873-882.
Rosing, M.T. (1999) ${ }^{13} \mathrm{C}$-depleted carbon microparticles in $>3700$-Ma sea-floor sedimentary rocks from West Greenland. Science 283:674-676.

Ross, C.A. and Poirier, M.A. (2005) What is the role of protein aggregation in neurodegeneration? Nat Rev Mol Cell Biol 6:891-898.

Roussel, E.G., Bonavita, M.A.C., Querellou, J., Cragg, B.A., Webster, G., Prieur, D., and Parkes, R.J. (2008) Extending the sub-sea-floor biosphere. Science 320:1046.

Ruby, C., Abdelmoula, M., Naille, S., Renard, A., Khare, V., Ona-Nguema, G., Morin, G., and Génin, J.-M.R. (2010) Oxidation modes and thermodynamics of FeII-III oxyhydroxycarbonate green rust: dissolution-precipitation versus in situ deprotonation. Geochim Cosmochim Acta 74:953-966.

Ruffini, R. and Wheeler, J.A. (1971) Introducing the black hole. Phys Today 24:30-36.

Rugheimer, S., Kaltenegger, L., Zsom, A., Segura, A., and Sasselov, D. (2013) Spectral fingerprints of Earth-like planets around FGK stars. Astrobiology 13:251-269.

Russell, M.J. (1991) The Inorganic-Organic Interface: Geological, Chemical and Biological Potential, University of Glasgow, Department of Geology \& Applied Geology, Glasgow.

Russell, M.J. (2007) The alkaline solution to the emergence of life: energy, entropy and early evolution. Acta Biotheor 55: 133-179.

Russell, M.J. and Arndt, N.T. (2005) Geodynamic and metabolic cycles in the Hadean. Biogeosciences 2:97-111.

Russell, M.J. and Hall, A.J. (1997) The emergence of life from iron monosulphide bubbles at a submarine hydrothermal redox and pH front. J Geol Soc London 154:377-402.

Russell, M.J. and Hall, A.J. (1999) On the inevitable emergence of life on Mars. In The Search for Life on Mars: Proceedings of the $1^{\text {st }} U K$ Conference, edited by J.A. Hiscox, British Interplanetary Society, London, pp 26-36.

Russell, M.J. and Hall, A.J. (2006) The onset and early evolution of life. In Evolution of Early Earth's Atmosphere, Hydrosphere, and Biosphere-Constraints from Ore Deposits, Geological Society of America Memoir 198, edited by S. Kesler and H. Ohmoto, Geological Society of America, Boulder, CO, pp 1-32.

Russell, M.J. and Hall, A.J. (2009) A hydrothermal source of energy and materials at the origin of life. In Chemical Evolution II: From the Origins of Life to Modern Society, edited by L. Zaikowski, J.M. Friedrich, and S.R. Seidel, American Chemical Society, Washington, DC, pp 45-62.

Russell, M.J. and Kanik, I. (2010) Why does life start, what does it do, where will it be, and how might we find it? The Journal of Cosmology 5:1008-1039.

Russell, M.J. and Martin, W. (2004) The rocky roots of the acetyl-CoA pathway. Trends Biochem Sci 29:358-363.

Russell, M.J., Hall, A.J., and Turner, D. (1989) In vitro growth of iron sulphide chimneys: possible culture chambers for origin-of-life experiments. Terra Nova 1:238-241.

Russell, M.J., Daniel, R.M., and Hall, A.J. (1993) On the emergence of life via catalytic iron sulphide membranes. Terra Nova 5:343-347.

Russell, M.J., Daniel, R.M., Hall, A.J., and Sherringham, J. (1994) A hydrothermally precipitated catalytic iron sulphide membrane as a first step toward life. J Mol Evol 39: 231-243.

Russell, M.J., Daia, D.E., and Hall, A.J. (1998) The emergence of life from FeS bubbles at alkaline hot springs in an acid ocean. In Thermophiles: The Keys to Molecular Evolution 
and the Origin of Life? edited by J. Wiegel and M.W. Adams, Taylor and Francis, London, pp 77-126.

Russell, M.J., Hall, A.J., and Mellersh, A.R. (2003) On the dissipation of thermal and chemical energies on the early Earth: the onsets of hydrothermal convection, chemiosmosis, genetically regulated metabolism and oxygenic photosynthesis. In Natural and Laboratory-Simulated Thermal Geochemical Processes, edited by R. Ikan, Kluwer Academic Publishers, Dordrecht, the Netherlands, pp 325-388.

Russell, M.J., Allen, J.F., and Milner-White, E.J. (2008) Inorganic complexes enabled the onset of life and oxygenic photosynthesis. In Energy from the Sun: $14^{\text {th }}$ International Congress on Photosynthesis, edited by J.F. Allen, E. Gantt, J.H. Golbeck, and B. Osmond, Springer, New York, pp 1193-1198.

Russell, M.J., Hall, A.J., and Martin, W. (2010) Serpentinization as a source of energy at the origin of life. Geobiology 8:355-371.

Russell, M.J., Nitschke, W., and Branscomb, E. (2013) The inevitable journey to being. Philos Trans $R$ Soc Lond B Biol Sci 368, doi:10.1098/rstb.2012.0254.

Sagnotti, L., Roberts, A.P., Weaver, R., Verosub, K.L., Florindo, F., Pike, C.R., Clayton, T., and Wilson, G.S. (2005) Apparent magnetic polarity reversals due to remagnetization resulting from late diagenetic growth of greigite from siderite. Geophysical Journal International 160:89-100.

Saiki, R.K., Gelfand, D.H., Stoffel, S., Scharf, S.J., Higuchi, R., Horn, G.T., Mullis, K.B., and Erlich, H.A. (1988) Primerdirected enzymatic amplification of DNA with a thermostable DNA polymerase. Science 239:487-491.

Saladino, R., Crestini, C., Pino, S., Costanzo, G., and DiMauro, E. (2012) Formamide and the origin of life. Phys Life Rev 9:84-104.

Sanchez, R.A., Ferbis, J.P., and Orgel, L.E. (1967) Studies in prebiotic synthesis: II. Synthesis of purine precursors and amino acids from aqueous hydrogen cyanide. J Mol Biol 30:223-253.

Sauter, D., Cannat, M., Rouméjon, S., Andreani, M., Birot, D., Bronner, A., Brunelli, D., Carlut, J., Delacour, A., Guyader, V., MacLeod, C.J., Manatschal, G., Mendel, V., Ménez, B., Pasini, V., Ruellan, E., and Searle, R. (2013) Continuous exhumation of mantle-derived rocks at the Southwest Indian Ridge for 11 million years. Nat Geosci 6:314-320.

Say, R.F. and Fuchs, G. (2010) Fructose 1,6-bisphosphate aldolase/phosphatase may be an ancestral gluconeogenic enzyme. Nature 464:1077-1081.

Sazama, P., Sathu, N.K., Tabor, E., Wichterlová, B., Sklenák, Š., and Sobalík, Z. (2013) Structure and critical function of Fe and acid sites in Fe-ZSM-5 in propane oxidative dehydrogenation with $\mathrm{N}_{2} \mathrm{O}$ and $\mathrm{N}_{2} \mathrm{O}$ decomposition. J Catal 299:188-203.

Scharf, C.A. (2012) Gravity's Engines: How Bubble-Blowing Black Holes Rule Galaxies, Stars, and Life in the Cosmos, Scientific American/Farrar, Straus and Giroux, New York.

Schneckenburger, P., Adam, P., and Albrecht, P. (1998) Thioketones as key intermediates in the reduction of ketones to thiols by $\mathrm{HS}^{-}$in natural environments. Tetrahedron Lett 39:447-450. Schoepp-Cothenet, B., van Lis, R., Philippot, P., Magalon, A., Russell, M.J., and Nitschke, W. (2012) The ineluctable requirement for the trans-iron elements molybdenum and/or tungsten in the origin of life. Sci Rep 2, doi:10.1038/srep00263.

Schoepp-Cothenet, B., van Lis, R., Atteia, A., Baymann, F., Capowiez, L., Ducluzeau, A.-L., Duval, S., ten Brink, F., Russell, M.J., and Nitschke, W. (2013) On the universal core of bioenergetics. Biochim Biophys Acta Bioenergetics 1827: 79-93.
Schoonen, M., Smirnov, A., and Cohn, C. (2004) A perspective on the role of minerals in prebiotic synthesis. Ambio 33:539-551.

Schoonen, M.A.A., Xu, Y., and Bebie, J. (1999) Energetics and kinetics of the prebiotic synthesis of simple organic acids and amino acids with the $\mathrm{FeS}-\mathrm{H}_{2} \mathrm{~S} / \mathrm{FeS}_{2}$ redox couple as reductant. Orig Life Evol Biosph 29:5-32.

Schoonen, M.A.A. and Xu, Y. (2001) Nitrogen reduction under hydrothermal vent conditions: implications for the prebiotic synthesis of C-H-O-N compounds. Astrobiology 1:133-141.

Schouten, S., van Driel, G.B., Sinninghe Damsté, J.S., and de Leeuw, J.W. (1993) Natural sulfurization of ketones and aldehydes: a key reaction in the formation of organic sulphur compounds. Geochim Cosmochim Acta 57:23-24.

Schrenk, M.O., Brazelton, W.J., and Lang, S.Q. (2013) Serpentinization, carbon, and deep life. Reviews in Mineralogy and Geochemistry 75:575-606.

Schulze-Makuch, D. and Irwin, L.N. (2002) Energy cycling and hypothetical organisms in Europa's ocean. Astrobiology 2:105-121.

Schumann, U. and Huntrieser, H. (2007) The global lightninginduced nitrogen oxides source. Atmos Chem Phys 7:3823-3907.

Schwarz, H. (2011) Chemistry with methane: concepts rather than recipes. Angew Chem Int Ed 50:10096-10115.

Shanker, U., Singh, G., and Kamaluddin. (2013) Interaction of aromatic amines with iron oxides: implications for prebiotic chemistry. Orig Life Evol Biosph 43:207-220.

Shanks, W.C.P., III, and Thurston, R. (2010) Volcanogenic Massive Sulfide Occurrence Model, Scientific Investigations Report 2010-5070-C, U.S. Geological Survey, Reston, VA.

Shibuya, T., Kitajima, K., Komiya, T., Terabayashi, M., and Maruyama, S. (2007) Middle Archaean ocean ridge hydrothermal metamorphism and alteration recorded in the Cleaverville area, Pilbara Craton, Western Australia. Journal of Metamorphic Geology 25:751-767.

Shibuya, T., Komiya, T., Nakamura, K., Takai, K., and Maruyama, S. (2010) Highly alkaline, high-temperature hydrothermal fluids in the early Archean ocean. Precambrian Res 182:230-238.

Shibuya, T., Tahata, M., Kitajima, K., Ueno, Y., Komiya, T., Yamamoto, S., Igisu, M., Terabayashi, M., Sawaki, Y., Takai, K., Yoshida, N., and Maruyama, S. (2012) Depth variation of carbon and oxygen isotopes of calcites in Archean altered upper oceanic crust: implications for the $\mathrm{CO}_{2}$ flux from ocean to oceanic crust in the Archean. Earth Planet Sci Lett 321322:64-73.

Shock, E.L. (1990) Geochemical constraints on the origin of organic compounds in hydrothermal systems. Orig Life Evol Biosph 20:331-367.

Shock, E.L. (1992) Chemical environments of submarine hydrothermal systems. Orig Life Evol Biosph 22:67-107.

Sievers, A., Beringer, M., Rodnina, M.V., and Wolfenden, R. (2004) The ribosome as an entropy trap. Proc Natl Acad Sci USA 101:7897-7901.

Simoncini, E., Russell, M.J., and Kleidon, A. (2011) Modeling free energy availability from Hadean hydrothermal systems to the first metabolism. Orig Life Evol Biosph 41:529-532.

Sleep, N.H., Zahnle, K.J., and Lupu, R.E. (2014) Terrestrial aftermath of the Moon-forming impact. Proceedings of the Royal Society, in press.

Smirnov, A., Hausner, D., Laffers, R., Strongin, D.R., and Schoonen, M.A.A. (2008) Abiotic ammonium formation in the presence of Ni-Fe metals and alloys and its implications for the Hadean nitrogen cycle. Geochem Trans 9, doi: 10.1186/1467-4866-9-5. 
Smith, E. and Morowitz, H.J. (2004) Universality in intermediary metabolism. Proc Natl Acad Sci USA 101:13168-13173.

Sobolev, A.V., Hofmann, A.W., Sobolev, S.V., and Nikogosian, I.K. (2005) An olivine-free mantle source of Hawaiian shield basalts. Nature 434:590-597.

Sousa, F.L., Thiergart, T., Landan, G., Nelson-Sathi, S., Pereira, I.A., Allen, J.F., Lane, L., and Martin, W.F. (2013) Early bioenergetic evolution. Philos Trans $R$ Soc Lond B Biol Sci 368, doi:10.1098/rstb.2013.0088.

Spitzer, J. and Poole, B. (2009) The role of biomacromolecular crowding, ionic strength and physicochemical gradients in the complexities of life's emergence. Microbiol Mol Biol Rev 73:371-388.

Srinivasan, V. and Morowitz, H.J. (2009) The canonical network of autotrophic intermediary metabolism: minimal metabolome of a reductive chemoautotroph. Biol Bull 216: 126-130.

Starokon, E.V., Parfenov, M.V., Pirutko, L.V., Abornev, S.I., and Panov, G.I. (2011) Room-temperature oxidation of methane by $\alpha$-oxygen and extraction of products from the FeZSM-5 surface. J Phys Chem 115:2155-2161.

Starokon, E.V., Parfenov, M.V., Arzumanov, S.S., Pirutko, L.V., Stepanov, A.G., and Panov, G.I. (2013) Oxidation of methane to methanol on the surface of FeZSM-5 zeolite. $J$ Catal 300:47-54.

Stricks, W., Frischmann, J.K., and Mueller, R.G. (1962) Polarography of mercaptoalkyl compounds and their disulfides. J Electrochem Soc 109:518-521.

Stüeken, E.E., Anderson, R.E., Bowman, J.S., Brazelton, W.J., Colangelo-Lillis, J., Goldman, A.D., Som, S.M., and Baross, J.A. (2013) Did life originate from a global chemical reactor? Geobiology 11:101-126.

Summers, D.P. and Chang, S. (1993) Prebiotic ammonia from reduction of nitrite by iron (II) on the early Earth. Nature 365:630-633.

Suzuki, S., Ishii, S.I., Wu, A., Cheung, A., Tenney, A., Wanger, G., Kuenen, J.G., and Nealson, K.H. (2013) Microbial diversity in The Cedars, an ultrabasic, ultrareducing, and low salinity serpentinizing ecosystem. Proc Natl Acad Sci USA 110:15336-15341.

Szent-Györgyi, A. (1968a) Bioelectronics. Science 161:988-990.

Szent-Györgyi, A. (1968b) Bioelectronics: A Study in Cellular Regulations, Defense, and Cancer, Academic Press, New York.

Takahashi, Y. and Mihara, H. (2004) Construction of a chemically and conformationally self-replicating system of amyloid-like fibrils. Bioorg Med Chem 12:693-699.

Takai, K., Gamo, T., Tsunogai, U., Nakayama, N., Hirayama, H., Nealson, K.H., and Horikoshi, K. (2004) Geochemical and microbiological evidence for a hydrogen-based, hyperthermophilic subsurface lithoautotrophic microbial ecosystem (HyperSLiME) beneath an active deep-sea hydrothermal field. Extremophiles 8:269-282.

Takami, H., Noguchi, H., Takaki, Y., Uchiyama, I., Toyoda, A., Nishi, S., Chee, G.-J., Arai, W., Nunoura, T., Itoh, T., Hattori, M., and Takai, K. (2012) A deeply branching thermophilic bacterium with an ancient acetyl-CoA pathway dominates a subsurface ecosystem. PLoS One 7:e30559.

Thauer, R.K., Jungermann, K., and Decker, K., (1977) Energy conservation in chemotrophic anaerobic bacteria. Bacteriol Rev 41:100-180.

Thyveetil, M.A., Coveney, P.V., Greenwell, H.C., and Suter, J.L. (2008) Role of host layer flexibility in DNA guest intercalation revealed by computer simulation of layered nanomaterials. J Am Chem Soc 130:12485-12495.
Trail, D., Watson, E.B., and Tailby, N.D. (2011) The oxidation state of Hadean magmas and implications for early Earth's atmosphere. Nature 480:79-82.

Trail, D., Watson, E.B., and Tailby, N.D. (2012) Ce and Eu anomalies in zircon as proxies for the oxidation state of magmas. Geochim Cosmochim Acta 97:70-87.

Travis, B.J., Palguta, J., and Schubert, G. (2012) A whole-moon thermal history model of Europa: impact of hydrothermal circulation and salt transport. Icarus 218:1006-1019.

Trolard, F. and Bourrié, G. (2012) Fougerite a natural layered double hydroxide in gley soil: habitus, structure, and some properties. In Clay Minerals in Nature: Their Characterization, Modification and Application, edited by M. Valaškova and G.S. Martynkova, InTech, Rijeka, Croatia, pp 171-188.

Trolard, F., Génin, J.M., Abdelmoula, M., Bourrié, G., Humbert, B., and Herbillon, A. (1997) Identification of a green rust mineral in a reductomorphic soil by Mössbauer and Raman spectroscopies. Geochim Cosmochim Acta 61:1107-1111.

Turcotte, D.L. and Schubert, G. (2002) Geodynamics, Cambridge University Press, Cambridge.

Van Mierlo, W.L., Langenhorst, F., Frost, D.J., and Rubie, D.C. (2013) Stagnation of subducting slabs in the transition zone due to slow diffusion in majoritic garnet. Nat Geosci 6:400-403.

Vance, S., Harnmeijer, J., Kimura, J., Hussmann, H., Demartin, B., and Brown, J.M. (2007) Hydrothermal systems in small ocean planets. Astrobiology 7:987-1005.

Vattuone, L., Smerieri, M., Savio, L., Asaduzzaman, A.M., Muralidharan, K., Drake, M.J., and Rocca, M. (2013) Accretion disc origin of the Earth's water. Philos Transact A Math Phys Eng Sci 371, doi:10.1098/rsta.2011.0585.

Vaughan, D.J. and Craig, J.R. (1978) Mineral Chemistry of Metal Sulfides, Cambridge University Press, Cambridge.

Violante, A., de Cristofaro, A., Rao, M.A., and Gianfreda, L. (1995) Physicochemical properties of protein-smectite and protein-Al $(\mathrm{OH})_{x}$-smectite complexes. Clay Miner 30:325336.

Vladimirov, M.G., Ryzhkov, Y.F., Alekseev, V.A., Bogdanovskaya, V.A., Otroshchenko, V.A., and Kritsky, M.S. (2004) Electrochemical reduction of carbon dioxide on pyrite as a pathway for abiogenic formation of organic molecules. Orig Life Evol Biosph 34:347-360.

Volbeda, A. and Fontecilla-Camps, J.C. (2006) Catalytic nickel-iron-sulfur clusters: from minerals to enzymes. In Topics in Organometallic Chemistry, Vol. 17, edited by G. Simmonneaux, Springer, Berlin, pp 57-82.

Wächtershäuser, G. (1990) Evolution of the first metabolic cycles. Proc Natl Acad Sci USA 87:200-204.

Wächtershäuser, G. (2007) On the chemistry and evolution of the pioneer organism. Chemistry Biodivers 4:584-602.

Wander, M.C., Rosso, K.M., and Schoonen, M.A. (2007) Structure and charge hopping dynamics in green rust. J Phys Chem C 111:11414-11423.

Wang, W., Yang, B., Qu, Y., Liu, X., and Su, W. (2011) FeS/S/ $\mathrm{FeS}_{2}$ redox system and its oxidoreductase-like chemistry in the iron-sulfur world. Astrobiology 11:471-476.

Webster, C.R., Mahaffy, P.R., Flesch, G.J., Niles, P.B., Jones, J.H., Leshin, L.A., Atreya, S.K., Stern, J.C., Christensen, L.E., Owen, T., Franz, H., Pepin, R.O., Steele, A., and the MSL Science Team. (2013) Isotope ratios of $\mathrm{H}, \mathrm{C}$, and $\mathrm{O}$ in $\mathrm{CO}_{2}$ and $\mathrm{H}_{2} \mathrm{O}$ of the martian atmosphere. Science 342:260-263.

Welhan, J.A. (1988) Origins of methane in hydrothermal systems. Chem Geol 71:183-198.

Westheimer, F.H. (1962) Mechanisms related to enzyme catalysis. In Advances in Enzymology and Related Subjects of 
Biochemistry, Vol. 24, edited by F.F Nord, Interscience, New York, pp 441-482.

Wetzel, D.T., Rutherford, M.J., Jacobsen, S.D., Hauri, E.H., and Saal, A.E. (2013) Degassing of reduced carbon from planetary basalts. Proc Natl Acad Sci USA 110:8010-8013.

White, H.B. (1976) Coenzymes as fossils of an earlier metabolic state. J Mol Evol 7:101-104.

Wicken, J.S. (1987) Evolution, Information and Thermodynamics: Extending the Darwinian Program, Oxford University Press, New York.

Wikström, M.K. and Berden, J.A. (1972) Oxidoreduction of cytochrome $b$ in the presence of antimycin. Biochim Biophys Acta Bioenergetics 283:403-420.

Wikström, M.K. and Saari, H.T. (1977) The mechanism of energy conservation and transduction by mitochondrial cytochrome $c$ oxidase. Biochim Biophys Acta Bioenergetics 462:347-361.

Williams, A.C. and Ramsden, D.B. (2007) Hydrogen symbioses in evolution and disease. $Q \mathrm{~J} \mathrm{Med} \mathrm{100:451-459.}$

Woese, C.R. (2002) On the evolution of cells. Proc Natl Acad Sci USA 99:8742-8747.

Woese, C.R., Kandler, O., and Wheelis, M.L. (1990) Towards a natural system of organisms: proposal for the domains Archaea, Bacteria, and Eucarya. Proc Natl Acad Sci USA 87:4576-4579.

Wolthers, M., Van der Gaast, S.J., and Rickard, D. (2003) The structure of disordered mackinawite. Am Mineral 88:2007-2015.

Wood, B.J., Bryndzia, L.T., and Johnson, K.E. (1990) Mantle oxidation state and its relation to tectonic environment and fluid speciation. Science 248:337-345.

Wood, B.J., Walter, M.J., and Wade, J. (2006) Accretion of the Earth and segregation of its core. Nature 441:825-833.

Wordsworth, R. and Pierrehumbert, R. (2013) Hydrogen-nitrogen greenhouse warming in Earth's early atmosphere. Science 339:64-67.

Yabuta, H., Williams, L.B., Cody, G.D., Alexander, C.M.D., and Pizzarello, S. (2007) The insoluble carbonaceous material of CM chondrites: a possible source of discrete organic compounds under hydrothermal conditions. Meteorit Planet Sci 42:37-48.

Yamagata, Y. and Inomata, K. (1997) Condensation of glycylglycine to oligoglycines with trimetaphosphate in aqueous solution II: catalytic effect of magnesium ion. Orig Life Evol Biosph 27:339-344.

Yamagata, Y., Watanabe, H., Saitoh, M., and Namba, T. (1991) Volcanic production of polyphosphates and its relevance to prebiotic evolution. Nature 352:516-519.

Yamanaka, J., Inomata, K., and Yamagata, Y. (1988) Condensation of oligoglycines with trimeta- and tetrametaphosphate in aqueous solutions. Orig Life Evol Biosph 18:165-178.

Yan, L.G., Xu, Y.Y., Yu, H.Q., Xin, X.D., Wei, Q., and Du, B. (2010) Adsorption of phosphate from aqueous solution by hydroxy-aluminum, hydroxy-iron and hydroxy-iron-aluminum pillared bentonites. J Hazard Mater 179:244-250.
Yarus, M. (2011) Getting past the RNA world: the initial Darwinian ancestor. Cold Spring Harb Perspect Biol 3, doi:10.1101/cshperspect.a003590.

Yoshida, M., Muneyuki, E., and Hisabori, T. (2001) ATP synthase-a marvellous rotary engine of the cell. Nat Rev Mol Cell Biol 2:669-677.

Yoshizawa, K., Suzuki, A., Shiota, Y., and Yamabe, T. (2000) Conversion of methane to methanol on diiron and dicopper enzyme models of methane monooxygenase: a theoretical study on a concerted reaction pathway. Bull Chem Soc Japan 73:815-827.

Yung, Y.L. and McElroy, M.B. (1979) Fixation of nitrogen in the prebiotic atmosphere. Science 203:1002-1004.

Zahnle, K., Arndt, N., Cockell, C., Halliday, A., Nisbet, E., Selsis, F., and Sleep, N.H. (2007) Emergence of a habitable planet. Space Sci Rev 129:35-78.

Zahnle, K., Schaefer, L., and Fegley, B. (2010) Earth's earliest atmospheres. Cold Spring Harb Perspect Biol 2, doi:10.1101/ cshperspect.a004895.

Zhang, S., Holmes, T., Lockshin, C., and Rich, A. (1993) Spontaneous assembly of a self-complimentary oligopeptide to form a stable macroscopic membrane. Proc Natl Acad Sci USA 90:3334-3338.

Zhou, J., Xu, Z.P., Qiao, S., Liu, Q., Xu, Y., and Qian, G. (2011) Enhanced removal of triphosphate by $\mathrm{MgCaFe}-\mathrm{Cl}-$ LDH: synergism of precipitation with intercalation and surface uptake. J Hazard Mater 189:586-594.

Zolensky, M.E. (1984) Hydrothermal alternation of CM carbonaceous chondrites: implications of the identification of tochilinite as one type of meteoritic PCP. Meteoritics 19:346347.

Zolotov, M.Y. and Kargel, J. (2009) On the chemical composition of Europa's icy shell, ocean, and underlying rocks. In Europa, edited by R.T. Pappalardo, W.B. McKinnon, and K. Khurana, University of Arizona Press, Tucson, AZ, pp 431-458.

Zolotov, M.Y. and Shock, E.L. (2003) Energy for biologic sulfate reduction in a hydrothermally formed ocean on Europa. $J$ Geophys Res Planets 108, doi:10.1029/2002JE001966.

Address correspondence to: Michael Russell

Chemistry and Astrobiology Section 3225

MS:183-301

Jet Propulsion Laboratory California Institute of Technology 4800 Oak Grove Drive Pasadena, CA 91109-8099

E-mail: mrussell@jpl.nasa.gov

Submitted 21 October 2013 Accepted 2 February 2014 